STOCHASTIC DYNAMIC PROGRAMMING BASED RESOURCE ALLOCATION FOR MULTI TARGET TRACKING FOR ELECTRONICALLY STEERED ANTENNA RADAR

A THESIS SUBMITTED TO

THE GRADUATE SCHOOL OF NATURAL AND APPLIED SCIENCES

$\mathrm{OF}$

MIDDLE EAST TECHNICAL UNIVERSITY

BY

ÇAĞLAR UZUN

IN PARTIAL FULLFILLMENT OF THE REQUIREMENTS

FOR

THE DEGREE OF MASTER OF SCIENCE

IN

ELECTRICAL AND ELECTRONICS ENGINEERING

JANUARY 2015 

Approval of the thesis:

\section{STOCHASTIC DYNAMIC PROGRAMMING BASED RESOURCE ALLOCATION FOR MULTI TARGET TRACKING FOR ELECTRONICALLY STEERED ANTENNA RADAR}

submitted by ÇAĞLAR UZUN in partial fulfillment of the requirements for the degree of Master of Science in Electrical and Electronics Engineering Department, Middle East Technical University by,

Prof. Dr. Gülbin Dural Ünver

Dean, Graduate School of Natural and Applied Sciences

Prof. Dr. Gönül Turhan Sayan

Head of Department, Electrical and Electronics Engineering

Prof. Dr. Mübeccel Demirekler

Supervisor, Electrical and Electronics Eng. Dept., METU

\section{Examining Committee Members:}

Prof. Dr. Mustafa Kuzuoğlu

Electrical and Electronics Engineering Dept., METU

Prof. Dr. Mübeccel Demirekler

Electrical and Electronics Engineering Dept., METU

Assoc. Prof. Dr. Umut Orguner

Electrical and Electronics Engineering Dept., METU

Assoc. Prof. Dr. Çağatay Candan

Electrical and Electronics Engineering Dept., METU

Dr. Recep Firat Tiğrek

Phase Array Radar Systems Design Dept., ASELSAN

Date:

30.01.2015 
I hereby declare that all information in this document has been obtained and presented in accordance with academic rules and ethical conduct. I also declare that, as required by these rules and conduct, I have fully cited and referenced all material and results that are not original to this work.

Name, Last Name : Çağlar UZUN

Signature : 


\title{
ABSTRACT \\ STOCHASTIC DYNAMIC PROGRAMMING BASED RESOURCE \\ ALLOCATION FOR MULTI TARGET TRACKING FOR ELECTRONICALLY STEERED ANTENNA RADAR
}

\author{
Uzun, Çağlar \\ M.S., Department of Electrical and Electronics Engineering \\ Supervisor: Prof. Dr. Mübeccel Demirekler
}

January 2015, 108 pages

In this work, the concept of sensor management is introduced and stochastic dynamic programming based resource allocation approach is proposed to track multiple targets. The core of this approach is to use Lagrange relaxation for decreasing the state space dimension. By this approximation, the overall problem is separated into components instead of using joint Markov model to optimize large scale stochastic control problem. The aim of this study is to adaptively allocate radar resources in an optimal way in order to maintain track qualities for multi-target case. The radar is electronically steered antenna radar. Resource allocation is done only for tracking excluding the search beams. Adaptive target tracking is performed by Kalman filter. Problem is modeled as a set of controlled Markov chains each dedicated to one track. Time scale is divided into two levels that are called as micro management and macro management. During the thesis, we deal with macro management part that aims to construct a policy which is optimal for a given objective function under the resource constraints. Stochastic dynamic programming with constraints in the sense of [32] is the method used. In this thesis, five different scenarios are constructed and corresponding algorithms are confirmed by simulation results. The performances of 
the algorithms are also compared. Their performances are analyzed on the average number of update decision and average number of target drops in time horizon.

Keywords: Sensor Management, Optimization-based Scheduling, Beam Scheduling, Dynamic Programming, Lagrange Relaxation Method, Markov Decision Process, Resource Allocation For Electronically Steered Antenna Radar 


\title{
ÖZ
}

\section{ELEKTRONIK TARAMALI RADARLARDA ÇOKLU HEDEF TAKİBİ İÇIN STOKASTIK DINAMIK PROGRAMLAMA TABANLI KAYNAK PAYLAŞIMI}

\author{
Uzun, Çağlar \\ Yüksek Lisans, Elektrik ve Elektronik Mühendisliği Bölümü \\ Tez Yöneticisi: Prof. Dr. Mübeccel Demirekler
}

Ocak 2015, 108 sayfa

Bu çalışmada, sensör yönetim kavramı tanıtılmış ve çoklu hedef takip etmek için stokastik dinamik programlama tabanlı kaynak paylaşım yaklaşımı önerilmiştir. $\mathrm{Bu}$ yaklaşımın temeli, durum uzay boyutunu azaltmak için Lagrange rahatlatması kullanılmasıdır. Bu yaklaşım ile geniş ölçekli stokastik kontrol problemini en iyi şekilde çözmek için birleşik Markov modeli kullanmak yerine, bütün problem parçalarına ayrılmıştır. Bu çalışmanın amacı çoklu hedef durumunda iz kalitelerini sürdürmek için radar kaynaklarını en iyi şekilde uyarlayarak ayırmaktır. Çalışma elektronik taramalı radarlar içindir. Kaynak paylaşımı arama huzmeleri dışarıda tutularak sadece hedef takibi için yapılmıştır. Uyarlamalı hedef takibi Kalman filtresi ile gerçekleştirilmiştir. Problem her biri bir ize atanmış, kontrol edilen Markov zincirleri ile modellenmiştir. Zaman ölçüsü mikro yönetim ve makro yönetim adında iki seviyeye bölünmüştür. Tez boyunca makro yönetimi ile ilgilenilmiştir. Makro yönetim kısmı, verilen hedef fonksiyonu ve kaynak kısıtları altında en uygun strateji oluşturmayı hedeflemektedir. Kullanılan metot [32] deki gibi kısıtlı stokastik dinamik programlamadır. $\mathrm{Bu}$ tezde, beş farklı senaryo oluşturulmuş ve ilgili algoritmalar simülasyon sonuçları ile doğrulanmıştır. Algoritmaların performansları 
da karşılaştırılmıştır. Algoritmaların performansları ortalama güncelleme kararı ve ortalama hedef düşme sayıları ile analiz edilmiştir.

Anahtar Kelimeler: Sensör Yönetimi, Optimizasyon tabanlı Planlama, Huzme Planlamas1, Dinamik Programlama, Lagrange Rahatlatma Metodu, Markov Karar İşleyişi, Elektronik Taramalı Radarlar için Kaynak Paylaşımı 
To My Family, 


\section{ACKNOWLEDGMENTS}

Foremost, I would like to express my deepest gratitude to my supervisor Prof. Dr. Mübeccel Demirekler, who has endless positive energy and polite attitude, for her immense knowledge, valuable guidance and encouragements throughout the research.

I would like to thank ASELSAN Inc. for supporting me and providing facilities to complete this thesis.

I would like to forward my appreciation to all my friends and colleagues who contributed to my thesis with their continuous encouragement.

I would like to thank Hasan HAMZAÇEBİ especially for his unforgettable and valuable help in my studies.

I would also like to express my profound appreciation to my family, my father (Kubilay UZUN), my mother (Dilek UZUN), my sister (Pınar UZUN KUTANIS) and my little brother (Çağrı UZUN) for making me who I am now with their neverending love, continuous support and understanding throughout my life.

Finally, I wish to express special thanks to my wonderful wife, Başak Işık UZUN, whose love, patience and trust encouraged me all the way. I would not have pursued this research without her. 
ABSTRACT .................................................................................................................... v

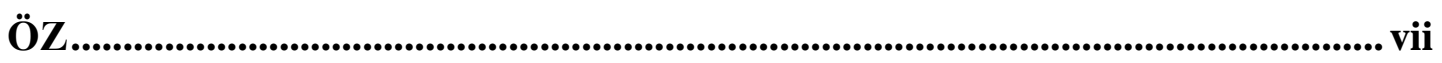

ACKNOWLEDGMENTS ............................................................................................... $\mathrm{x}$

TABLE OF CONTENTS ...................................................................................... $\times 1$

LIST OF TABLES ............................................................................................................ xiv

LIST OF FIGURES ........................................................................................................ xvi

\section{CHAPTERS}

1 INTRODUCTION ............................................................................................. 1

2 THEORETICAL BACKGROUND .................................................................... 5

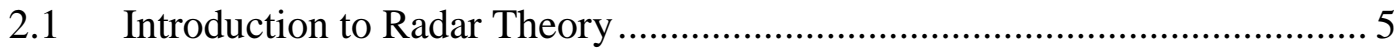

2.1.1 Fundamentals of Radar ................................................................... 6

2.1.2 Types of Radar Based on Scan Pattern ............................................... 7

2.1.3 Electronically Steered Antenna Radars............................................... 10

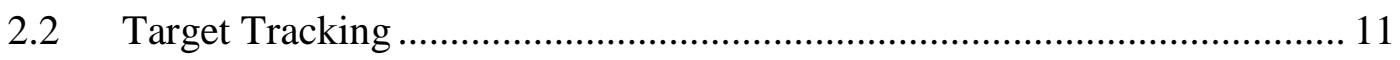

2.2.1 Motion Model: The Constant Velocity Model........................................ 13

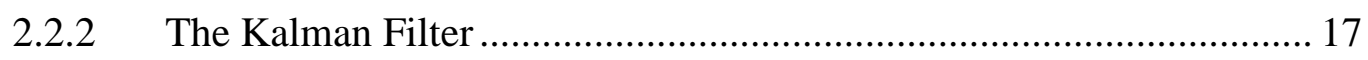

2.2.3 Adaptive Target Tracking ................................................................... 20

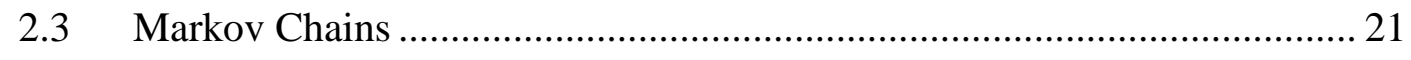

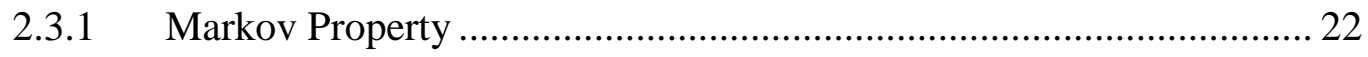

2.3.2 Regular (Ergodic) Markov Chain ......................................................... 24

2.3.3 Absorbing Markov Chain ……………………………………….... 24 
2.3.4 Markov Chain with Rewards.......................................................25

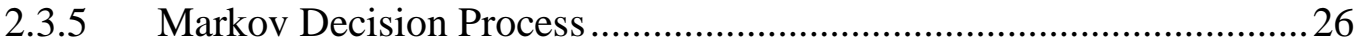

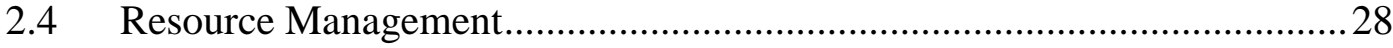

2.4.1 Radar Resource Management......................................................... 30

2.4.2 Rule-Based Heuristic Scheduling ..................................................... 34

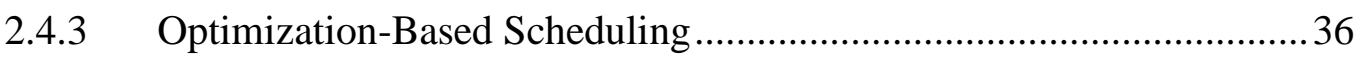

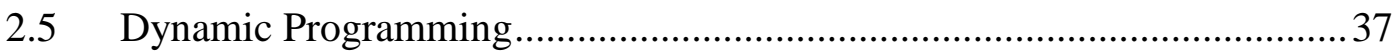

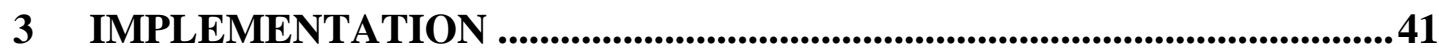

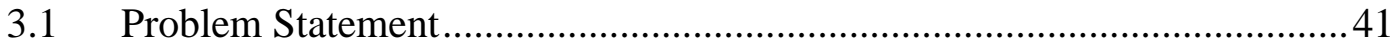

3.1.1 Target and Tracking Performance Model ........................................ 43

3.1.2 Discrete Parameterization of State Rewards ....................................... 45

3.1.3 Tracking Performance Characterization.......................................... 49

3.1.4 Markov Model Used in the Thesis ....................................................50

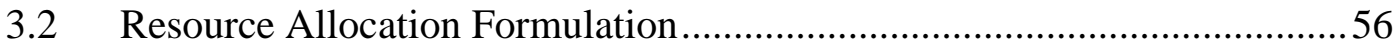

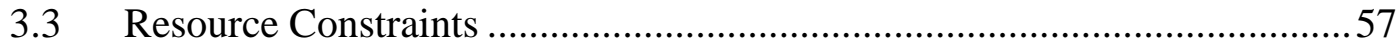

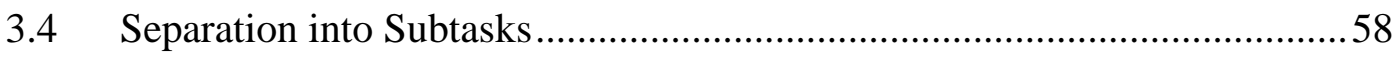

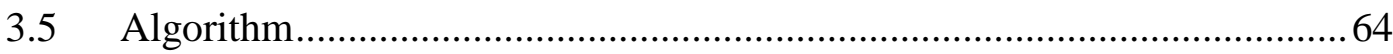

4 SIMULATIONS AND RESULTS .......................................................................69

4.1 DP-Based Optimal Resource Allocation for One Target ........................... 70

4.2 Modified DP-Based Optimal Resource Allocation for One Target with a

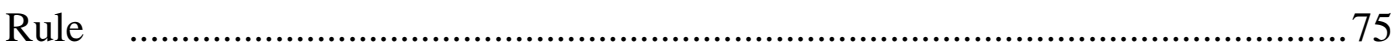

4.3 Optimization-Based Resource Allocation for Two Targets ........................77

4.4 Optimization-Based Resource Allocation for Two Targets with

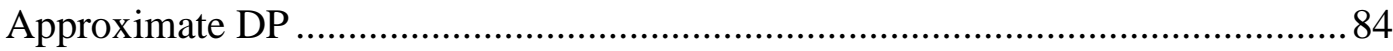

4.5 Optimization-Based Resource Allocation for Eight Targets with

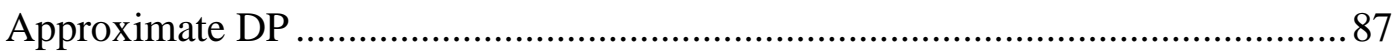




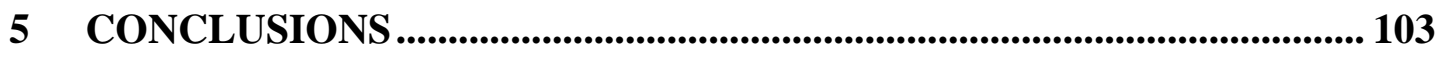

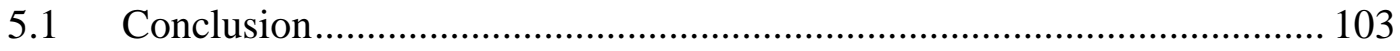

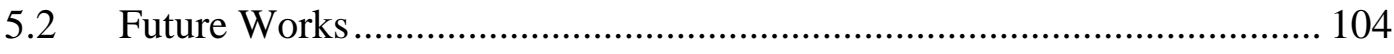

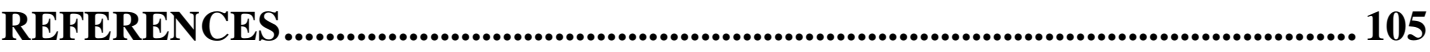




\section{LIST OF TABLES}

\section{TABLES}

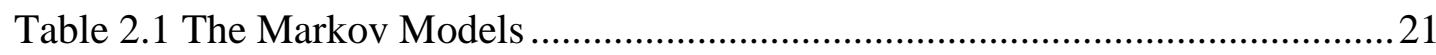

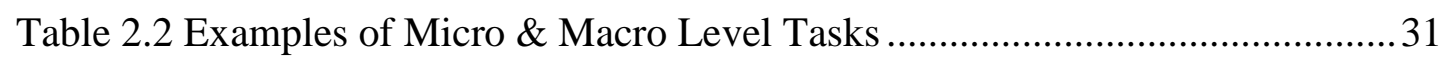

Table 3.1 A Pseudo Code for Discrete Parameterization of State Rewards................48

Table 3.2 Pseudo Code for Searching Optimal Lagrange Multipliers ........................ 64

Table 3.3 Pseudo Code for the Separated Solution to Resource Allocation ...............67

Table 4.1 Quantized Values of the State Quality .................................................. 71

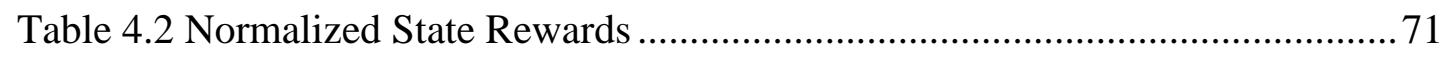

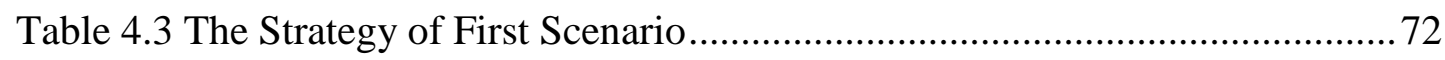

Table 4.4 Simulation Results of DP-Based Optimal Resource Allocation for One

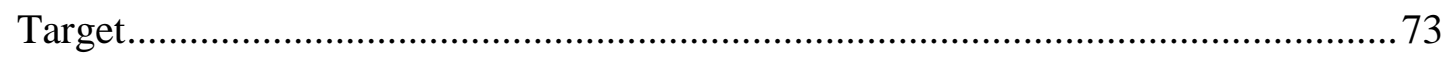

Table 4.5 Pseudo Code for DP-Based Optimal Resource Allocation for One Target 74

Table 4.6 Simulation Results of Modified DP-Based Optimal Resource Allocation

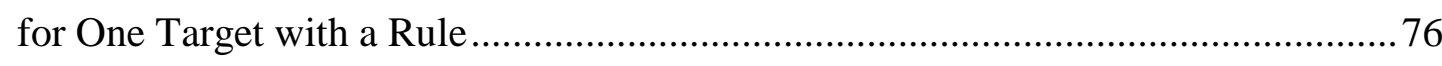

Table 4.7 Joint State Space Representation for Two Targets with Four Individual

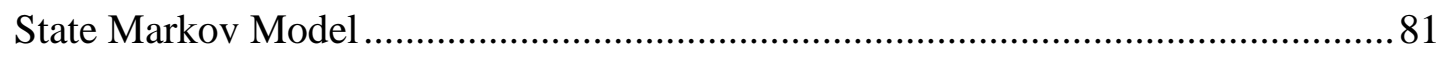

Table 4.8 An Example of Optimized Policy for Joint Markov Model ....................... 82

Table 4.9 Simulation Results of Optimal Resource Allocation for Joint Markov Model. .83

Table 4.10 An Example of Optimized Policy for Target 1 ................................... 84

Table 4.11 An Example of Optimized Policy for Target 2 .................................. 85 
Table 4.12 Simulation Results of Optimization-Based Resource Allocation with

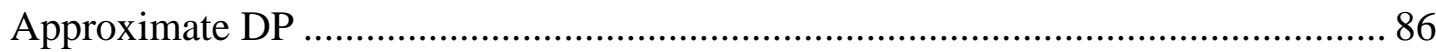

Table 4.13 The Optimal Strategy of First Target..................................................... 89

Table 4.14 The Optimal Strategy of Second Target ................................................ 90

Table 4.15 The Optimal Strategy of Third Target ..................................................... 91

Table 4.16 The Optimal Strategy of Fourth Target ................................................ 92

Table 4.17 The Optimal Strategy of Fifth Target ..................................................... 93

Table 4.18 The Optimal Strategy of Sixth Target..................................................... 94

Table 4.19 The Optimal Strategy of Seventh Target ............................................... 95

Table 4.20 The Optimal Strategy of Eighth Target ................................................ 96

Table 4.21 Optimal Lagrange Multipliers for Each Time Instances......................... 97

Table 4.22 Selected Initial States of Targets......................................................... 98

Table 4.23 Simulation Results of Optimization-Based Resource Allocation with

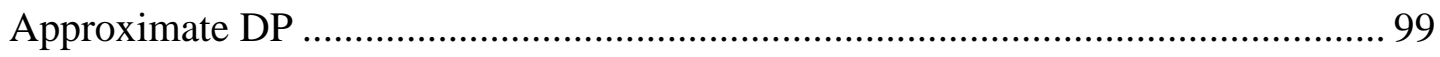

Table 4.24 Simulation Results of Optimization-Based Resource Allocation with

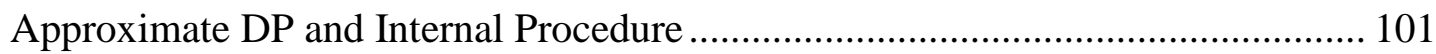




\section{LIST OF FIGURES}

\section{FIGURES}

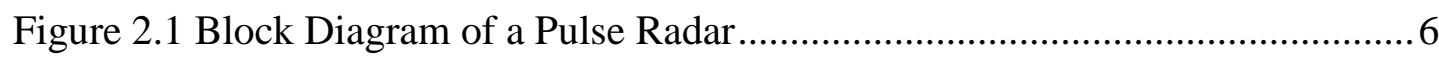

Figure 2.2 A Typical Radar Timeline ….............................................................

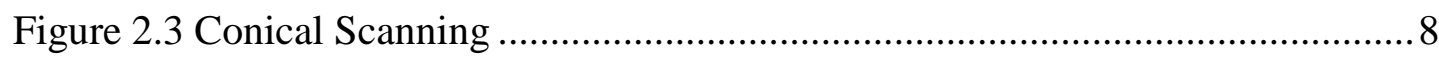

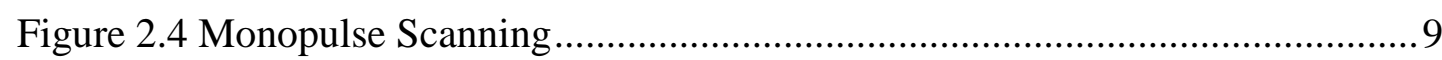

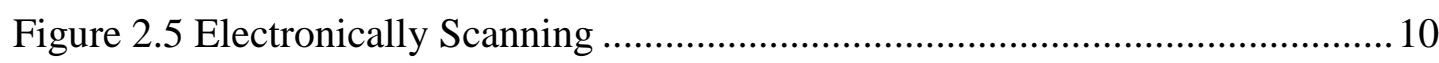

Figure 2.6 An Example of a Track .................................................................... 12

Figure 2.7 The Recursive Progress of Kalman Filter............................................. 19

Figure 2.8 An Example of an Adaptive Update Strategy ......................................2 20

Figure 2.9 Operator as Feedback Controller ....................................................... 28

Figure 2.10 Sensor Manager as Feedback Controller .............................................2 29

Figure 2.11 Partitioning Sensor Management into Macro/Micro Elements ............... 32

Figure 2.12 An Example of Macro and Micro Manager Outputs .............................. 33

Figure 2.13 An Example of a Rule Based System Taken From [30] ........................ 35

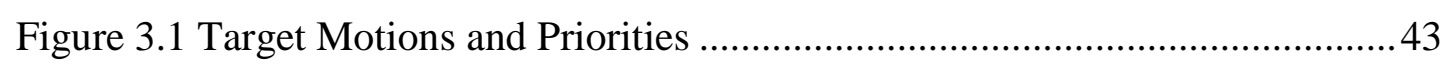

Figure 3.2 A Simple Example of a 10-State Topology ..........................................4

Figure 3.3 Target-Wise Markov Chain for Update Decision ...................................52

Figure 3.4 Target-Wise Markov Chain for Do Not Update Decision .........................53

Figure 4.1 A Simple Markov Model of Each Target .............................................. 78

Figure 4.2 Joint Markov Model with Respect to Update Decisions of Target 1........ 79

Figure 4.3 Joint Markov Model with Respect to Update Decisions of Target 2........ 79 
Figure 4.4 Joint Markov Model with Respect to do not Update Decision of Both

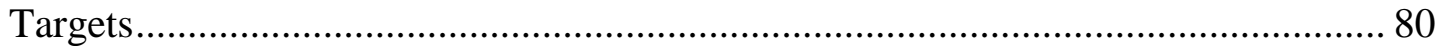





\section{CHAPTER 1}

\section{INTRODUCTION}

Radar is an acronym of "Radio Detection and Ranging" and it is an object detection system that uses radio waves or microwaves to determine the range, direction, altitude or speed of both moving and stationary objects. It was first developed as an object detection system to warn of coming hostile aircraft. In recent years, radar is the most common sensor used in tracking applications. It gives highly accurate information about the range and the velocity of a target [1].

Perhaps the most important improvement in radar technology is the introduction of multifunction radar in recent years. Multifunction radar systems can perform a variety of applications that differ from old generation radar systems that perform an individual function. By the development in solid-state technology, multifunction radar that performs several applications within the same radar system is developed [2].

Active electronically steered antenna radar is a type of multifunction radar whose transmitter and receiver functions are composed of a great number of small solidstate transmit/receive modules (TRMs). Mechanical steering is a big problem for some radar applications especially in target tracking. To improve radar abilities an agile beam should be constructed. Electronically steering antenna produces agile beams without any mechanical constraint. This type of radar uses a group of 
antennas that radiates effective pattern in a desired direction and suppresses in undesired directions. Array of antennas are employed by using a shift in the signal phase in order to separate desired/undesired directions. Some explanation about ESA radars and their advantages are described in Section 2.1.3.

Electronically scanned antenna (ESA) radars have the advantage of using an agile beam. Optimal or near optimal use of this flexibility is a challenge so there is an increasing motivation in designing optimal radar resource allocation algorithms that take advantage of agile beam used by ESA radars.

Sensor management deals with how to manage, coordinate and organize the usage of scarce sensor resources in a manner of improving and optimizing the quality of services. If there are insufficient radar resources to perform all desired tasks, the sensor manager allocates the available resources optimally according to the some properties such as task priority and/or maximum reward. In order to handle global optimization problem which is highly complex to solve, usually the overall problem is divided into many smaller sub-problems that can be considered separately. Resource allocation is essentially a decision-making process about what information needs to be collected from the environment and what actions need to be taken to obtain the most desirable outcome. For target tracking, 'update track i' or 'search sector $\mathrm{j}$ ' decisions are necessary to operate any tracking system. The resource allocation can be modeled as an optimization problem for which the objective is a function of sensor capability, number of tracked targets and also priorities of the targets. Uncertainty management is also an important issue in tracking: The uncertainty of the target increases when a sensor does not update a track. Therefore, the track must be updated adaptively at acceptable time intervals to avoid track drops. A utility function is defined to compare the benefits obtained from the different actions. As a result of this comparison the best solution is aimed to be chosen.

Sensor scheduling is to construct a policy which is optimal for a given objective function under the resource constraints. More detailed information about sensor management can be found in Section 2.4, see also [3] and [4]. 
In this thesis we present the concept of radar beam scheduling. Beam scheduling itself is again a very complex problem. In the literature the problem is usually treated as a two stage problem: micro level scheduling and macro level scheduling [27], [32]. The two levels are called as slow time scale and large time scale. Slow time scale is usually taken on the order of few seconds and with usually fixed intervals of one second. Fast time scale aims to schedule for each interval of slow time scale so its time intervals are in the order of milliseconds. The purposes of the two time scale schedulers so the methods that they use are different from each other. Usually slow time scale scheduler, called the macro scheduler, lists the jobs that should be done in the next (slow time scale) interval and fast time scheduler, called the micro scheduler, determines the exact times that the jobs should be done. This study aims macro scheduling.

In this thesis the resource allocation problem is modeled as a constrained Markov decision process. Macro management algorithm developed for multi target tracking is based on stochastic dynamic programming. The method is very similar to the method given in [32], which is based on constrained stochastic dynamic programming.

The outline of the thesis is as follows:

The background information, radar theory, motion model, target tracking, Kalman filtering, Markov chains, dynamic programming and sensor management are introduced in Chapter 2.

In Chapter 3, the scheduling problem is stated. Its implementation is presented. The model and algorithms that we used in this thesis are detailed.

Chapter 4 concentrates on several scenarios for stochastic dynamic programming based resource allocation applications. Simulations are performed by proposed algorithms and the corresponding results are compared to each other.

In Chapter 5, this thesis is concluded and some future works are suggested. 


\section{CHAPTER 2}

\section{THEORETICAL BACKGROUND}

In this section we give brief information about the radar, target tracking and controlled Markov chains.

\subsection{Introduction to Radar Theory}

Radars work on the ground, on the sea, in the air and in space. Modern radar systems are used for early detection of surface or air objects and provide extremely accurate information on distance, direction, height, and speed of the objects. Ground-based radars are used to detect, locate and track the aircrafts and space targets. Shipboard radars are used to navigate and locate buoys, shore lines and other ships, prevent collisions on the sea, find direction at the same time observe the aircrafts. Airborne radars are used to detect other aircrafts, ships and grounded objects. Meteorologists use radar for monitoring weather or forecasting weather conditions. Radars are also used in space to guide the space crafts. As you see, the modern uses of radars are different in several areas [5]. Some detailed applications are given below.

Radars are the basic sensors in military applications. Radar types according to their functions can be classified as: Search radars, ballistic missile defense radars, radar seekers and fire control radars, missile support radars etc. For the civil applications, 
they are used as process control radars, airport surveillance radars, weather radars, marine navigation radars, satellite mapping radars, police speed measuring radars, automotive collision avoidance radars etc.

\subsubsection{Fundamentals of Radar}

Radar consists of a transmitter, duplexer and receiver in a very simple case. Only one antenna is usually enough for both transmitting and receiving. The radar signal is generated by a powerful transmitter and received by a highly sensitive receiver. Therefore the receiver must be protected from the high power of the transmitter. Duplexer is used for this objective. Transmitters emit radio waves called radar signals in a particular type of waveform such as pulse modulated sine wave to the predetermined directions. When these signals come into contact with an object they are usually reflected in many directions. The radar signals that are reflected back towards the transmitter are the desirable signals that make radar works. Radar receivers are usually in the same location as the transmitter. The reflected radar signals captured by the receiving antenna are usually very weak depending on their travelling path and are strengthened by amplifiers [1]. A block diagram that shows the operation of typical pulse radar is given in the Figure 2.1.

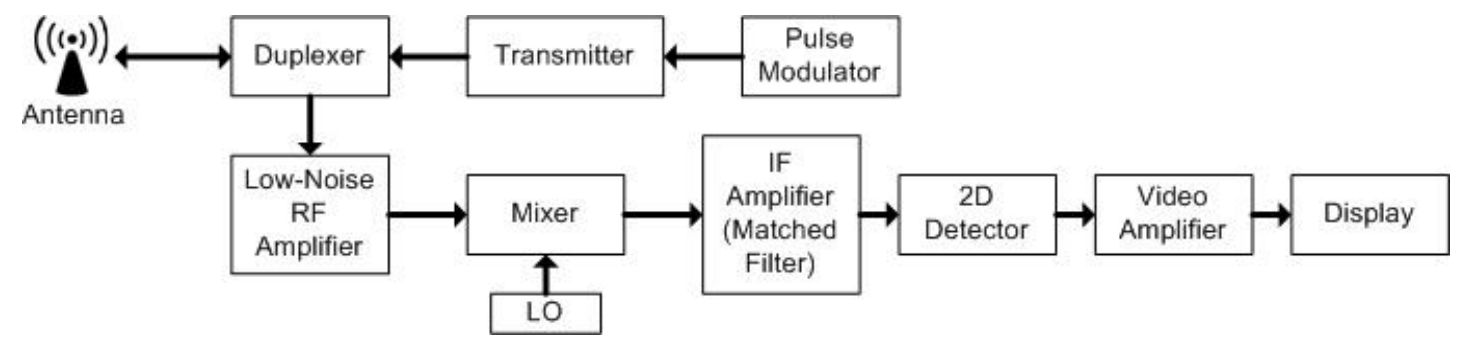

Figure 2.1 Block Diagram of a Pulse Radar 
The most common radar waveform is a train of pulses modulating a sine wave carrier [1]. A typical radar time line is shown in the Figure 2.2. Radar transmits a powerful signal and waits for weak attenuated echo signal. By the time between these operations radar can calculate the range of the target by using;

$$
R=\frac{c \times T_{r}}{2}
$$

where $\mathrm{c}$ is the speed of light, $T_{r}$ is the time between transmitted radar signal and observed echo signal.

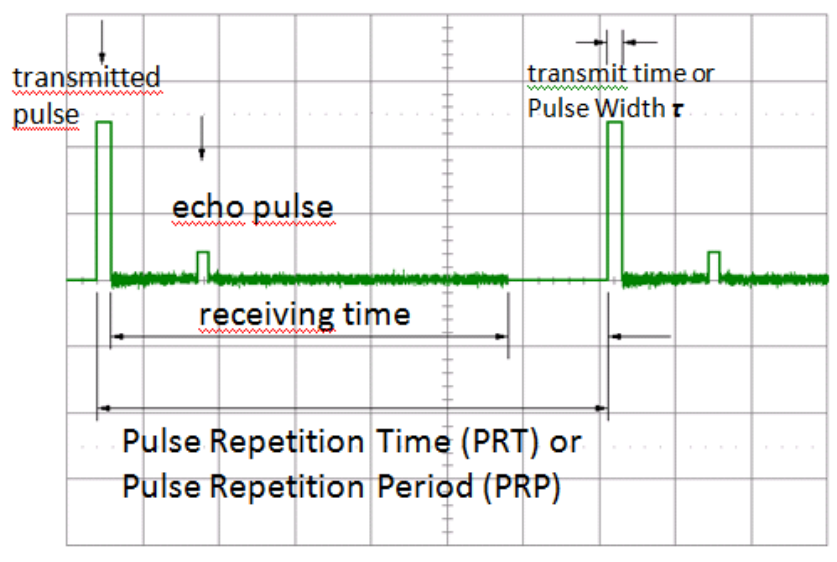

Figure 2.2 A Typical Radar Timeline

\subsubsection{Types of Radar Based on Scan Pattern}

Radars can be classified by the type of their scan patterns. Scanning can be defined as the motion of the beam in a specific pattern while tracking a target or searching a sector. In some cases, there are different scan patterns to achieve some particular system functions such as searching or tracking. 
Conical Scan: Conical scanning is the simplest type of scanning. In this type, a radar beam is produced by the mechanically steered antenna. Antenna rotates $360^{\circ}$ to cover the azimuth plane and beam is produced in the direction of antenna's main lobe. If there is a target on the bore sight line, maximum reflection will occur. When the target is away from the main lobe of the beam, reflected radar signal will decrease due to the distance from the bore sight. Target location can be found by the received maximum reflected signal. The disadvantages of conical scan type radars are the mechanical constraints and large side lobes which lead to signal losses and reduce the sensitivity of the variation in the received signal. It means that the target position is determined only by the power of the received signal and variations will cause misleading results. A typical conical scanning is shown in the Figure 2.3.

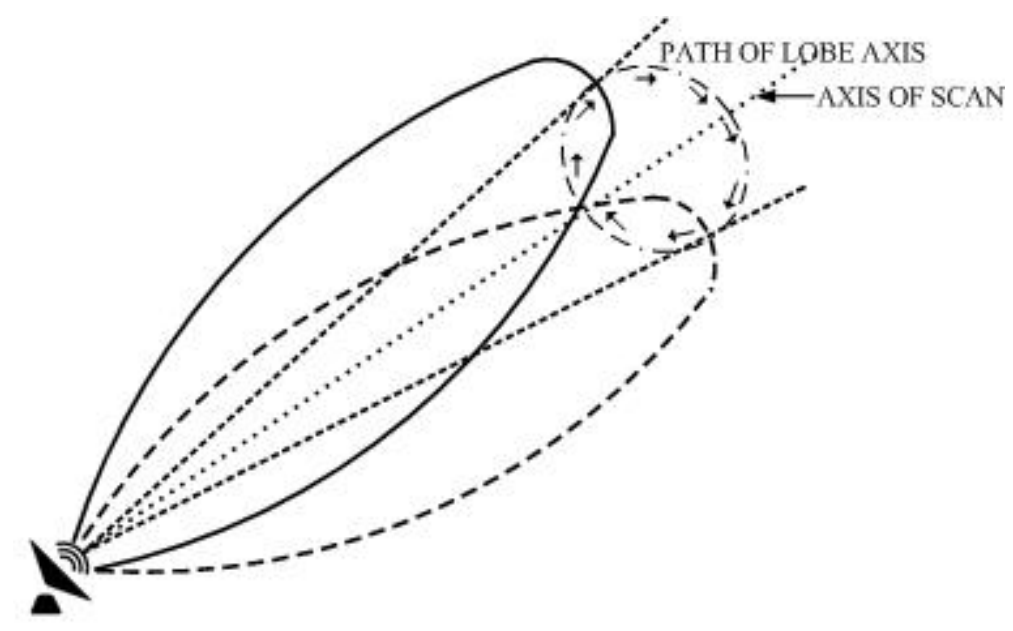

Figure 2.3 Conical Scanning

Track-While-Scan (TWS) Radars: TWS Radars allocate part of its resources to tracking targets while remaining part of its resource is used for searching for new targets. The disadvantage of TWS radars is to be highly vulnerable to jamming because of wide area scanning.

Monopulse Scan Radars: This type of radar is similar to conical scan type radars. The difference is to split the beam into sectors that are called lobes and send radar 
signals in slightly different directions. Received signals are compared to each other. A typical monopulse scanning is shown in the Figure 2.4.

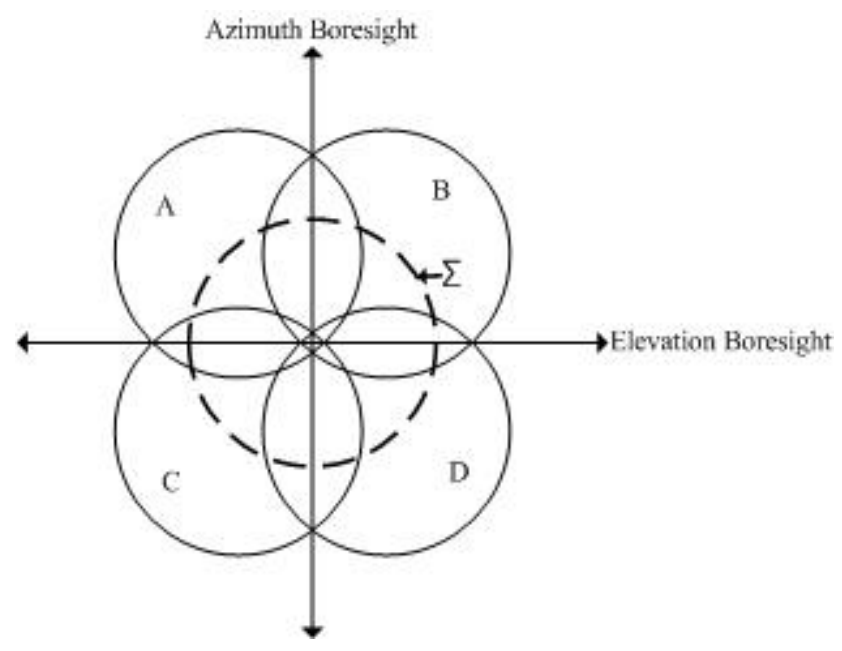

Figure 2.4 Monopulse Scanning

Electronically Scanning Radars: As we mentioned before, mechanical constraints is a big problem for some radar application such as maneuvering high speed targets will not be able to position the radar beam optimally due to the mechanical constraints. Electronically steering antenna produces agile beams without any mechanical constraint. Agile beams are produced by a group of antennas that radiates effective pattern in the desired directions and suppresses it in the undesired directions. Electronic steering and shaping of a beam provides extremely useful beam agility. It means beam shape and direction can be changed instantaneously and also controlled digitally. It is possible to use one phase array radar as multiple radars and each radar has a different beam shape and scan pattern. This is referred to as interleaving radar modes. In other words, the same radar can be used for tracking airborne threats by using one beam shape and scan pattern and searching for ground targets by using another type of beam shape and scan pattern. A typical electronically scanning radar is shown in the Figure 2.5 [6], [38]. 


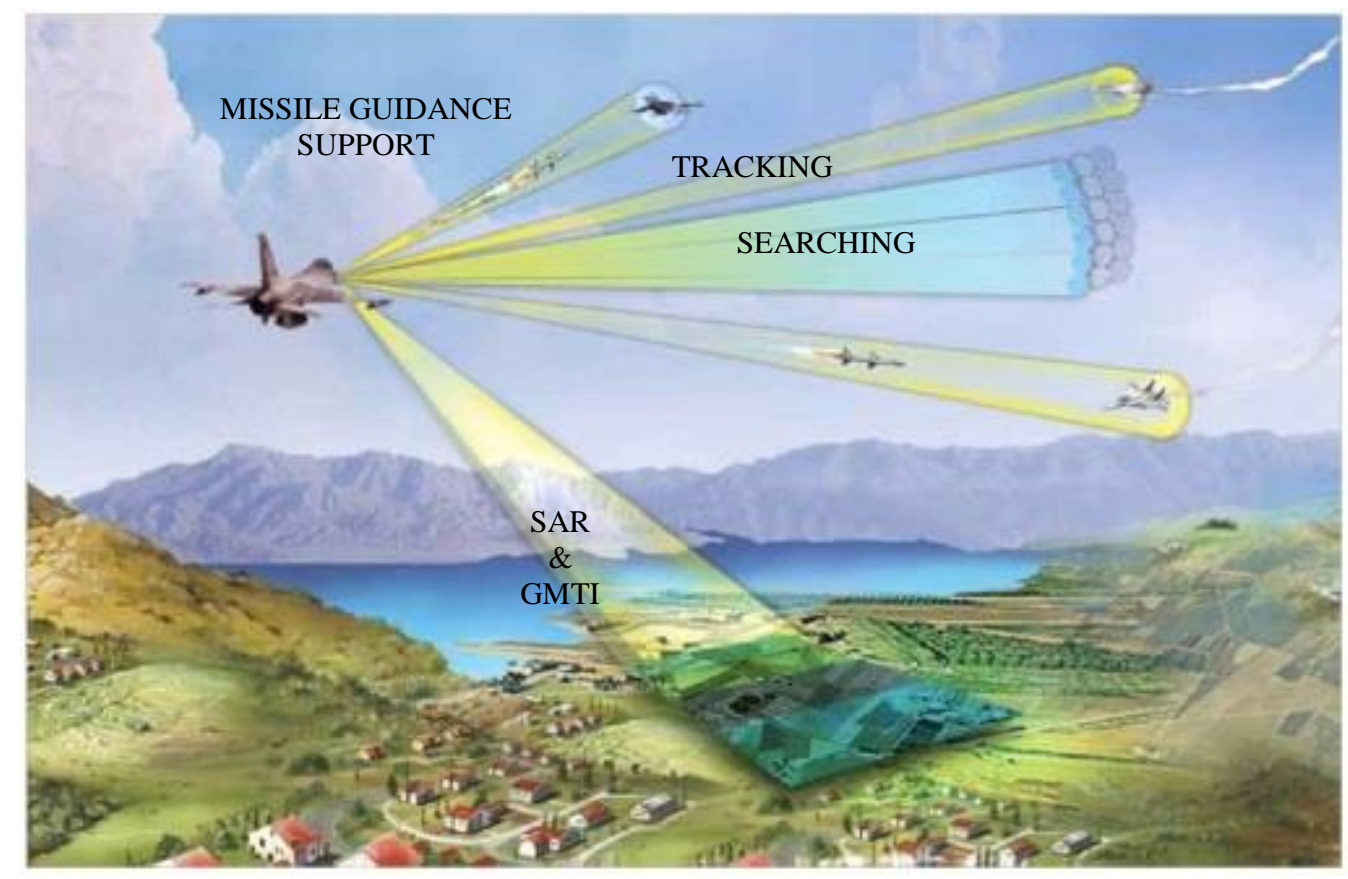

Figure 2.5 Electronically Scanning

\subsubsection{Electronically Steered Antenna Radars}

Electronically steered antenna (ESA) radars have the advantage of having an agile beam that means transmitted energy can be allocated adaptively in space and time. Radars that are equipped with an electronically steered antenna have the capability of directing the radar beam without mechanically adjusting the antenna. Furthermore, the beam can be redirected instantaneously towards any location in space. Hence, the mechanical constraint of a traditional antenna is relaxed. It is a significant improvement that targets can be observed in any order in multiple target tracking applications.

ESA radar has several advantages compared to ordinary radar systems.

- The direction of the radar beam is not fixed to the antenna,

- ESA radars have the ability to adaptively allocate radar energy in time and space where the demand is highest. 
- ESA radars have the ability to send beams in different directions and in an arbitrary order, so the high priority targets can be observed more frequently.

- ESA radars permit spending more time on one particular measurement. On the other hand, less time will then be available for other tasks.

The earliest phased array antenna system called as passive electronically scanned array (PESA) has one large central power amplifier tube to send the energy into phase shift modules for adjusting signal phases in a desired direction by using various emitting elements in the front of the antenna. On the other hand, an active electronically scanned array (AESA) device, also known as active phased array radar (APAR), has individual source in each emitting elements. Transmitter and receiver functions are merged in small solid-state transmit/receive modules (TRMs). Therefore, PESA radar is simpler and cheaper to construct than an AESA. But, the AESA architecture has significant advantages such as controlling the amplitude and phase of each element, adaptively.

Thus, the allocation of time and energy to various tasks is important for the overall performance of the radar system. The problem of resource allocation can be defined as "how to adaptively allocate the constrained radar resource in time and space to handle all tasks in the optimal way". This can be solved by designing a measurement policy that optimally utilizes the radar resources. Sensor management is used to achieve this purpose. The concepts of sensor management and radar resource management will be explained in Section 2.4.

\subsection{Target Tracking}

The aim of this thesis is to track multiple targets by ESA radar efficiently. In this section we will give brief information about the tracking problem and briefly define what tracking is and one of the motion models that is mostly used: constant velocity model. 
A target is anything whose state interests us. On the other hand, a track is a state trajectory estimated from a sequence of measurements that has been associated with a single source. Measurements are noisy observations related to the (partial) state of a target. Generally each arriving measurement starts or updates a track. Tracking is the processing of measurements obtained from a target in order to maintain an estimate of target's current state [7]. Detection is to know the presence of an object, meanwhile tracking is to maintain a state of an object over time. It maintains the object's state and identity despite detection errors (false negatives, false alarms), occlusions, and in the presence of other objects. An example that explains the tracking process is given below in Figure 2.6 [8].

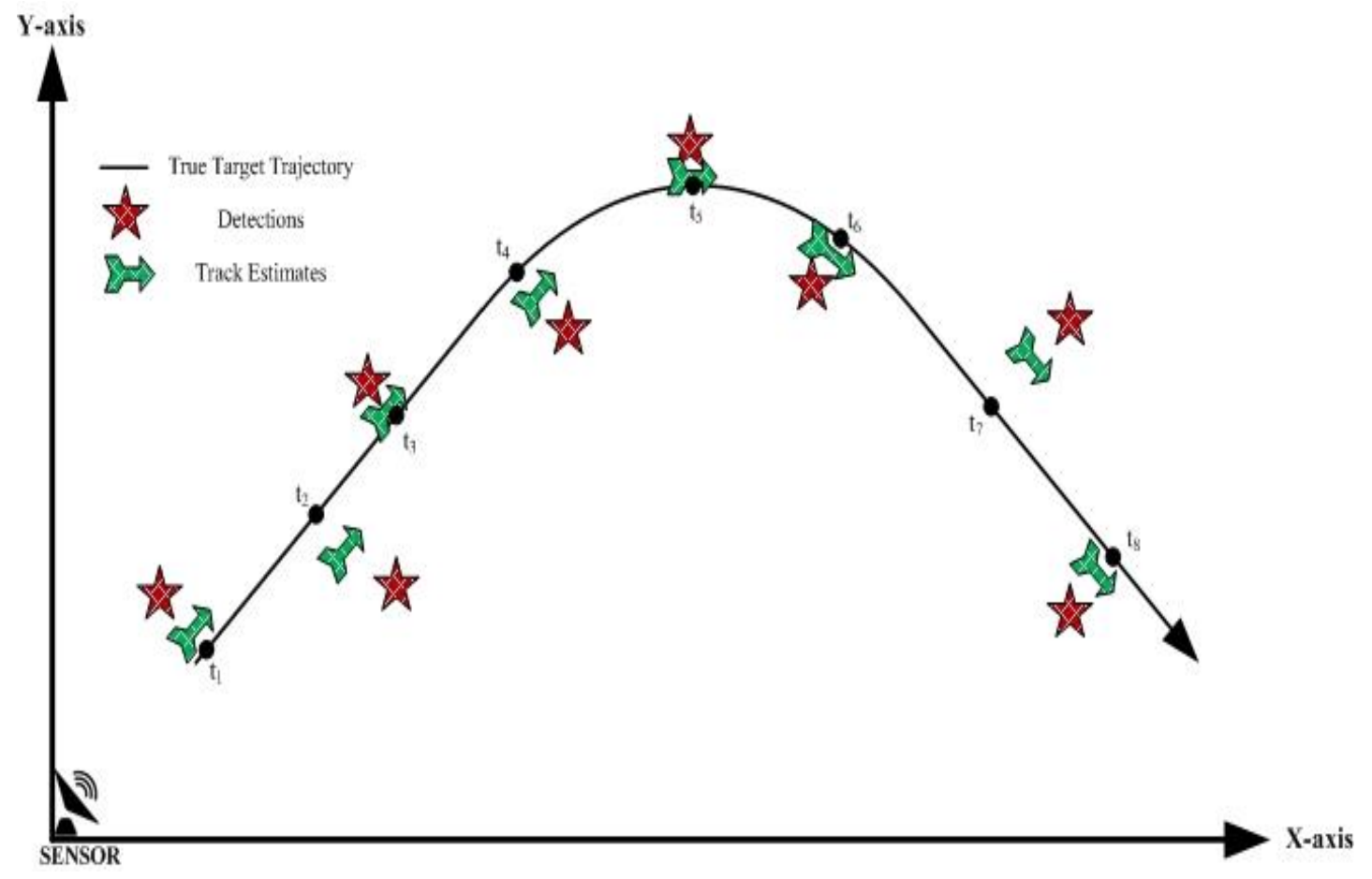

Figure 2.6 An Example of a Track

According to their different life stages, tracks can be classified into three cases [9]. 
Tentative (initiator): A track that is in the track initiation process. We are not sure that there is sufficient evidence that it is actually a target or not.

Confirmed: A track that is decided to belong to a valid target.

Deleted: A track that is decided to come from false alarms.

Tracker uses the measurements obtained from the neighborhood of the predicted position of a target to maintain the track. The predicted position is delivered by the motion model. Several problems are involved in this procedure. One problem is the computation of the predicted position. This is done by using the motion model of the target. However since motion of a target is not static usual practice is to use several models. Another problem is how to use the new measurement for track maintenance. For simple linear motion models Kalman filter seems to be the best tool for this purpose. For more complicated realistic cases some algorithms derived from the Kalman filter are used. Measurement-track association is another important issue. There are several ways of solving the association problem starting from the rule 'associate the nearest measurement' towards very complicated algorithms like 'multiple hypothesis tracking'.

In the remaining part of this sub section we will explain the simplest model that can be used for tracking so called constant velocity model. Then we explain the Kalman filter very briefly.

\subsubsection{Motion Model: The Constant Velocity Model}

The motion model is a state space model of the track motion, usually linear and the measurements are the position of the target in the $3 \mathrm{D}$ or $2 \mathrm{D}$ space. Kalman filtering and its variations are the mostly used tools in tracking problems.

The simplest model that is used for a tracking system is the 'constant velocity' model. It is used to represent the non-maneuvering targets motion. As its name 
implies model assumes that the target is moving on a straight line with constant velocity. Here we explain the constant velocity model.

Let $p(t)$ denote the target position, so the velocity is the first order derivative of the position, $v(t)=\dot{p}(t)$ and the acceleration is the second order derivative of the position $a(t)=\ddot{p}(t)$. Since we will use constant velocity model, acceleration is assumed to be almost zero so is modeled as a zero mean white Gaussian noise.

$$
\ddot{p}(t)=w(t)
$$

The state equations in one dimension are:

$$
x=\left[\begin{array}{c}
p \\
\dot{p}
\end{array}\right] ; \quad \dot{x}(t)=\left[\begin{array}{ll}
0 & 1 \\
0 & 0
\end{array}\right] x(t)+\left[\begin{array}{l}
0 \\
1
\end{array}\right] w(t)
$$

The model is usually used in discrete time since the measurements are obtained at discrete times. The discrete time equivalent of the above continuous time model is as follows.

Let $p_{k}$ and $v_{k}$ denote the target position and velocity at time $t_{k}$.

$$
x_{k}=\left[\begin{array}{c}
p_{k} \\
v_{k}
\end{array}\right] \text { and } T=t_{k+1}-t_{k}
$$

For real world, the perfect constant velocity assumption is unrealistic. Therefore some variation of velocity that is described by piecewise constant white acceleration is applied. The relaxed state equations then become: 


$$
\begin{gathered}
p_{k+1}=p_{k}+v_{k} T+\frac{1}{2} w_{k} T^{2} \\
v_{k+1}=v_{k}+w_{k} T
\end{gathered}
$$

where $w_{k}$ is called as process noise and it is a zero-mean Gaussian white noise: $w_{k} \sim N\left(0, \sigma_{w}^{2}(k)\right)$

$$
\begin{gathered}
x_{k+1}=\left[\begin{array}{c}
p_{k+1} \\
v_{k+1}
\end{array}\right]=\left[\begin{array}{ll}
1 & T \\
0 & 1
\end{array}\right] \cdot x_{k}+\left[\begin{array}{c}
\frac{1}{2} T^{2} \\
T
\end{array}\right] \cdot w_{k} \\
{\left[\begin{array}{c}
\frac{1}{2} T^{2} \\
T
\end{array}\right] \cdot w_{k} \sim N(0, Q(k))}
\end{gathered}
$$

For n-Dimensional Cartesian coordinate system, state equations are similarly;

$$
\begin{aligned}
x_{k+1}= & {\left[\begin{array}{cc}
I_{n x n} & T \cdot I_{n x n} \\
0_{n x n} & I_{n x n}
\end{array}\right] \cdot x_{k}+\left[\begin{array}{c}
\frac{1}{2} \cdot T^{2} \cdot I_{n x n} \\
T \cdot I_{n x n}
\end{array}\right] \cdot w_{k} } \\
& {\left[\begin{array}{c}
\frac{1}{2} \cdot T^{2} \cdot I_{n x n} \\
T \cdot I_{n x n}
\end{array}\right] \cdot w_{k} \sim N(0, Q(k)) }
\end{aligned}
$$

where $Q(k)=\left[\begin{array}{cc}\frac{1}{4} T^{4} I_{n x n} & \frac{1}{2} T^{3} I_{n x n} \\ \frac{1}{2} T^{3} I_{n x n} & T^{2} I_{n x n}\end{array}\right] \sigma_{w}{ }^{2}(k)$ characterize the modeling uncertainty and $\sigma_{w}{ }^{2}(k)$ should be related to the acceleration magnitude. 
We assume only the positions can be measured. The measurement model can be given by

$$
y_{k}=\left[\begin{array}{ll}
I & 0
\end{array}\right] x_{k}+v(k), \quad v(k) \sim N(0, R(k))
$$

where the measurement uncertainty is specified by $R(k)$.

In this thesis, 2-D Cartesian coordinate system is used. $p_{x_{k}}$ and $p_{y_{k}}$ are the positions, $v_{x_{k}}$ and $v_{y_{k}}$ are the velocities in $\mathrm{x}$ and $\mathrm{y}$-axis, respectively. The state equations are given below.

$$
\begin{aligned}
& x_{k}=\left[\begin{array}{l}
p_{x_{k}} \\
p_{y_{k}} \\
v_{x_{k}} \\
v_{y_{k}}
\end{array}\right] \\
& x_{k+1}=\left[\begin{array}{cccc}
1 & 0 & T & 0 \\
0 & 1 & 0 & T \\
0 & 0 & 1 & 0 \\
0 & 0 & 0 & 1
\end{array}\right] \cdot x_{k}+\left[\begin{array}{cc}
T^{2} / 2 & 0 \\
0 & T^{2} / 2 \\
& \\
T & 0 \\
0 & T
\end{array}\right] \cdot w_{k}, \\
& w_{k} \sim N(0, Q(k)) \\
& y_{k}=\left[\begin{array}{llll}
1 & 0 & 0 & 0 \\
0 & 1 & 0 & 0
\end{array}\right] x_{k}+v(k), \\
& v(k) \sim N(0, R(k))
\end{aligned}
$$


where $Q(k)$ and $R(k)$ characterize the modeling uncertainty and measurement uncertainty. An accurate estimate of the state $x_{k}$ is needed to control the system. This is achieved by the Kalman filter.

The constant velocity model is too simplistic for many applications. This is mainly due to the unknown nature of the motion of the target: targets usually maneuver in some time intervals that the constant velocity model is insufficient. To overcome the motion uncertainties, more than one model is used in most applications [7], [10]. Interactive Multiple Model (IMM) is a famous modeling technique used for this purpose [7].

\subsubsection{The Kalman Filter}

Target tracking is a state estimation problem. A state space model is constructed in the previous section. 2-D motion state includes the target position and velocity in each axis at every time instant and observation model models the relationship with the current target state and the current observations. Over the past half century many techniques have been developed for target tracking. All of the techniques are related with the classical Kalman filtering, so here we explain the Kalman filter briefly. If the state model is linear and process and measurement noise are modeled as zeromean Gaussian white, the Kalman filter is the optimal estimator in the minimum mean square error (MMSE) sense [11].

The Kalman filter is a recursive data processing algorithm that generates optimal estimate of the states given the set of measurements. For the linear Gaussian system the posterior density at every time step becomes Gaussian and so is characterized by its mean and covariance matrix. The state space equations that are used in Kalman filtering are as follows. 


$$
\begin{array}{ll}
x_{k}=A \cdot x_{k-1}+w_{k-1}, & w_{k-1} \sim N(0, Q) \\
y_{k}=H x_{k}+v_{k}, & v_{k} \sim N(0, R)
\end{array}
$$

where $A$ and $H$ are known system and measurement matrices that define the linear function. Random variables $w_{k}$ and $v_{k}$ are mutually independent zero-mean white Gaussian with covariances $Q_{k}$ and $R_{k}$ respectively.

Kalman filtering can be divided into two parts as prediction and correction [12].

Prediction Step:

$$
\begin{gathered}
\hat{x}_{k \mid k-1}=A \hat{x}_{k-1 \mid k-1} \\
P_{k \mid k-1}=A P_{k-1 \mid k-1} A^{T}+Q_{k-1}
\end{gathered}
$$

Correction Step:

$$
\begin{gathered}
\hat{x}_{k \mid k}=\hat{x}_{k \mid k-1}+K_{k}\left(y_{k}-H \hat{x}_{k \mid k-1}\right) \\
P_{k \mid k}=P_{k \mid k-1}-K_{k} S_{k} K_{k}^{T}
\end{gathered}
$$

where

$\hat{x}$ : Estimated state

$A$ : State transition matrix

$P:$ State variance matrix

$Q$ : Process variance matrix

$R$ : Measurement variance matrix 
$y_{k}:$ Measurement

$H$ : Measurement matrix

$S_{k}=H_{k} P_{k \mid k-1} H_{k}{ }^{T}+R_{k}$ is the covariance of the innovation term $\left(y_{k}-H \hat{x}_{k \mid k-1}\right)$

$K_{k}=P_{k \mid k-1} H_{k}{ }^{T} S_{k}{ }^{-1}$ is the Kalman gain. Note that, covariance update can be rewritten as;

$$
P_{k \mid k}=\left(I-K_{k} H_{k}\right) P_{k \mid k-1}
$$

where $I$ is the identity matrix of dimension $n x n$.

After each prediction and correction step, the Kalman filter proceeds with previous a posteriori estimates used to predict the current prior estimates. The Kalman filter computes the mean and the covariance matrix recursively. The recursive process of Kalman filter is given below in Figure 2.7.

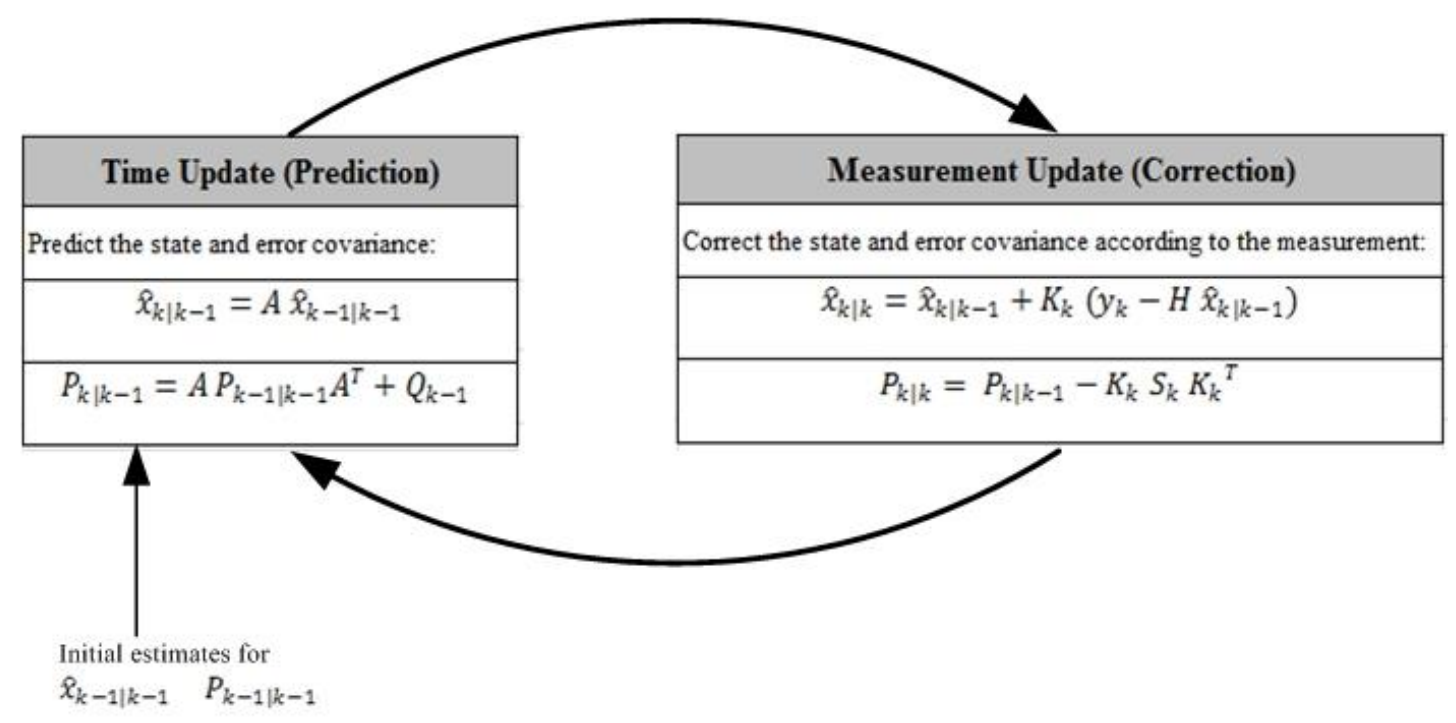

Figure 2.7 The Recursive Progress of Kalman Filter 


\subsubsection{Adaptive Target Tracking}

Track update rates need not be the same for all targets. An extreme example is that a ship and a missile clearly shouldn't be updated at the same rate due to the slow motion of the first one compared to the agility of the second. The update rate depends on the uncertainty of the state of the target compared to the beam width. If target uncertainty is low enough, radar resource can be used for other targets. By this way, more targets can be tracked in an acceptable uncertainty level. In Kalman filtering uncertainty parameter of the target (state covariance matrix) reaches the steady state value exponentially in case of regular updates. Therefore, after a few updates, uncertainty reaches its steady state value. However if the target is not updated, the error covariance matrix will continue to increase exponentially. When this value is under a certain threshold value, track does not need to be updated. An illustration is shown in Figure 2.8 below.

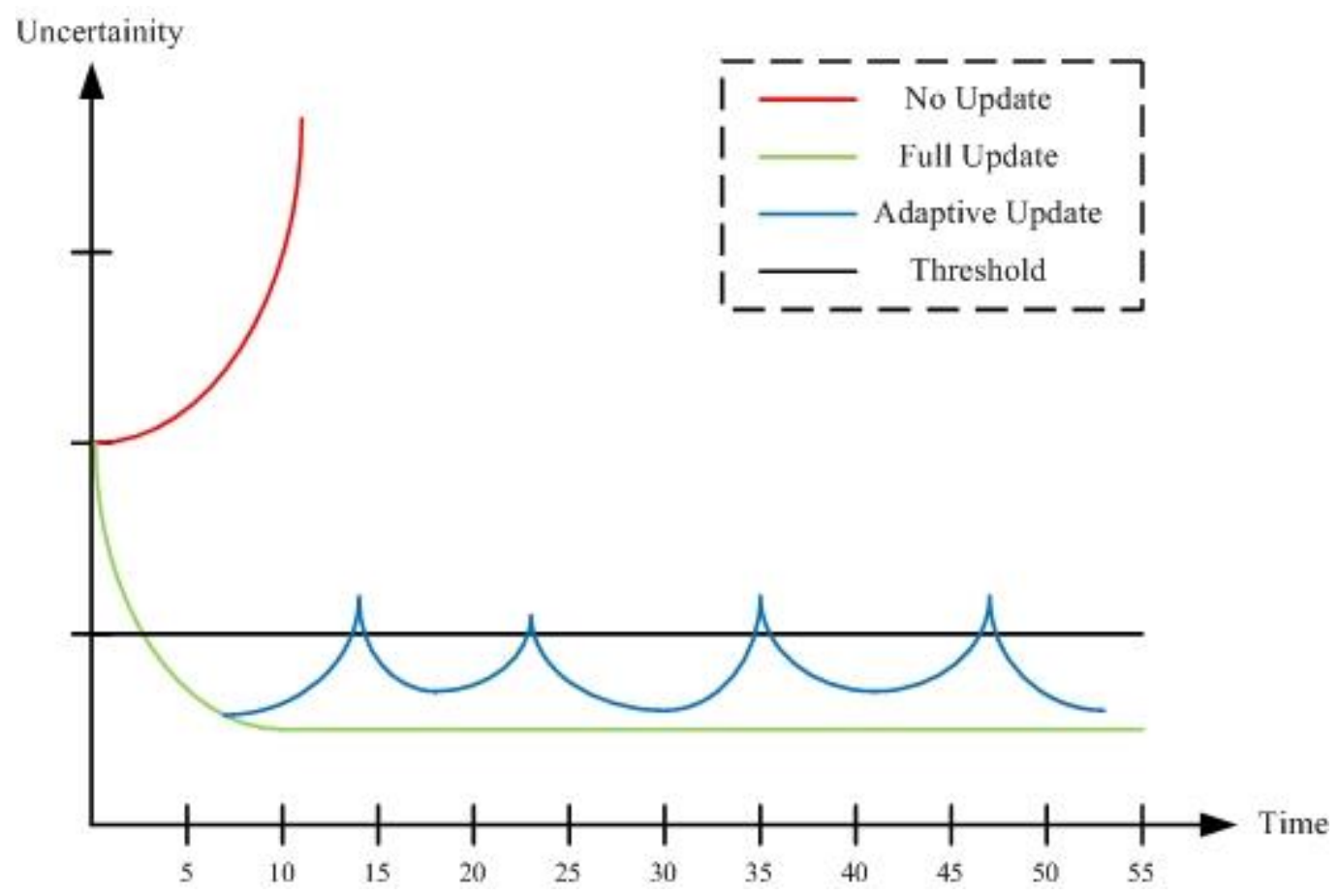

Figure 2.8 An Example of an Adaptive Update Strategy 
Adaptive update strategy is useful when limited radar resource is not enough to track desired number of targets. To find a reasonable update strategy for each target is the tracking scheduling problem. In Section 4.1 and Section 4.2, an optimal update strategy is constructed by using dynamic programming for one sensor and one target.

\subsection{Markov Chains}

The model used for solving the scheduling problem is a controlled Markov chain. So in this section we briefly explain what a Markov chain and a Markov Decision Process (MDP) are.

Markov process is a stochastic process that the conditional distribution at any time given the value at the previous times is same as the case that only the last value is given. For the discrete time and finite state case Markov process is named as 'finite state Markov chain'. When we have a control on the system, usually Markov chain is named as controlled Markov chain. In some systems it may not be possible to exactly know the state of the chain but only an observation is given related statistically with the state. The name used for the two cases is either Hidden Markov Model (HMM) if chain is not controlled or Partially Observable Markov Decision Process (POMDP) if control exists. The summary of this classification is given in Table 2.1.

Table 2.1 The Markov Models

\begin{tabular}{|l|c|c|}
\hline & $\begin{array}{l}\text { System state is fully } \\
\text { observable }\end{array}$ & $\begin{array}{l}\text { System state is partially } \\
\text { observable }\end{array}$ \\
\hline System is autonomous & Markov Chain & Hidden Markov Model \\
\hline System is controlled & Markov Decision Process & $\begin{array}{c}\text { Partially Observable } \\
\text { Markov Decision Process }\end{array}$ \\
\hline
\end{tabular}

The formal definition of a Markov chain and some of its properties are given below. 


\subsubsection{Markov Property}

This subsection gives a more formal approach to Markov chains.

Let $\Omega=\left\{a_{1}, a_{2} \ldots a_{N}\right\}$ be the set of states $x_{t}$ of a system. A Markov chain is a triple $\left(\Omega, \mathrm{P}, P_{0}\right)$ where $\Omega$ is the finite set of states, $\mathrm{P}$ is the transition probability matrix and $P_{0}=P_{r}\left(x_{0}\right)$ is the initial probability vector. This triple satisfies the following axioms:

1) The probability $P_{r}$ for each state of the system satisfies the Markov property i.e.,

$$
P_{r}\left(x_{t} \mid x_{0}, x_{1}, x_{2}, x_{3}, \ldots x_{t-1}\right)=P_{r}\left(x_{t} \mid x_{t-1}\right)
$$

2) A transition matrix of a Markov chain is called stochastic matrix which is a square matrix that has non-negative elements and each row sum is equal to 1 . For a system that has the $\mathrm{N} \times \mathrm{N}$ state transition matrix is defined by:

$$
P=\left(p_{i j}\right) \quad 1 \leq i, j \leq N
$$

where $p_{i j}=P_{r}\left(x_{t+1}=a_{j} \mid x_{t}=a_{i}\right) \geq 0$ and $\sum_{j=1}^{N} p_{i j}=1$ for $i=1,2 \ldots N$

3) $P_{0}=P_{r}\left(x_{0}\right)$ is the initial probability vector. 
Let us consider $n$-step transition probabilities $\mathrm{p}_{\mathrm{ij}}{ }^{\mathrm{n}}$ in terms of $\mathrm{P}$. The probability, starting in state $\mathrm{i}$, of going to state $\mathrm{j}$ in two steps is the sum over $\mathrm{k}$ of the probability of going first to $\mathrm{k}$ and then to $\mathrm{j}$. Using the Markov property in (2.20):

$$
p_{i j}^{2}=\sum_{k=1}^{N} p_{i k} p_{k j}
$$

It can be seen that this is just the $i j$ term of the product of the matrix $P$ with itself, i.e., that $\mathrm{p}_{\mathrm{ij}}{ }^{2}$ is the $i, j$ element of the matrix $P^{2}$. Similarly,

$\mathrm{p}_{\mathrm{ij}}{ }^{\mathrm{n}}$ is the $i j$ element of the $n$th power of the matrix $P$. Since $P^{m+n}=P^{m} P^{n}$

$$
\mathrm{p}_{\mathrm{ij}}^{\mathrm{m}+\mathrm{n}}=\sum_{k=1}^{N} p_{i k}{ }^{m} p_{k j}^{n}
$$

This is known as the Chapman-Kolmogorov equation.

Let $P_{t}$ denote the vector of the probabilities of each state at time $t$ :

$$
P_{t}=P_{r}\left(x_{t}\right)=\left(\begin{array}{c}
P_{r}\left(x_{t}=a_{1}\right) \\
P_{r}\left(x_{t}=a_{2}\right) \\
\vdots \\
P_{r}\left(x_{t}=a_{N}\right)
\end{array}\right)^{T}
$$

Note that $P_{t}$ satisfies following relation:

$$
P_{t}=P_{t-1} P=P_{0} P^{t}
$$




\subsubsection{Regular (Ergodic) Markov Chain}

$\mathrm{N}$-state Markov chain is regular (ergodic) if $P_{i j}{ }^{(k)}>0$ for all $i, j$, and all $k \geq(N-$ $1)^{2}+1$ [13]. This means that it is possible to go from any state $S_{i}$ to any state $S_{j}$ in $k$ steps with nonzero probability. A property of regular Markov chains is that the powers of $P$ converge, or $\lim _{n \rightarrow \infty}(P)^{n}=\Pi$ where the rows of $\Pi$ are identical. It is known that for the regular Markov chains one eigenvalue of $P$ is equal to 1 and all others are less than 1 in magnitude. Let $\omega=\left[\omega_{1} \omega_{2} \ldots \omega_{n}\right]$ be the unique normalized left eigenvector of $P$ corresponding to the eigenvalue one. For the regular chains $\omega_{i}>0$ for all $i$ and $\sum_{i=1}^{N} \omega_{i}=1$. That is $\omega P=\omega$. Furthermore each row of $\Pi$ is equal to $\omega$ and $P_{n} \rightarrow P_{0} \Pi=\omega$. That means at the steady state the probability of being in state $S_{i}$ is $\omega_{i}, 1 \leq i \leq N$ independent of the initial condition $P_{0}$.

\subsubsection{Absorbing Markov Chain}

A state $S_{i}$ is absorbing if $p_{i i}=1$, so $p_{i j}=0$ for $i \neq j$. That means once you are in the state $S_{i}$, you can never leave it. Suppose there are $k$ absorbing states, $1 \leq k \leq N$, and then we may rename the states (if needed) so that the transition matrix $P$ can be written as

$$
P=\left(\begin{array}{ll}
I & O \\
R & Q
\end{array}\right)
$$

where $I$ is the $k x k$ identity, $O$ is the $k x(N-k)$ zero matrix. $R$ is $(N-k) x k$ and $Q$ is $(N-k) x(N-k)$. The Markov chain is called an absorbing Markov chain if it has at least one absorbing state. The expected time of reaching an absorbing state from a non-absorbing state is finite. Note that for the absorbing chains we have 


$$
P^{n}=\left(\begin{array}{cc}
I & O \\
S R & Q^{n}
\end{array}\right)
$$

where $S=I+Q+\cdots+Q^{n-1}$.

Then, $\lim _{n \rightarrow \infty}(P)^{n}=\Pi$ where

$$
\Pi=\left(\begin{array}{cc}
I & 0 \\
R^{*} & 0
\end{array}\right)
$$

for $R^{*}=(I-Q)^{-1} R$. Notice the zero columns in $\Pi$ which imply that the probability that the process will eventually enter an absorbing state is one. The process eventually ends up with an absorbing state.

\subsubsection{Markov Chain with Rewards}

In some applications like the scheduling problem, a reward $R_{i}$ is associated to each state $S_{i}$ of the Markov chain. When Markov chain evolves, total reward is collected and it depends on the states that are visited by the chain. So the aggregated reward is related to the state transition matrix $P$. In this thesis, the reward of each state is related with the parameterized error covariance matrix. To increase the aggregated reward a parameter called the control variable would be necessary. Possibility of selecting the control parameter for each time instant makes the system a Markov Decision Process. In Section 2.3.5 and Section 2.5 we explain Markov Decision Processes and the corresponding optimal control methodology: dynamic programming. 


\subsubsection{Markov Decision Process}

MDP explained here is based on [13]. Markov decision process (MDP) is a mathematical model for decision making in situations where outcomes are partly under the control of a decision maker and partly random.

A Markov decision process is a 5-tuple $\left(\Omega, \mathrm{U}, P_{.}(., .),. R_{.}(.,),. \gamma\right)$ where;

- $\Omega$ is a finite set of states,

- $\mathrm{U}$ is a finite set of actions, (alternatively, $U_{s}$ is the finite set of actions available from state $s$,

- $P_{U}\left(S_{i}, S_{j}\right)=\operatorname{Pr}\left(S_{t+1}=S_{j} \mid S_{t}=S_{i}, U_{t}=U\right)$ is the probability that action $U$ in state $S_{i}$ at time $t$ will lead to state $S_{j}$ at time $t+1$.

- $R_{U}\left(S_{i}, S_{j}\right)$ is the immediate reward (or expected immediate reward) received after transition to state $S_{j}$ from state $S_{i}$,

- $\gamma \in[0,1]$ is the discount factor, which represents the difference in importance between future rewards and present rewards.

The total reward that must be maximized is the expected total reward that can be written as

$$
E\left\{\sum_{t=1}^{T} \gamma^{t} R_{U(t)}\left(S_{i}(t), S_{j}(t)\right)\right\}
$$

With this objective function the optimization problem can be written as

$$
\max _{U(t)} E\left\{\sum_{t=1}^{T} \gamma^{t} R_{U(t)}\left(S_{i}(t), S_{j}(t)\right)\right\}
$$


The problem is: At each time instant $k$, the Markov process is in some state $S_{i}$ and the decision maker may choose any action $U$ that is available in state $S_{i}$. The process moves randomly into a new state at the next time instant $k+1$ according to the given controlled Markov chain and this movement between states has a corresponding reward $R_{U}\left(S_{i}, S_{j}\right)$. The chosen action affects the probability of moving to a new state $S_{j}$. State transition matrix that depends on the decision action $U$, gives the probability of moving to a new state $S_{j}$. Therefore, the state $S_{j}$ in next time instant $k+1$ depends on the current state and the decision action $U$ that we made. On the other hand, it is conditionally independent of all previous states and actions given that $S_{i}$ and $U$. The difference between Markov chain and MDP is the addition of actions $\left(U_{i}\right.$ 's) and rewards $\left(R_{U}\left(S_{i}, S_{j}\right)\right)$. Conversely, if only one action exists for each state and all rewards are the same a Markov decision process reduces to a Markov chain.

Decision maker uses a set of rules that is called as 'policy' in selecting alternative at each time. The aim of MDPs is to find a decision policy that can be represented as a matrix that relates the states to the decisions. We want to consider the expected aggregate reward over a long time interval such as n steps of the 'Markov chain' as a function of the policy used by the decision maker. There are two types of policies that can be used by the decision maker. If the fixed decision is made for all states independent of time, past decisions and past transitions, it is called as stationary policy. On the other hand, optimal policy is used to maximize the expected aggregate reward over a long time interval. Optimal policy changes depend on the selected length of the long time interval. A final reward should be determined appropriately. Optimal dynamic policy for that final reward is an optimized strategy and is a function of the length of the long time interval and the determined final reward. The objective is to generate an optimal policy that will maximize the random aggregated reward in a finite time horizon. This policy can be found by using the dynamic programming algorithm which is defined in Section 2.5. 


\subsection{Resource Management}

The aim of the resource management is to optimize the overall performance and effectively perform tasks of detecting new targets and track the existing ones in a tracking system by allocating the available resources. The main resource of the problem mentioned here is the time. The parameters that determine the effectiveness of the use of this resource are usually track loss, tracks that are not initiated, track uncertainty or quality and track priority.

The state error covariance matrix gives the information about the current state quality of the tracking system. The part of the state error covariance matrix that corresponds to the target position is usually used in the scheduling problems. State error covariance matrix is obtained from the filter output which is a variant of Kalman filtering for most of the time [14], [15], [16]. For example in [16] multi sensor scheduling method by using IMM filtering is presented.

Sensor manager tries to optimize the overall system performance usually by using the track quality derived from the covariance matrix and the related reward function.

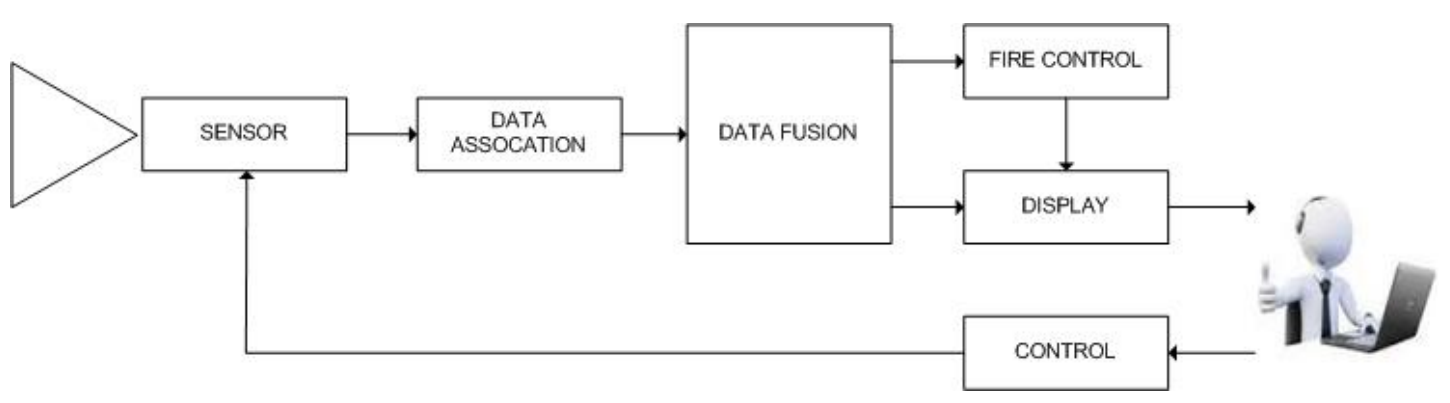

Figure 2.9 Operator as Feedback Controller 


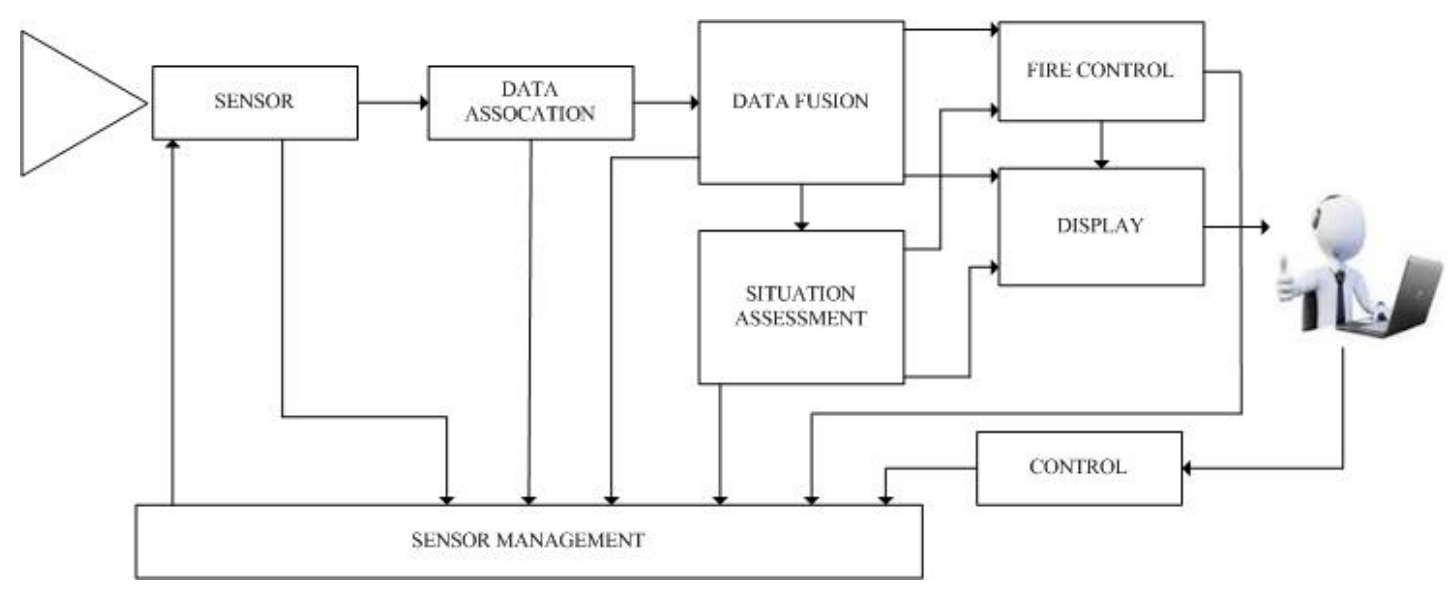

Figure 2.10 Sensor Manager as Feedback Controller

The role of automatic sensor management, compared to human operator, is to control the future sensor behavior while the operator still makes higher order tactical decisions. Note that in a system without sensor management, the operator makes all decisions related to the sensor for the next measurement time. On the other hand in a system with sensor management, primary feedback is provided by the sensor manager, under the possible guiding input from the operator. Figure 2.9 and Figure 2.10 illustrate the situations above.

Major advantages of sensor management can be summarized as follows.

Reduced pilot workload:

- Past information is used to determine the future behavior of the sensor by the sensor management.

- The operator is responsible to give only higher level decisions (tracks priority, degree of active radiation) 
Sensor tasking based on finer detail:

- Only limited amount of detail is displayed on screen, not the all information

- Therefore, operator focuses the tactical decision more deeply.

Faster adaptation:

- Since sensor management system is automated, it has faster adaptation to changing environment.

Other necessities of the sensor management:

- Effective use of limited radar resources

- Track maintenance

- Sensor fusion and synergism

- Support of specific goals

\subsubsection{Radar Resource Management}

This section gives general information about radar resource management which is more general then only scheduling. Radar resource management algorithms aim to enhance the overall radar system performance. The resource allocation problem of efficiently conducting several parallel tracking and searching tasks using the radar's antenna is an important part of the scheduling problem that needs to be considered. Due to the stochastic nature of radar detection and target dynamics, scheduling of radar measurements is a stochastic control problem [39].

The selection of all parameters that define the operation of the sensor determines the allocation of the limited resources. Parameters can be general tactical decisions, field of view, scanning types, measurement scheduling, waveform selection and processing directives. Each of these parameters is specified by a number of degrees of freedom. For example, waveform selection entails frequency, pulse repetition 
frequency (PRF), length of coherent integration and total time on target. The overall system performance depends on all these parameters. The overall system performance can be divided into two views to be managed. The parameter view of sensors and the mode view of sensors. The parameter view of managing sensors requires the sensor manager to directly control each parameter and the mode view is the upper level manager that simplifies the sensor management decision making. This is called as two-level two-timescale scheduling. Mode and parameter view of sensors refer as macro and micro management, respectively [17].

\section{Two-Level Two-Timescale Scheduling}

Scheduling of radar measurements naturally decomposes into two different scales. Macro level includes all high level tasking best summarized by the expression which task should the sensor perform. On the other hand micro level includes low level tasking such as how a particular Macro-task can be accomplished best. A few macro and micro manager tasks are given in Table 2.2, as examples [18], [19].

Table 2.2 Examples of Micro \& Macro Level Tasks

\begin{tabular}{|c|c|}
\hline $\begin{array}{c}\text { Micro Level Tasks } \\
\text { (Parameter Design) }\end{array}$ & $\begin{array}{c}\text { Macro Level Tasks } \\
\text { (Mode Selection) }\end{array}$ \\
\hline Pulse Reputation Frequency (PRF) & Long Range Search \\
\hline Pulse Width & Self-Protect Search \\
\hline Coherent Integration & Fire Control Search \\
\hline Time on Target & Alert Acquisition \\
\hline Detection Threshold & Track Update \\
\hline Peak Transmitted Power & Track Confirm \\
\hline Average Transmitted Power & Track ID Update \\
\hline Target Revisit Time & ECM Assessment \\
\hline Aperture Beamwidth & ECCM Support \\
\hline
\end{tabular}

As stated before in this study we are only interested in the scheduling problem so in the remaining part we will concentrate on this subject. An example of sensor management architecture for multi sensor system is shown in the Figure 2.11. [20] 
This architecture has one central macro manager and several individually located micro managers. Macro level seems to be a decision maker. Micro manager performs detailed sensor behaviors and tasks that are determined and prioritized by macro manager.

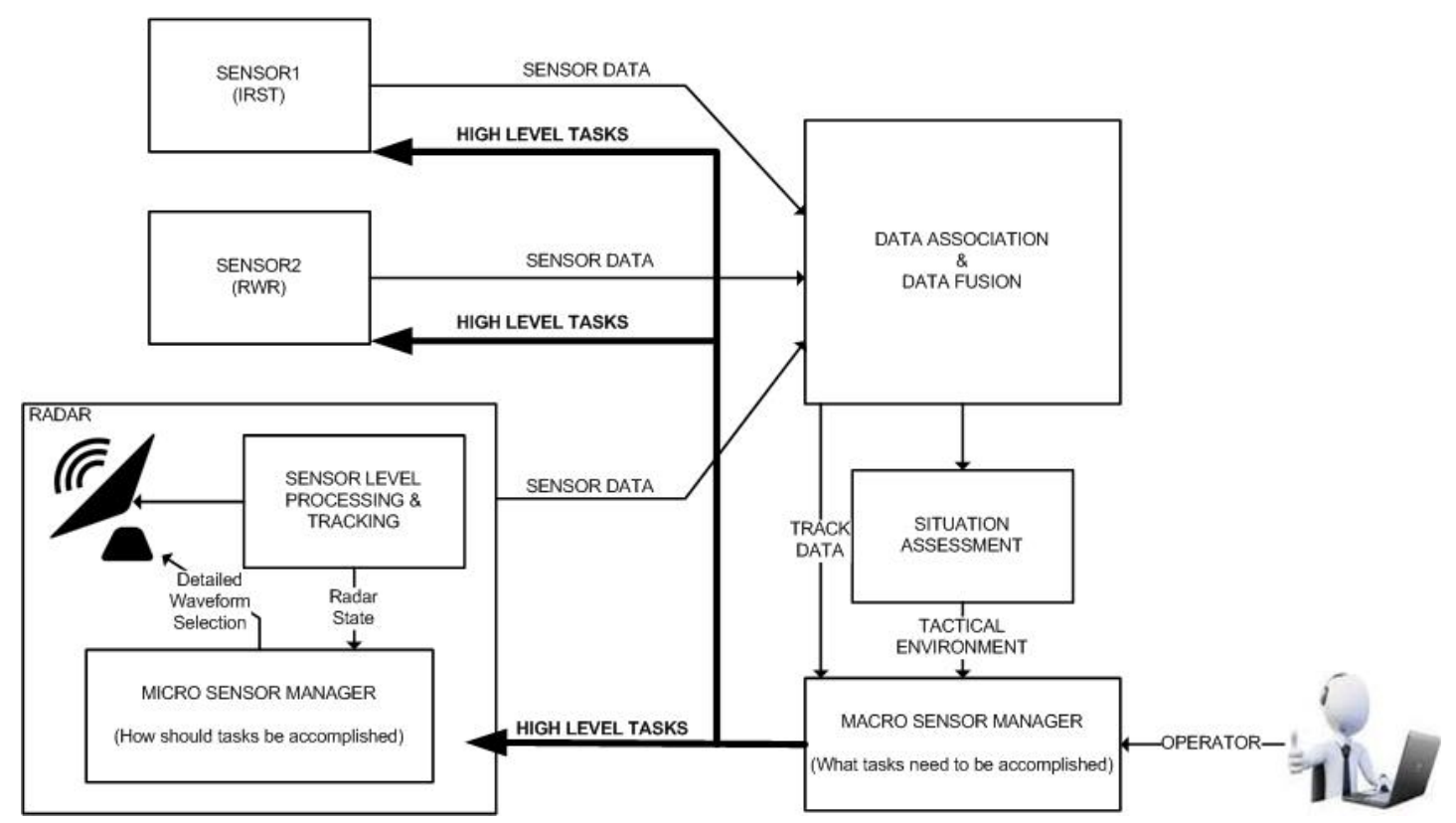

Figure 2.11 Partitioning Sensor Management into Macro/Micro Elements

Macro manager has slow time scale nearly $1 \mathrm{sec}$ and determines high level tasks such as update a track $(\mathrm{Tx})$, search a sector $(\mathrm{Sx})$ or update a missile track $(\mathrm{Mx})$, etc. in each period. The Macro level tasks may have some specific characteristics [21]. The tasks

- may have different priorities.

- may have different execution time durations.

- may suddenly become necessary or unnecessary.

- may be of uncertain duration.

- may not be interruptible. 
On the other hand, micro manager operates at fast time scale nearly $0.1 \mathrm{sec}$. It decides the order of these tasks and constructs a schedule to perform all tasks in the best way. Macro level sends tasks unorderly such as S1-S2-T1-T6-T9-M1 to the micro manager and scheduling is performed at the micro level. An example of sensor manager output is illustrated in Figure 2.12.

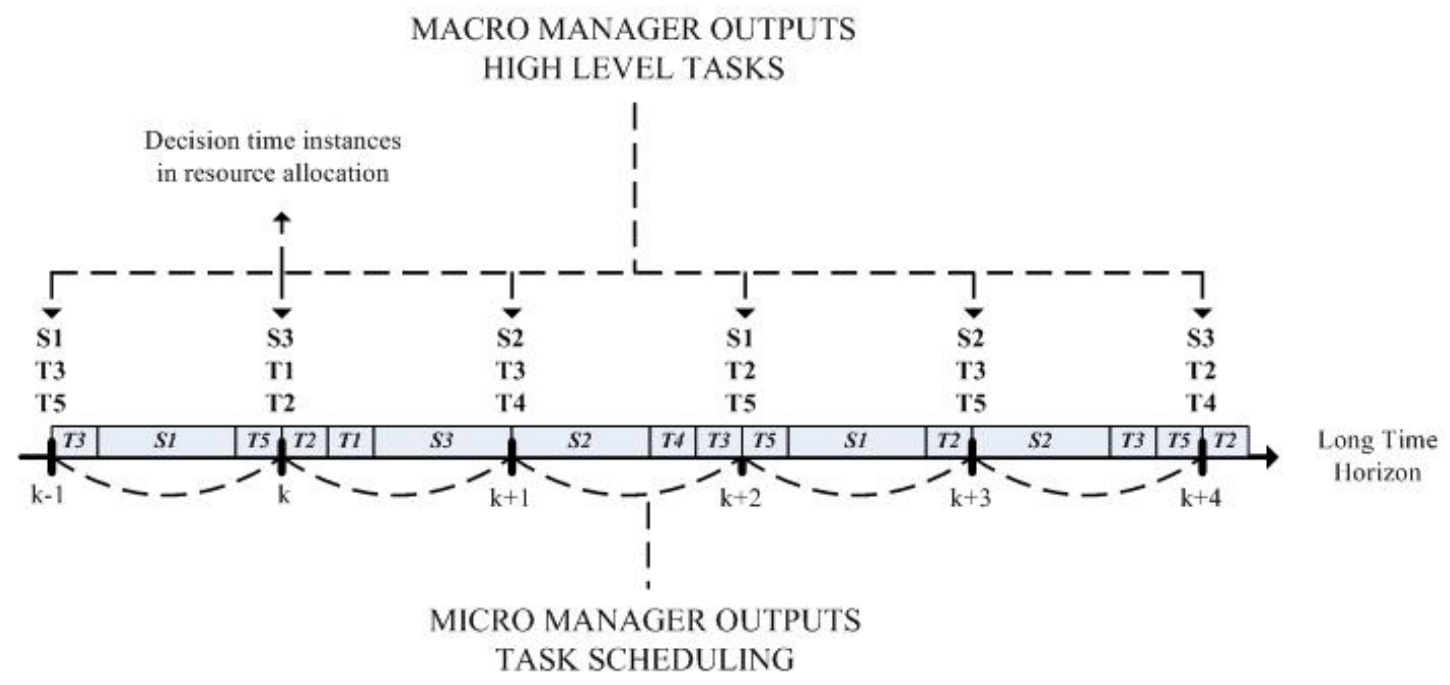

Figure 2.12 An Example of Macro and Micro Manager Outputs

In the literature, two general approaches are used to perform micro scheduling namely, myopic or best first and local optimum or brick packing approaches. Since we deal with macro management part of the sensor management, micro-management scheduling techniques are out of scope of this thesis. Detailed information about micro scheduling techniques is described in [22], [23], [24], [25], [26].

There are the two broad methodologies for macro scheduling: Heuristic Scheduling which is based on Rule-Based Design and Optimization-Based Scheduling. Brief information about these techniques is given in Section 2.4.2 and Section 2.4.3 respectively. 


\subsubsection{Rule-Based Heuristic Scheduling}

Rule based heuristic scheduling uses descriptive (if-then) rules. In these systems, macro level management is performed by fuzzy logic and/or neural network approaches where the inputs are the decisions of the operator and the outputs are the priority orders of targets and searching sectors. Since heuristic schedulers are not based on optimizing a cost function, their performance is difficult to predict.

Examples that are related to the rule-based heuristic scheduling are given in [27], [28], [29].

In rule based scheduling the policy performance standard provides the control mechanism which determines when tasks are sent to the sensor. The rules can be implemented with the fuzzy logic technology. Priority order between the objects is developed by fuzzy set memberships. The rules have the form:

Maintain <value> (performance metric) for sensor management object.

The adaption procedure determines the system adaptation in changing loads. Rules specify a fuzzy change to a set point or macro command parameter. The adaptation rule has the form:

IF: (sensor loading) is 〈value>

IF: premise

THEN: adjust (set point or macro parameter) <amount>

A simple example given in Figure 2.13 for Macro-level rule-based decisions, taken from [30], is shown below. The example first describes the performance standard then gives certain rules to satisfy this standard. 


\section{Performance Standard}

- P1: Maintain <good> Fire Control Track Quality on any track the operator has designated as <Operator Priority One>

- P2: Maintain <good> Fire Control Track Quality on any track which Situation Assessment System assessed to be <Engageable>

- P3: Maintain <good> Keep Track Quality on any track that has been detected

- P4: Maintain <good> Pop-Up Performance in self-protect volume

- P5: Maintain <excellent> Self-Protect on nose targets

- P6: Maintain < excellent> Fire Control on nose targets

- $\quad$.

\section{Adaptation Procedure}

- IF radar loading is excessive:

\section{- $\underline{\text { RULE1 }}$}

IF IR Self-Protect average performance is <good>

THEN raise IR Threshold <slightly>

\section{- RULE2}

IF IR Self-Protect average performance is <excellent>

THEN raise IR Threshold <moderately>

\section{- $\underline{\text { RULE3 }}$}

IF Pop-up average performance is <good> or better

THEN lower radar Self-Protect set point <slightly>

Figure 2.13 An Example of a Rule Based System Taken From [30] 


\subsubsection{Optimization-Based Scheduling}

Optimization based scheduling assumes a (multi-stage) cost function to be minimized or a reward function to be maximized over a finite or infinite horizon. Stochastic optimization methods such as stochastic dynamic programming (SDP) can be used to determine the optimal radar resource management policy. Unfortunately, when a large number of states and targets are used, the complexity and the dimensionality of the DP problem will be huge. In the literature the use of these techniques are relatively new due to their high computational power requirement [31], [32] and [33].

In resource management, we desire to optimize a non-instantaneous reward criterion. A non-instantaneous reward means that future consequences over a finite or infinite time-horizon are considered when making a decision. Within the time horizon, new decisions will be made, and this is handled in the modeling by formulating a multistage decision problem.

Unfortunately, in all of the models used for this purpose the size of the state space explodes exponentially with the number of targets in the scenario, and an optimal approach is infeasible even for a small number of targets. Therefore, approximate solutions are needed. In [32] it is suggested to separate the problem into components, so that each component can be optimized locally (Separation into Subtasks).

In this thesis, we will present hierarchical resource management algorithm for ESA radars. The resource management problem will be formulated as a constrained Markov decision process that is detailed in Section 3.2 and macro level of a twolevel (two-timescale) resource management algorithm is presented in Section 3.5. 


\subsection{Dynamic Programming}

Dynamic programming is an efficient method to solve recursive optimization problems. For the MDP described in Section 2.3.5, backward dynamic programming is applied. The basic idea is to start from the last time of the problem horizon [1 T] and to find the value of the objective function assuming that the state is ' $i$ ' at this time for each ' $i$ '. At time $T-1$ it is again assumed that the state is ' $i$ ', and the incremental reward and the expected value of the reward of going from time $T-1$ to time $T$ is maximized with respect to the input. Detailed explanation of the algorithm is given below [34], [13].

Let $n$ be the time horizon that we try to maximize the expected aggregate reward. Time interval starts from " $m$ " to " $m+n-1$ ", $[m, m+n-1]$, with a final reward at time $m+n$. Suppose $n=1$, decision $\mathrm{k}$ is made with instantaneous reward $r_{i}{ }^{(k)}$, given $X_{m}=i$. The next state $X_{m+1}=j$ with probability $P_{i j}{ }^{(k)}$ and the final reward is $u_{j}$. The expected aggregate reward over times " $m$ " and " $m+1$ ", maximized over the decision $k$, is then

$$
v_{i}^{*}(1, u)=\max _{k}\left\{r_{i}^{(k)}+\sum_{j} P_{i j}^{(k)} u_{j}\right\}
$$

Note that, only one decision is made at time $m$, but there are 2 rewards. One is at time $m$ and the other is the final reward at $m+1$.

The notation $v_{i}^{*}(n, u)$ is used to represent the maximum expected aggregate reward from time $m$ to $m+n$ starting at $X_{m}=i$. 
With these notation (2.31) become

$$
v^{*}(1, u)=\max _{k}\left\{r^{k}+\left[P^{k}\right] u\right\}
$$

where $k=\left(k_{1}, k_{2}, \ldots, k_{M}\right)^{T}, r^{k}=\left(r_{1}{ }^{k_{1}}, r_{2}{ }^{k_{2}}, \ldots, r_{M}{ }^{k_{M}}\right)^{T}$,

Now, consider $v_{i}^{*}(2, u)$ which is the maximum expected aggregate reward starting from $X_{m}=i$ with decisions made at times $m$ and $m+1$ and a final reward at time $m+2$. An optimal decision at time $m+1$ can be selected based only on the state $j$ at time $m+1$. The decision at time $m+1$ (given $X_{m+1}=j$ ) is optimal independent of the decision at time $m$.

Note that using optimized decision at time $\mathrm{m}+1$, given $X_{m}=i$ and decision $k$ is made at time $m$, then the sum of expected rewards at times $m+1$ and $m+2$ is $\sum_{j} P_{i j}{ }^{(k)} v_{j}{ }^{*}(1, u)$. Adding the expected reward at time $m$ and maximizing over decisions at time $m$,

$$
v_{i}^{*}(2, u)=\max _{k}\left\{r_{i}{ }^{(k)}+\sum_{j} P_{i j}{ }^{(k)} v_{j}{ }^{*}(1, u)\right\}
$$

This same argument can be used for all larger numbers of trials. To find the maximum expected aggregate reward from time $m$ to $m+n$, we first find the maximum expected aggregate reward from $m+1$ to $m+n$, conditional on $X_{m+1}=j$ for each state $j$. This is the same as the maximum expected aggregate reward from time $m$ to $m+n-1$, which is $v_{j}^{*}(n-1, u)$. This gives us the general expression for $n \geq 2$ : 


$$
v_{i}^{*}(n, u)=\max _{k}\left\{r_{i}^{(k)}+\sum_{j} P_{i j}^{(k)} v_{j}^{*}(n-1, u)\right\}
$$

We can also write this in vector form as;

$$
v^{*}(n, u)=\max _{k}\left\{r^{k}+\left[P^{k}\right] v^{*}(n, u)\right\}
$$

where $\mathrm{k}$ is a set of decisions $k=\left(k_{1}, k_{2}, \ldots, k_{M}\right)^{T}$ each $k_{i}$ is the decision for the state $i$. $\left[P^{k}\right]$ is the state transition matrix whose $i j^{\text {th }}$ element is $P_{i j}{ }^{\left(k_{i}\right)}$ and $r^{k}$ denotes a vector whose $i^{\text {th }}$ element is $r_{i}{ }^{\left(k_{i}\right)}$. The maximization over $k$ in (2.35) is really M separate and independent maximizations; one for each state, i.e., (2.35) is simply a vector form of (2.34).

The dynamic programming algorithm performs the calculation of (2.34) or (2.35) iteratively/recursively for $\mathrm{n}=1,2,3, \ldots$. This algorithm is developed by Bellman [35]. Note that the algorithm is independent of the starting time $m$; the parameter $n$ is the number of decisions over the long time horizon that the expected aggregate gain is optimized. This algorithm provides the optimal dynamic policy for a given final reward vector $u$ and any given time horizon $n$. 


\section{CHAPTER 3}

\section{IMPLEMENTATION}

\subsection{Problem Statement}

Radar sensor scheduling for multi target tracking for ESA radar is realized by a stochastic dynamic programming based resource allocation algorithm. Sensor performance is measured by summing target wise utilities over a long time horizon. Our aim is to solve the macro scheduling problem by using optimization based methods. The problem is simplified and reduced to efficient tracking of isolated tracks that are not in the same beam. Searching is not included. The reduced problem is: for each time period decide on which tracks should be measured. Although the aim is to solve the simplified problem it is still too complex to solve by using dynamic programming. So we made several simplifications.

- Target is assumed to be tracked by a Kalman filter using constant velocity model.

- Target's probabilities of detections are constant on the given time horizon and known.

- Targets are already tracked at the beginning of the interval. 
- There is no search function. We deal only with the tracking task.

- There is no track initiation process. If a target drops, it will never be reinitiated.

- There is no false alarm.

- The multidimensional kinematic state of each target is quantized to a single Markov chain.

Under these conditions the scheduling problem is formulated as a Markov decision process. Since the size of the Markov chain increases exponentially with the number of targets, Lagrange relaxation is applied to dynamic programming to simplify the state space dimension. The interval of the slow time scale is in the order of seconds. Macro manager decides which targets will be tracked at each macro time interval over the time horizon under certain constraints. The sensor performance is characterized by a target-wise utility function which is called 'reward function' of the target. The macro manager decides to allocate more radar resources to where the demand is high such as the high priority targets, adaptively.

We present in Section 3.1 the general scenario, target dynamic model that is used and the objective function that determines the performance. These lead to the construction of the related Markov chains given in Section 3.1.4. Resource allocation formulation on the slow timescale as a stochastic optimization problem is given in Section 3.2 and the resource constraints are defined in Section 3.3. By using Lagrange relaxation, overall problem can be divided into subtasks. The way we perform sub task separation is given in Section 3.4 and corresponding algorithm that is used for implementation is given in Section 3.5. 


\subsubsection{Target and Tracking Performance Model}

In this thesis, we optimize a Markov decision process by using dynamic programming to obtain the optimal policy that maximizes the cumulative expected reward. We assume that there are $n$ targets that are moving with constant velocity. They are indexed by $i \in\{1,2, \ldots, n\}$. An illustration is shown in Figure 3.1.

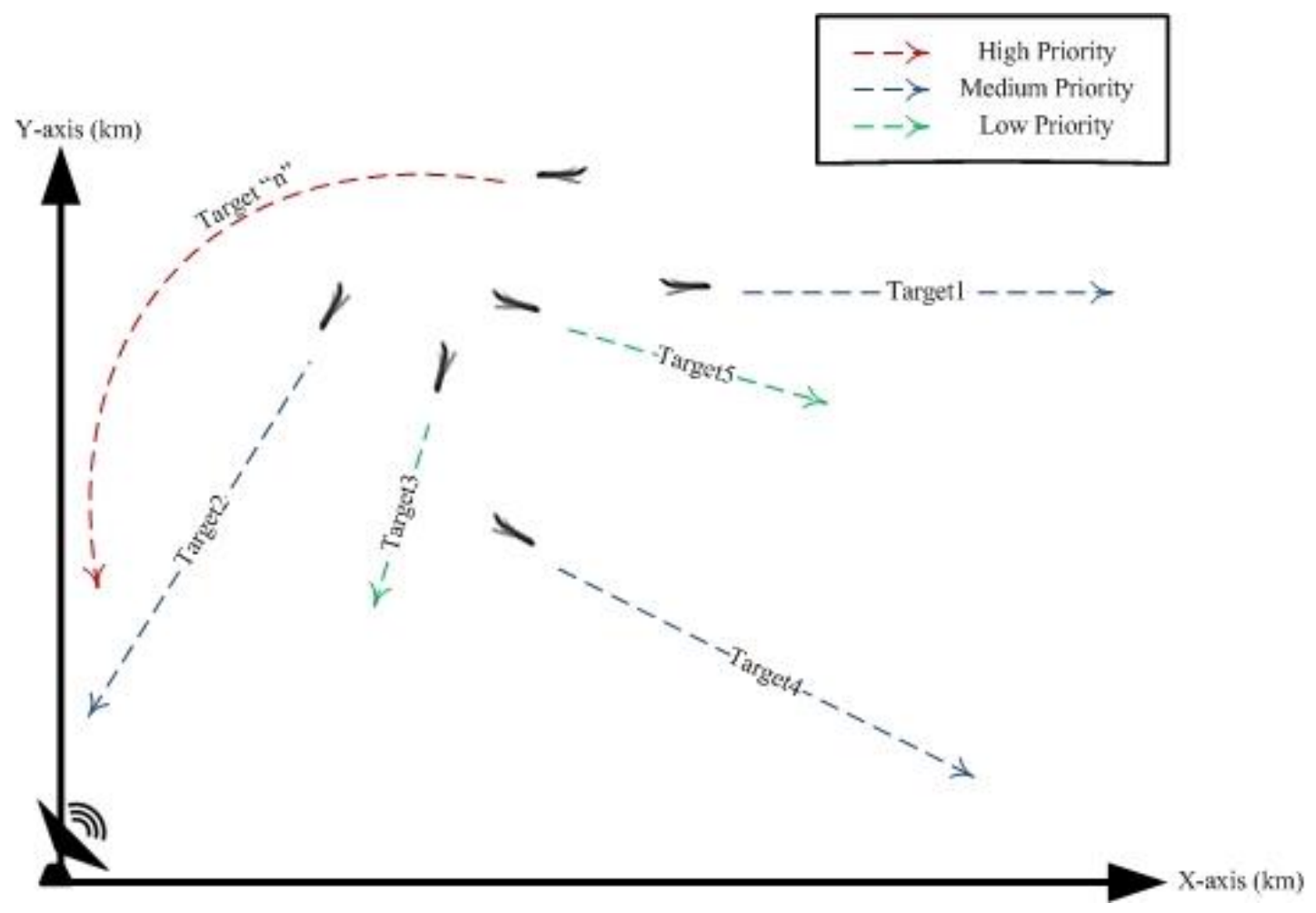

Figure 3.1 Target Motions and Priorities 
The target 2-D kinematic states are defined as:

$$
\xi_{i}(t)=\left[r_{x, i}(t), r_{y, i}(t), v_{x, i}(t), v_{y, i}(t)\right]^{T}
$$

where $r_{x, i}(t), r_{y, i}(t)$ are the position parameters of the target and $v_{x, i}(t), v_{y, i}(t)$ are the velocity parameters. The linear state space model is defined as:

$$
\xi_{i}(t+T)=F(T) \xi_{i}(t)+w_{i}(T)
$$

where $F(T)$ is the state transition matrix of the target state model and $w_{i}(T)$ is the white Gaussian process noise $w_{i}(T) \sim N\left(0, Q_{i}(T)\right)$.

Measurement model is expressed as:

$$
y_{i}(t)=C \xi_{i}(t)+v_{i}(t)
$$

where $C$ is the observation matrix of the target state model and $v_{i}(t)$ is the white Gaussian measurement noise $v_{i}(t) \sim N\left(0, R_{i}\right)$.

For simplicity, Kalman filter is used to evaluate state estimate $\hat{\xi}_{i, t \mid s}(t)$ of the track of the target $i$ at time $t$ given the measurement at time $s$. The conditional covariance is

$$
P_{i, t \mid s}=E\left\{\tilde{\xi}_{i, t \mid s} \tilde{\xi}_{i, t \mid s}{ }^{T}\right\}
$$


where $\tilde{\xi}_{i, t \mid s}=\xi_{i}(t)-\hat{\xi}_{i, t \mid s}(t)$

In general, $P_{i, t \mid s}$ is the most important input of the resource allocation process. For high priority targets, conditional covariance matrix is tried to be minimized. There is a direct dependence between covariance matrix and how often measurements are taken from the corresponding target. $Q_{a c c, i}\left(P_{i, t \mid s}\right)$ is derived from covariance matrix and it is a measure of the accuracy of the corresponding target.

A discrete parameterization of $P_{i, t \mid s}$ that represents the current state accuracy is given by the Kalman filter when the target is tracked.

\subsubsection{Discrete Parameterization of State Rewards}

The discrete parameterization of the Kalman filter covariance is presented in this section. This is needed to specify the state quality at a finite number of discrete values. Later, reward of a track is related to the discrete parameterization of covariance matrix.

Note that Kalman filter predicted and corrected covariance equations (2.16) and (2.18) are given in Section 2.2.2. When no beam is transmitted to the target according to the policy used, Kalman filter prediction step is applied. On the contrary if a measurement is taken, the both prediction and correction steps are applied. Two Markov chains are constructed for update / do not update decisions. The constructed Markov chains give the quantized accuracy $Q_{a c c, i}\left(P_{i, t \mid s}\right)$ of the next state. To be more precise let $k_{n}$ be the discrete time instance when the observation $n$ occurs. Let $T_{n}=k_{n}-k_{n-1}$ be the time between two update decisions. Actually, $T_{n}$ refers to the number of prediction steps. The Kalman filter covariance prediction and correction steps are progressed according to Riccati equation: 
Prediction Step:

$$
P_{i, k_{n} \mid k_{n-1}}=F\left(T_{n}\right) P_{i, k_{n-1} \mid k_{n-1}} F\left(T_{n}\right)^{T}+Q_{i}\left(T_{n}\right)
$$

\section{Correction Step:}

$$
\begin{aligned}
P_{i, k_{n} \mid k_{n}}=(I- & \left.K_{i, n} H\right) P_{i, k_{n} \mid k_{n-1}}\left(I-K_{i, n} H\right)^{T} \\
& +K_{i, n} R_{i, n} K_{i, n}^{T}
\end{aligned}
$$

where $Q_{i}\left(T_{n}\right)$ is the covariance of the process noise in the constant velocity motion model, $R_{i, n}$ is the covariance of the measurement noise, $K_{i, n}$ is the Kalman gain and $H$ is the observation matrix.

The trace of covariance matrix is accepted as the state quality. The Markov chain states correspond to quantized state quality $Q_{a c c, i}\left(P_{i, t \mid s}\right)$. In our applications the number of states is 26 meaning that quality is quantized into 25 values and the last state denotes the track drop. An algorithm is generated for the quantization of the quality. The algorithm is based on a fixed topology of the Markov chain. A simple example of a 10-state topology is given in Figure 3.2. The algorithm given in Table 3.1 determines the values of the covariance matrices for each state or equivalently quality of it according to the fixed topology. The approach of the algorithm is to find possible covariance matrices for different update/do not update events and then quantize the corresponding quality. Note that although the decision is for the Markov chain corresponding to the input 'update', due to miss detections, the update event may not occur. The examples in the pseudo code are for the 10-state example given in Figure 3.2. 
Figure 3.2 is constructed so that the quality decreases both as states moves to right and also down. The best state is State 1 and the smallest possible value of its covariance matrix is obtained when an update is applied at each time instant. The steady state covariance matrix gives an upper bound for the quality of this state. A lower bound is found by considering returns to this state from a state which has smallest quality. For the Markov chain of Figure 3.2, for initial state 1, this path is 47-3-6-9-3-6-9-3-1 and is obtained as a result of updating event of 0010010011 where 1 corresponds to a measurement update while 0 is only time update. The upper and lower bounds obtained in this way are used as bounds of quantization levels.

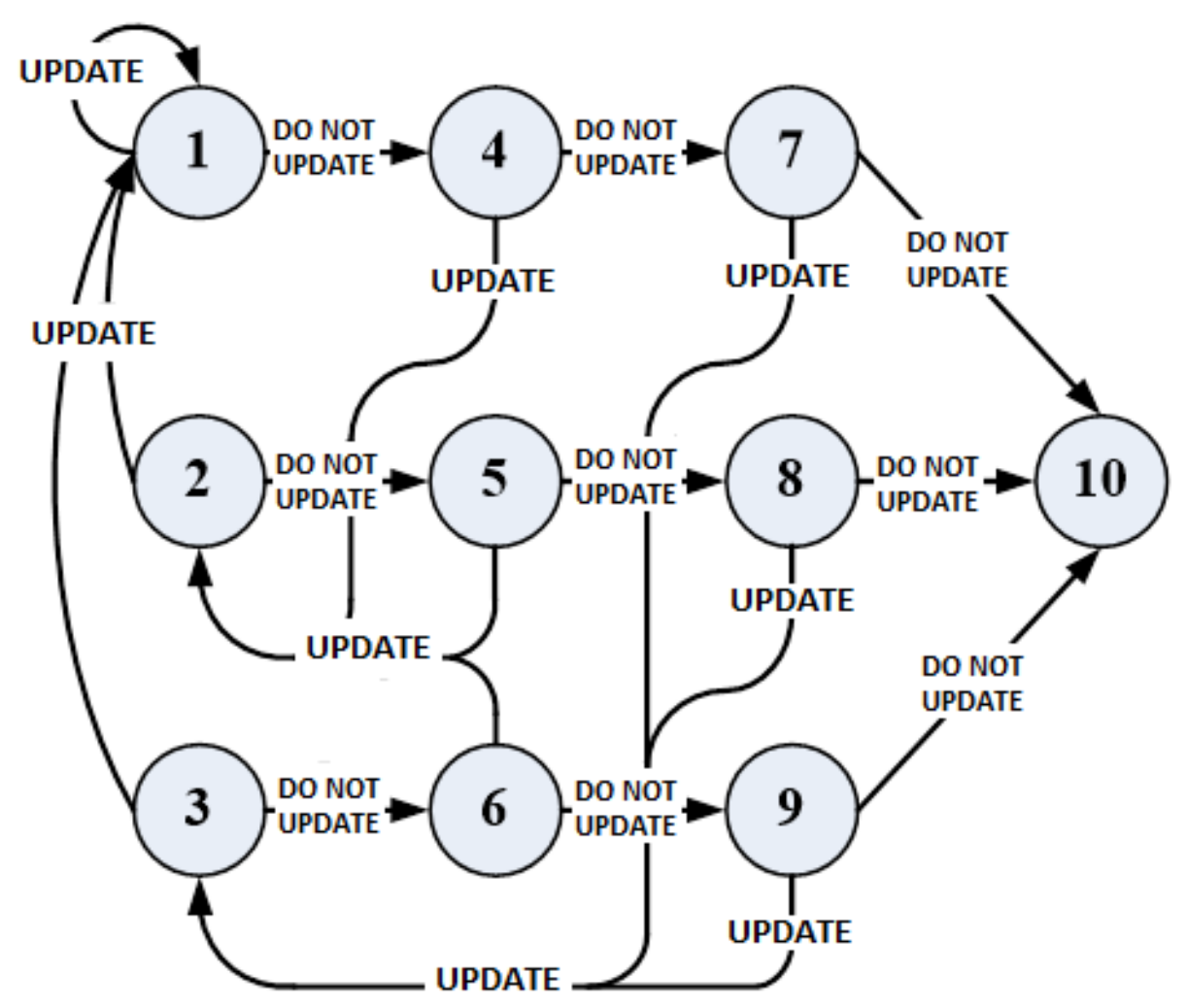

Figure 3.2 A Simple Example of a 10-State Topology 
A pseudo code for discrete parameterization of state rewards is given in Table 3.1.

Table 3.1 A Pseudo Code for Discrete Parameterization of State Rewards

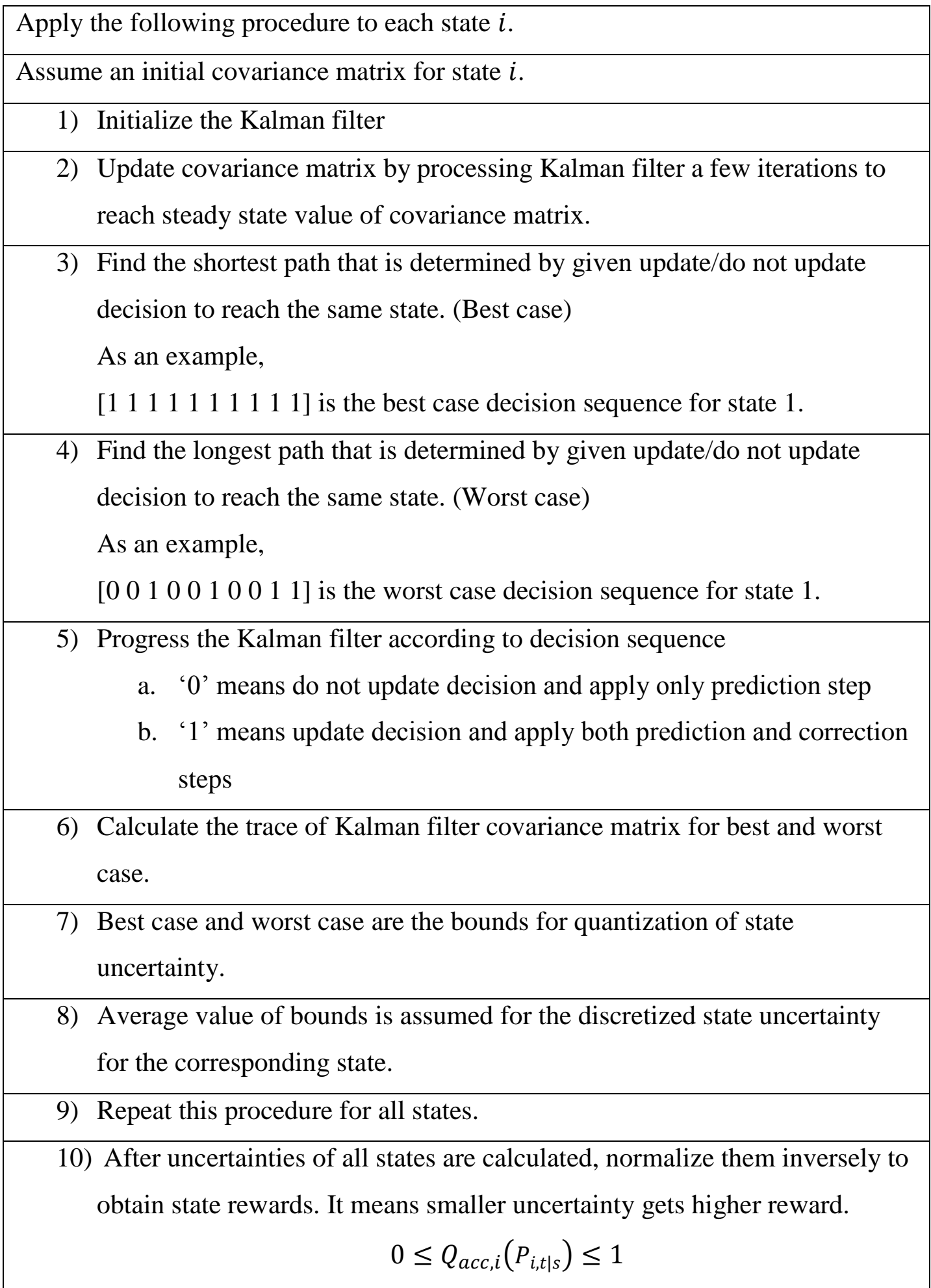




\subsubsection{Tracking Performance Characterization}

A finite valued discrete time state $x_{i, k}$ is defined for each target ' $i$ '. The tracking performance is determined by these states. ' $k$ ' is the slow timescale and the macro manager makes decisions on this slow timescale. At each time instant $k$, the state $x_{i, k}$ is an aggregate of state variables that are:

- $x_{i, \text { tracked }}(t) \in\{0,1\}$ refers as if a target is tracked or not in the time interval $k$.

- $\quad$ Current accuracy $Q_{a c c, i}\left(P_{i, k \mid k_{s}}\right)$.

These variables are needed to express the instantaneous utility $U_{i}\left(x_{i, k}\right)$ is defined as:

$$
U_{i}\left(x_{i, k}\right)=U_{n o m, i} Q_{a c c, i}\left(P_{i, k \mid k_{s}}\right) x_{\text {tracked }, i, k}(t)
$$

In this expression $U_{n o m, i}$ is the nominal utility function of the $i^{\text {th }}$ track, which must be determined by an external authority such as the operator. That value indicates the priority level of each target $i$. It is assumed that $U_{n o m, i}$ is constant during the long time horizon.

The overall instantaneous utility of the radar system at time $k$ is the sum of the individually defined utility functions that is specified for each target. It is defined as:

$$
\begin{gathered}
U\left(x_{k}\right)=\sum_{i=1}^{M} U_{i}\left(x_{i, k}\right) \\
x_{k}=\left\{x_{i, k}\right\}_{i=1}^{M}
\end{gathered}
$$


where $i$ is the index of the target, $k$ is the current time instance.

\subsubsection{Markov Model Used in the Thesis}

In this section, Markov models that are used in this thesis on the slow timescale are discussed. A controlled Markov chain is constructed for each target and state transitions are determined by the control action: "update/do not update track". All targets have the same controlled Markov chain structure. They differ by state transition probabilities that depend on detection probability of each target. We assume that detection probabilities depend on range of the target but do not change in the optimization interval. States of the Markov chain refer tracking quality that is determined by kinematic equations of target and derived from target error covariance matrix by quantizing the trace of the error covariance matrix given by the tracker.

Consider $p_{x_{i, k}}$ as the state probability vector of $x_{i, k}$. We assume that transitions in Markov chain depend on the current kinematic state and the measurement decision (update/do not update). Then, the target-wise dynamic model has the following form,

$$
p_{x_{i, k+1}}=P_{t r, i}\left(d_{k}, \xi_{i}(t)\right) p_{x_{i, k}}
$$

where $P_{t r, i}$ is the transition matrix of the Markov chain.

In our constructed Markov model, each target is represented by a twenty six state Markov chain. Markov chain states are numbered by considering their quantized track quality. First state (1) is the best state that has the least trace of the error covariance matrix. Last state (25) corresponds to the highest uncertainty and state 26 is the drop state that the tracker lost the target. The uncertainty depends on the state that the last update has occurred and the duration between two consecutive update instances. If a target is updated, the Markov chain jumps to one of the leftmost states 
depending on the time $T_{n}=k_{n}-k_{n-1}$ that is the time between the two update decisions. This means, if two consecutive update decisions are made, Markov chain jumps first state because of the time between two update decisions is 1. After an update decision, if two do not update decisions are made and then an update decision is made, Markov chain jumps two state to the right and jumps to the second state because of the time between two update decisions is 2 .

The constructed update and do not update decisions dependent Markov chains are shown in Figure 3.3 and Figure 3.4, respectively. 


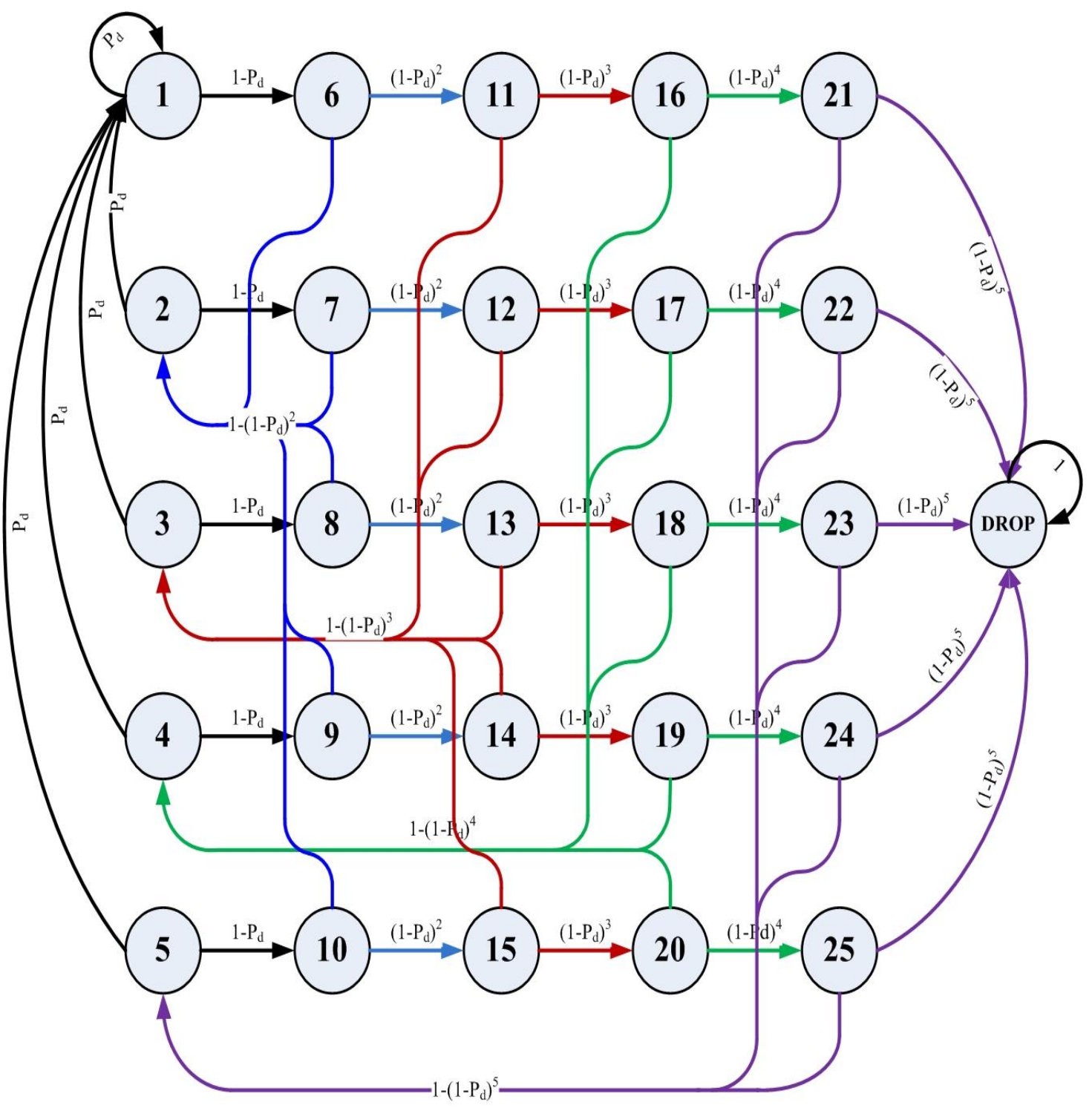

Figure 3.3 Target-Wise Markov Chain for Update Decision 


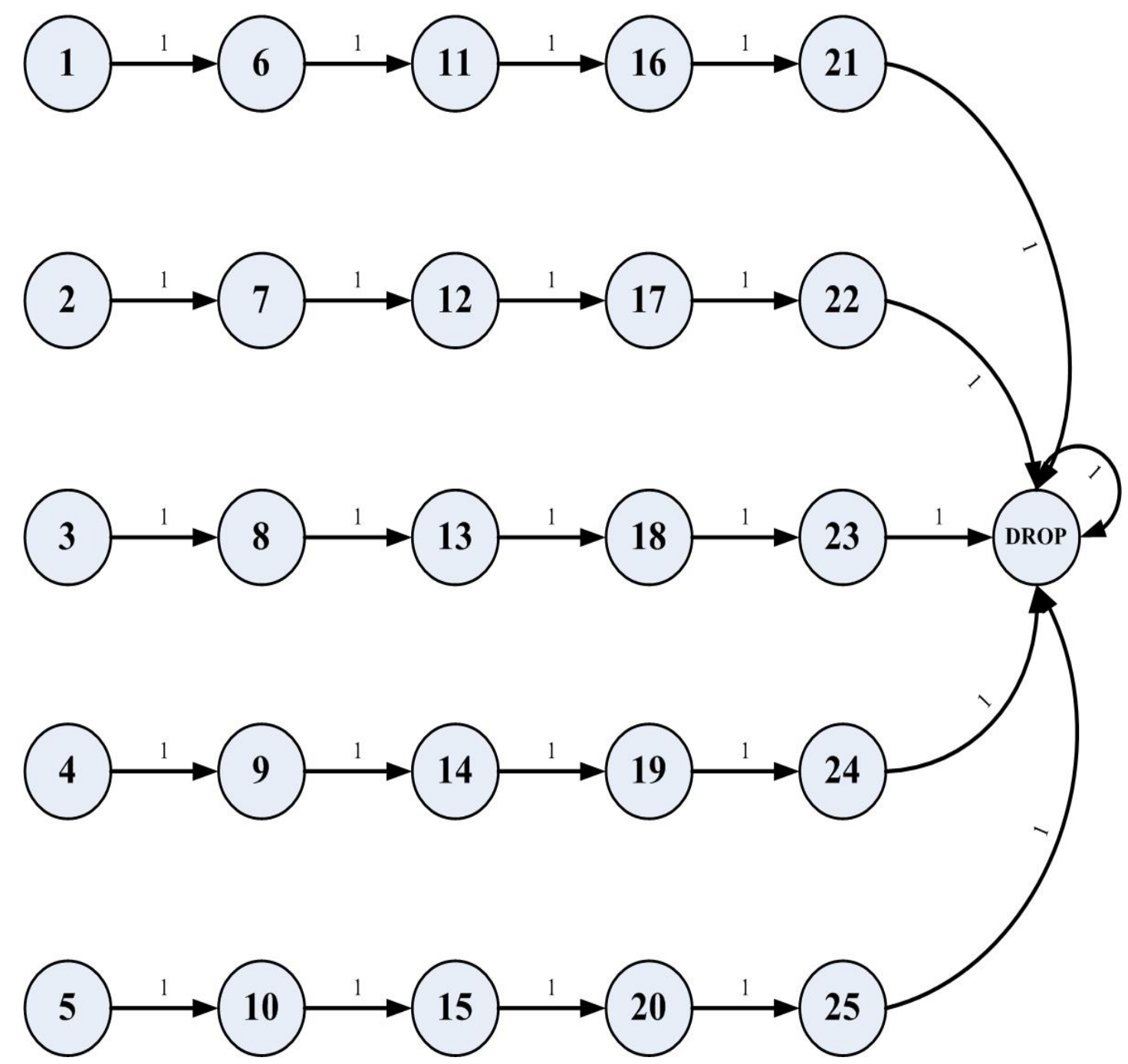

Figure 3.4 Target-Wise Markov Chain for Do Not Update Decision 
After we construct the Markov chains, the maximum numbers of looks that are used for improved detection probability are designed. This is needed because of the observation that if no such arrangements are done the target drops are excessive. Different numbers of update attempts are determined by the rule given below.

Main idea: Use less number of looks for better states. Each 'update' input triggers a possible sequence of look oriented to the target. For the case of unavailability of the observation the procedure is repeated. The number of possible repetitions in this application is given below for the 26 state Markov chain given in Figure 3.3.

- At most 1 look for states from 1 to 5 (the best quality states)

- At most 2 looks for states from 6 to 10

- At most 3 looks for states from 11 to 15

- At most 4 looks for states from 16 to 20

- At most 5 looks for states from 21 to 25 (the worst quality states)

State transition probabilities are different because of the number of looks used for repeated update attempts are different. According to the probability of detection a target may or may not be observed in a single look. At most ' $n$ ' ( $n$ is selected by the rule given above) looks are reserved for this purpose. The probability of detection of the target in:

- 1 look is: $1-\left(1-P_{d}\right)$

- 2 looks is: $1-\left(1-P_{d}\right)^{2}$

- 3 looks is: $1-\left(1-P_{d}\right)^{3}$

- 4 looks is: $1-\left(1-P_{d}\right)^{4}$

- 5 looks is: $1-\left(1-P_{d}\right)^{5}$ 
We assume that $T_{\text {onelook }}$ is a fixed parameter refers as the time spent for one look. As a result the expected time spent to detect a target is calculated by the rule below;

- For states from 1 to 5 :

- $T_{\text {onelook }}\left(1 . P_{d}+\left(1-P_{d}\right)\right)$ if at most one look is allowed.

- For states from 6 to 10 :

$\circ T_{\text {onelook }}\left(1 . P_{d}+2 P_{d}\left(1-P_{d}\right)+2\left(1-P_{d}\right)^{2}\right)$ if 2 looks are used.

- For states from 11 to 15 :

○ $T_{\text {onelook }}\left(1 . P_{d}+2 P_{d}\left(1-P_{d}\right)+3 P_{d}\left(1-P_{d}\right)^{2}\right)+3\left(1-P_{d}\right)^{3}$ if 3 looks are used.

- For states from 16 to 20 :

$\circ T_{\text {onelook }}\left(1 . P_{d}+2 P_{d}\left(1-P_{d}\right)+3 P_{d}\left(1-P_{d}\right)^{2}+4 P_{d}\left(1-P_{d}\right)^{3}+\right.$ $\left.4\left(1-P_{d}\right)^{4}\right)$ if 4 looks are used.

- For states from 21 to 25:

○ $T_{\text {onelook }}\left(1 . P_{d}+2 P_{d}\left(1-P_{d}\right)+3 P_{d}\left(1-P_{d}\right)^{2}\right)+4 P_{d}\left(1-P_{d}\right)^{3}+$ $5 P_{d}\left(1-P_{d}\right)^{4}+5\left(1-P_{d}\right)^{5}$ if 5 looks are used.

As an example for $P_{d}=0.8$ the average time spent on the target is $1.24 T_{\text {onelook }}$, for states from 11 to 15 and the probability of detection is 0.992 if 3 looks used case. 


\subsection{Resource Allocation Formulation}

The tracking performance model and motion model are described in the previous sections. The objective function and the constraints of the resource allocation problem are explained here.

The objective function that is used in this thesis, similar to [32], is a utility measure over a finite or infinite time horizon as desired. So we formulate the problem as a long horizon planning problem. Long time planning, compared to a myopic policy, is more advantageous. Long time planning not only includes present utility measure but also deals with expected future utilities. To achieve that purpose, a non-instantaneous track utility is defined by integrating the instantaneous utility over a time interval.

$$
U_{i}\left(t_{0}, t_{1}\right)=\int_{t_{0}}^{t_{1}} U_{\text {nom }, i} Q_{a c c, i}\left(x_{i}(t)\right) x_{\text {tracked }, i, k}(t) d t
$$

The current time instant corresponds to $t_{0}$ and the time horizon of the decisionmaking is $\left[t_{0}, t_{1}\right]$. In stochastic dynamic programming based problems, the expected utility refers to an objective function that should be maximized.

$$
E\left\{U_{i}\left(t_{0}, t_{1}\right) \mid x_{i}\left(t_{0}\right)\right\}
$$

Now, our aim is to maximize the objective function by making decisions over the long time horizon. So the objective function is:

$$
J_{0}\left(x_{0}\right)=E\left\{\sum_{k=0}^{N-1} U\left(x_{k}\right) \mid x_{0}\right\}
$$


Here, $N$ denotes the decision interval. The expectation includes the future radar measurements. The DP solution reduces the optimization problem to a nested set of smaller problems given in the recursive form. At time $t_{0}$ the optimization problem can be written as:

$$
\max _{d_{0}} U\left(x_{0}\right)+E_{x_{1} \mid x_{0}, d_{0}}\left\{J_{1}^{*}\left(x_{1}\right)\right\}
$$

where $J_{1}{ }^{*}\left(x_{1}\right)$ represents the future utility as a consequence of decisions $d_{0}$ made at $k=0$, and given a sequence of optimal future decision, i.e.,

$$
J_{k}^{*}\left(x_{k}\right)=\max _{d_{k}} U\left(x_{k}\right)+E_{x_{k+1} \mid x_{k}, d_{k}}\left\{J_{k+1}^{*}\left(x_{k+1}\right)\right\}
$$

The decisions are assumed to fulfill the resource constraints on available measurement time. Note that in the above equation, the modeling of the objective function has a recursive form of nested maximizations and expectations.

\subsection{Resource Constraints}

The randomness of the actual execution time of tracking a target task constraint the radar resources to allocate them in an efficient way. It is assumed that $T_{\text {onelook }}$ is defined as the time spent for one look. To track a target, the number of looks used is also random that depends on each targets current state in Markov chain as described in Section 3.1.4. All states are parameterized due to expected consuming resources according to the quality of each state. States in Markov chain are grouped into corresponding columns and each column has a different expected number of looks to track a target. Looks that are planned to track a target are expectedly allocated in a 
rule based fashion described in Section 3.1.4. According to this rule, expected loads of each state can be calculated. This load is called as state dependent load and it is used in dynamic programming. After the optimal strategy is obtained, we check the time dependent load. The sum of time dependent load should be equal or less than 1 which describes the percentage load of each slow time interval.

$$
\tilde{l}_{k}\left(x_{k}, d_{k}\right)=E\left\{l_{k}\left(x_{k}, d_{k}\right) \mid x_{k}, d_{k}\right\} \leq 1
$$

\subsection{Separation into Subtasks}

The problem and the corresponding stochastic dynamic programming solution given in (3.17) is a Markov decision process with a very large number of states even for few targets. Unfortunately, stochastic dynamic programming becomes harder while the number of states in state spaces is increasing as it is shown in Section 4.3 and Section 4.4. To solve the problem the Lagrange relaxation method, given in [32] is applied to the problem. The formulation here is taken from [32]. This formulation uses some approximations on the formulation. Approximate relaxation of resource constraints are investigated by Lagrange multipliers. Lagrange relaxation provides us to separate the problem into components that is described in this section.

Instead of optimizing the global complex stochastic control problem, the problem is separated into components and optimized locally. Then optimized components are collected together by the resource constraints given in (3.16). In this thesis, each tracking task is recognized as a sub problem. The overall system performance at time $k$ is the sum of each subtask's utility.

$$
U\left(x_{k}\right)=\sum_{s} U_{s}\left(x_{s, k}\right)
$$


The resource constraints (total load) in the interval $k$ is also described by the sum of the expected load of all subtasks,

$$
\begin{aligned}
\tilde{l}_{k}\left(x_{k}, d_{k}\right)= & \sum_{s} \tilde{l}_{s, k}\left(x_{s, k}, d_{s, k}\right) \\
& =\sum_{s} E\left\{l_{s, k}\left(x_{s, k}, d_{s, k}\right) \mid x_{s, k}, d_{s, k}\right\} \\
& \leq 1
\end{aligned}
$$

By Lagrange relaxation, the constraints are added to the objective function in the optimization problem.

$$
\begin{aligned}
& L_{k}\left(x_{k}, d_{k}, \lambda_{k}\right) \\
& =U\left(x_{k}\right)+\lambda_{k}\left(1-\tilde{l}_{k}\left(x_{k}, d_{k}\right)\right) \\
& +E_{x_{k+1} \mid x_{k}, d_{k}}\left\{\max _{d_{k+1}} L_{k+1}\left(x_{k+1}, d_{k+1}, \lambda_{k+1}^{*}\left(x_{k+1}\right)\right)\right\}
\end{aligned}
$$

where $\lambda_{k}$ corresponds the Lagrange multiplier at time $k$ and $\lambda_{k}{ }^{*}\left(x_{k}\right)$ is the Lagrange multiplier that the resource constraint is fulfilled with equality at optimum decisions at time $k$. The optimal Lagrangian at time $k, L_{k}\left(x_{k}, d_{k}{ }^{*}\left(x_{k}\right), \lambda_{k}{ }^{*}\left(x_{k}\right)\right)$ is equal to the optimal value-to-go function $J_{k}{ }^{*}\left(x_{k}\right)$. At the end of long time interval $N$, Lagrangian is equal to utility.

$$
L_{N}\left(x_{N}\right)=U\left(x_{N}\right)
$$


At time $k$ the Lagrangian expression can be written as

$$
\begin{aligned}
& L_{k}\left(x_{k}, d_{k}, \lambda_{k}\right) \\
& =\sum_{s} U_{s}\left(x_{s, k}\right)+\lambda_{k}\left(1-\sum_{s} \tilde{l}_{s, k}\left(x_{s, k}, d_{s, k}\right)\right) \\
& +E_{x_{k+1} \mid x_{k}, d_{k}}\left\{\max _{d_{k+1}} \sum_{s} U_{s}\left(x_{s, k+1}\right)\right. \\
& +\lambda_{k+1}{ }^{*}\left(x_{k+1}\right)\left(1-\sum_{s} \tilde{l}_{s, k+1}\left(x_{s, k+1}, d_{s, k+1}\right)\right) \\
& \left.+E_{x_{k+2} \mid x_{k+1}, d_{k+1}}\left\{\max _{d_{k+2}} L_{k+2}\left(x_{k+2}, d_{k+2}, \lambda^{*}{ }_{k+2}\left(x_{k+2}\right)\right)\right\}\right\}
\end{aligned}
$$

Rearranging the terms gives

$$
\begin{aligned}
& L_{k}\left(x_{k}, d_{k}, \lambda_{k}\right) \\
& =\sum_{s} U_{s}\left(x_{s, k}\right)-\lambda_{k} \tilde{l}_{s, k}\left(x_{s, k}, d_{s, k}\right)+\lambda_{k} \\
& +E_{x_{k+1} \mid x_{k}, d_{k}}\left\{\max _{d_{k+1}} \sum_{s} U_{s}\left(x_{s, k+1}\right)\right. \\
& -\lambda_{k+1}{ }^{*}\left(x_{k+1}\right) \tilde{l}_{s, k+1}\left(x_{s, k+1}, d_{s, k+1}\right) \\
& +E_{x_{k+2} \mid x_{k+1}, d_{k+1}}\left\{\max _{d_{k+2}} L_{k+2}\left(x_{k+2}, d_{k+2}, \lambda^{*}{ }_{k+2}\left(x_{k+2}\right)\right)\right\} \\
& \left.+\lambda_{k+1}{ }^{*}\left(x_{k+1}\right)\right\}
\end{aligned}
$$

A separation of (3.22) in terms of subtasks requires that the inner sums to be moved to the outside of both the maximizations and the expectations. In these expressions, $\lambda_{k}{ }^{*}\left(x_{k}\right)$ is a function of the global state, and this prevents the separation. However, it is assumed that the variation of $\lambda_{k}{ }^{*}\left(x_{k}\right)$ is moderate compared with the 
average $E_{x_{k} \mid x_{0}}\left\{\lambda_{k}{ }^{*}\left(x_{k}\right)\right\}$. It is then reasonable to replace $\lambda_{k}{ }^{*}\left(x_{k}\right)$ for $k>0$ with its estimates. These estimates are denoted $\hat{\lambda}_{k}{ }^{*}$, and are chosen such that

$$
E_{x_{k} \mid x_{0}}\left\{\tilde{l}_{k}\left(x_{k}, d_{k}^{*}\left(x_{k}\right)\right)\right\}=1, \quad k>0
$$

It will be a part of a global optimization algorithm to search for $\hat{\lambda}_{k}{ }^{*}$. It is said that the long term variation of the Lagrange multipliers typically depends on the number of tracked targets [32].

For notational convenience, define the vector of Lagrange multiplier estimates as $\tilde{\lambda}=\left[\tilde{\lambda}_{0}, \hat{\lambda}_{1}{ }^{*}, \hat{\lambda}_{2}{ }^{*}, \ldots, \hat{\lambda}_{N-1}{ }^{*}\right]$ and denote the element corresponding to time $k$ as $\tilde{\lambda}_{k}$. Assume that the Lagrangian at time $k+1$ can be rewritten as a sum of Lagrange components for each subtask, plus a term depending on the multipliers only,

$$
L_{k}\left(x_{k}, d_{k}, \tilde{\lambda}\right)=\sum_{s} L_{s, k}\left(x_{s, k}, d_{s, k}, \tilde{\lambda}\right)+\sum_{n=k}^{N-1} \tilde{\lambda}_{n}
$$

The Lagrangian at time $k$ is also expressed as

$$
\begin{aligned}
& L_{k}\left(x_{k}, d_{k}, \tilde{\lambda}\right) \\
& =\sum_{s} U_{s}\left(x_{s, k}\right)-\tilde{\lambda}_{k} \tilde{l}_{s, k}\left(x_{s, k}, d_{s, k}\right)+\tilde{\lambda}_{k} \\
& +E_{x_{k+1} \mid x_{k}, d_{k}}\left\{\max _{d_{k+1}} \sum_{s} L_{s, k+1}\left(x_{s, k+1}, d_{s, k+1}, \tilde{\lambda}\right)\right\} \\
& +\sum_{n=k}^{N-1} \tilde{\lambda}_{n}
\end{aligned}
$$


The maximum operation is separable in the subtasks due to the local influence of decision parameters in subtasks, e.g., if $f_{s}\left(d_{s}\right)$ is a set of functions representing local consequences of the decision $d_{s}$ regarding measurements of subtask $s$, we have that

$$
\max _{d} \sum_{s} f_{s}\left(d_{s}\right)=\sum_{s} \max _{d_{s}} f_{s}\left(d_{s}\right)
$$

Thus, the sum can be moved outside the maximization. Furthermore, the expectation is carried out per subtask due to the independence assumptions regarding target-wise performance. Consequently, given the assumption in (3.24), the Lagrangian at stage $k$ is also separable in the subtasks:

$$
\begin{aligned}
& L_{k}\left(x_{k}, d_{k}, \tilde{\lambda}\right) \\
& =\sum_{s} U_{s}\left(x_{s, k}\right)-\tilde{\lambda}_{k} \tilde{l}_{s, k}\left(x_{s, k}, d_{s, k}\right) \\
& +E_{x_{k+1} \mid x_{k}, d_{k}}\left\{\max _{d_{k+1}} \sum_{s} L_{s, k+1}\left(x_{s, k+1}, d_{s, k+1}, \tilde{\lambda}\right)\right\} \\
& +\sum_{n=k}^{N-1} \tilde{\lambda}_{n} \triangleq \sum_{s} L_{s, k}\left(x_{s, k}, d_{s, k}, \tilde{\lambda}\right)+\sum_{n=k}^{N-1} \tilde{\lambda}_{n}
\end{aligned}
$$

At the end of long time horizon, we have $L_{N}\left(x_{N}\right)=\sum_{s} U_{s}\left(x_{s, k}\right) \triangleq L_{s, N}\left(x_{s, N}\right)$. We apply dynamic programming in backward and perform a recursive process from time $N$. By the way, the Lagrangian at the decision time instant $\mathrm{k}=0$ separates in the subtasks. In [36] a similar approximate DP approach is given as an example of optimizing target classifications. 
The overall optimization problem is divided into several sub problems that are optimized locally by using Lagrange multipliers. Each Lagrange multiplier can be found iteratively to fulfill the resource constrains. But we have to give an initial value for each Lagrange multiplier to find the optimal value of Lagrangian. Initial value of each Lagrange multiplier is selected as very large so that the constraint is not satisfied. Then we begin to decrease Lagrange multipliers until the constraint is satisfied partially. After that, optimal Lagrange multipliers are calculated in two different ways.

First method: We have used the 'fminsearch' function of MATLAB,

Second method: Iterative solution of new search function that is described below.

$$
\begin{gathered}
\tilde{\lambda}^{j+1}=\tilde{\lambda}^{j}+\Delta \tilde{\lambda}^{j} \\
E\left\{\tilde{l}^{j}\right\}+\frac{\partial E\left\{\tilde{l}^{j}\right\}}{\partial \tilde{\lambda}} \Delta \tilde{\lambda}^{j}=1
\end{gathered}
$$

The expected load coming from the subtask is computed based on optimal update/do not update decisions and $E\left\{\tilde{l}^{j}\right\}$ is calculated by summing over all subtasks. Furthermore, $\frac{\partial E\left\{\tilde{l}^{j}\right\}}{\partial \widetilde{\lambda}}$ is summed from the partial derivatives of each subtask. The corresponding partial derivative of each term is computed numerically. The numerical procedure computes the objective function for $\tilde{\lambda}$ and $\tilde{\lambda}+\Delta \tilde{\lambda}^{j}$ and computes the derivative by using the difference in the values. Then, above equations (3.28) and (3.29) are used to generate the new $\tilde{\lambda}$.

A pseudo code for searching optimal Lagrange multipliers is formulated in Table 3.2. 
Table 3.2 Pseudo Code for Searching Optimal Lagrange Multipliers

1) Initiate all Lagrange multipliers from a large value and decrease until the resource constraint is satisfied.

2) Solve dynamic programming via these Lagrange multipliers

3) Select the Lagrange multiplier that exceeds the resource constraint by a higher value than others.

4) Decrease the selected Lagrange multiplier by a small value $\Delta \tilde{\lambda}$ and solve dynamic programming again.

5) Subtract new output (state independent load) from the old one and find each change in state independent load with respect to $\Delta \tilde{\lambda}$.

6) Divide $\Delta \tilde{\lambda}$ to each change in state independent load and find new change value that we will apply to the dynamic programing.

7) Repeat this until all outputs converges to one and never exceed.

The optimal strategy specifies the update or do not update decisions for each target in each interval and it is dependent on the current states of targets. An update command triggers one or more update attempts due to the quality of the target's current state. This rule is defined in Section 3.1.4. Update attempts may result with success or fail depend on probability of detection.

\subsection{Algorithm}

The aim of Markov decision process is to find a decision policy that can be represented as a matrix that relates the states to the decisions. "decision_depends_on_states" matrix specifies the action that the decision maker chooses depending on the current state. The objective is to generate an optimal policy that will maximize the random reward in a finite time horizon. 
Now, we define the calculation of the Lagrangian for adaptive target tracking task. All subtasks have the same form since we deal with only track updates. Equation (3.27) forms a base for dynamic programming. Resource constraints are included by the Lagrange multipliers. The Markov decision process is also defined in this section.

Let tracking a target $T_{i}$ be a sub task and $J_{i, k}\left(x_{i, k}\right)$ be the value-to-go function for $T_{i}$ at time $k . J_{i, k}\left(x_{i, k}\right)$ can be defined as the local Lagrangian of the sub task given the Lagrange multiplier vector $\tilde{\lambda}$.

$$
J_{i, k}\left(x_{i, k}\right)=L_{T_{i}, k}\left(x_{i, k}, d_{i, k}, \tilde{\lambda}\right)
$$

Given $\tilde{\lambda}$, the local decision problem is characterized as a Markov decision process. The solution of the optimization is achieved by dynamic programming backward recursions.

$$
\begin{aligned}
& J_{i, k}^{*}\left(x_{i, k}\right) \\
& =\max _{d_{i, k}}\left(U_{i}\left(x_{i, k}\right)-\tilde{\lambda}_{k} \tilde{l}_{i, k}\left(x_{i, k}, d_{i, k}\right)\right. \\
& \left.+\sum_{x_{i, k+1}} J_{i, k+1}{ }^{*}\left(x_{i, k+1}\right) P\left(x_{i, k+1} \mid x_{i, k}, d_{i, k}, \xi_{i, k}\right)\right)
\end{aligned}
$$

Here, $J_{i, N}=U_{i}\left(x_{i, N}\right)$ and $\tilde{l}_{i, k}\left(x_{i, k}, d_{i, k}\right)$ is the expected load given a scheduled track update, and given the filter covariance predicted by the state in time interval $k$. Since the decision can be update or do not update, $\tilde{l}_{i, k}\left(x_{i, k}, d_{i, k}\right)$ is zero when the decision is do not update. At each time and state a comparison is done and the maximum of result that is between update or do not update decisions is chosen. 


$$
\begin{aligned}
& \sum_{x_{i, k+1}} J_{i, k+1}{ }^{*}\left(x_{i, k+1}\right) P\left(x_{i, k+1} \mid x_{i, k}, d_{\text {update }}, \xi_{i, k}\right) \\
& -\sum_{x_{i, k+1}} J_{i, k+1}{ }^{*}\left(x_{i, k+1}\right) P\left(x_{i, k+1} \mid x_{i, k}, d_{\text {do_not_update }}, \xi_{i, k}\right)
\end{aligned}
$$

This value compared with the cost of update decision $\tilde{\lambda}_{k} \tilde{l}_{i, k}\left(x_{i, k}, d_{\text {update }}\right)$. Update decision is given when the reward is larger than the cost.

A pseudo code for separated solution to resource allocation is formulated in Table 3.3 . 
Table 3.3 Pseudo Code for the Separated Solution to Resource Allocation

Assume that an initial estimate of $\tilde{\lambda}$ exists and then an algorithm for generating a measurement batch is now the following.

1) Form subtasks: Each tracked target forms a subtask.

2) Construct the Markov Model

3) Calculate the expected time spent for each state

4) Initialize all parameters that are input from the operator.

a. Probability of Detection for each target $\left(P_{d}\right)$

b. Nominal utility $\left(U_{\text {nom }}\right)=100$

c. Time horizon $(N)=10 \mathrm{sec}$

d. Initial estimate of $\tilde{\lambda}$

e. Number of Monte Carlo simulation $=1000$

5) Calculate the utilities of each state for each target

6) Calculate the state dependent expected load for each target

7) Apply backwards recursive DP to obtain the optimal strategy for each tracked target

8) Form the initial state probability vector at time $k=0$ to initialize the state

9) Calculate $E\left\{\tilde{l}_{s}^{j}\right\}$ and $\frac{\partial E\left\{\tilde{l}_{s}^{j}\right\}}{\partial \tilde{\lambda}}$ for each subtask

10) Sum $E\left\{\tilde{l}_{s}^{j}\right\}$ and $\frac{\partial E\left\{\tilde{l}_{s}^{j}\right\}}{\partial \tilde{\lambda}}$ over the subtasks to calculate $E\left\{\tilde{l}^{j}\right\}$ and $\frac{\partial E\left\{\tilde{l}^{j}\right\}}{\partial \tilde{\lambda}}$

11) Update the Lagrange multiplier vector $\tilde{\lambda}$, according to (3.28) and (3.29)

12) If total state independent load is sufficiently close to one for all time intervals, proceed to 13 , otherwise continue with 7 .

13) Run Monte Carlo simulations to observe the number of updates and the average number of drops for each target and also number of coincidence for overloads. 



\section{CHAPTER 4}

\section{SIMULATIONS AND RESULTS}

In this section, we give several scenarios and their corresponding experimental results. The problems attempted in this study are a set of problems that start from the simplest one. We call them the 'scenarios'. The first scenario is a single target. DP based solution is feasible for a single target. The Markov model of this scenario was a simplified model. The performance of the algorithm is tested on this simple model as described in Section 4.1. 1000 Monte Carlo runs are done on this simple model to observe the number of updates and the average number of drops. Results show that the number of target drops is high. Therefore, the model is modified to include some rules which describe the expected number of looks used in each macro level decision interval depending on the target's current state. By this way, the number of drops is decreased as shown in Section 4.2. The extension of the method to even two targets needs a very large state space. DP based solution for more than one target is almost infeasible because of this very large state space. A simple two target example, given in Section 4.3 is solved by the joint Markov model that gives the optimal solution. This solution is used as reference to evaluate the results obtained with some approximations. Section 4.4 , the same problem is solved by using Lagrangian method. Then, in Section 4.5, following approach of [32], the problem is solved by using a single Markov chain for each target and writing the time budget as a constraint for eight targets. The constraint optimization problem is solved by using 
Lagrange relaxation. Lagrange relaxation is the key point of separating the problem into sub problems. As a result, the exponential explosion of the state space can be handled.

\subsection{DP-Based Optimal Resource Allocation for One Target}

In this part, there are some simulations that we have made to observe the usage of optimal radar resource instead of consuming all resource to one target by using dynamic programming algorithm. By this way, we can show how to use radar resources in an efficient way. The Markov chain is the same as the model defined in Section 3.1.4 except the state transition probabilities. For this scenario, we assume that each state consumes only one look in Markov decision process instead of the rule defined in Section 3.1.4. Therefore, state transitions are the same for all states and it is a constant value that is given by the operator. A cost for update decision is added to the dynamic programming to avoid the update decisions at all time intervals. The cost can be selected by the operator. We assume that the utility of do not update decision is 5 times greater than the utility of update decision. Inputs that are selected by the operator are given below:

- Probability of detection $\left(P_{d}\right)=0.8$ and 0.4

- $\quad$ Nominal utility $\left(U_{\text {nom }}\right)=100$

- $\quad$ Time horizon $(N)=10 \mathrm{sec}$

- $\quad$ Number of Monte Carlo simulation $=1000$

- The trace of covariance matrix of each state is calculated by Kalman filter and 'state_cov_value' vector that has the trace of covariance matrix of each state is constructed. This vector and corresponding normalized vector are defined below. 
Quantized values of the state quality defined in Chapter 3.1.2 are given in Table 4.1.

Table 4.1 Quantized Values of the State Quality

\begin{tabular}{|c|c|c|c|c|c|c|c|c|c|c|c|c|c|c|}
\hline State no: & $\mathbf{1}$ & $\mathbf{2}$ & $\mathbf{3}$ & $\mathbf{4}$ & $\mathbf{5}$ & $\mathbf{6}$ & $\mathbf{7}$ & $\mathbf{8}$ & $\mathbf{9}$ & $\mathbf{1 0}$ & $\mathbf{1 1}$ & $\mathbf{1 2}$ & $\mathbf{1 3}$ & Unit \\
\hline $\begin{array}{c}\text { State } \\
\text { Quality }\end{array}$ & 15 & 18 & 21 & 23 & 25 & 30 & 33 & 36 & 37 & 40 & 58 & 62 & 64 & $\mathrm{~m}^{2}$ \\
\hline State no: & $\mathbf{1 4}$ & $\mathbf{1 5}$ & $\mathbf{1 6}$ & $\mathbf{1 7}$ & $\mathbf{1 8}$ & $\mathbf{1 9}$ & $\mathbf{2 0}$ & $\mathbf{2 1}$ & $\mathbf{2 2}$ & $\mathbf{2 3}$ & $\mathbf{2 4}$ & $\mathbf{2 5}$ & $\mathbf{2 6}$ & Unit \\
\hline $\begin{array}{c}\text { State } \\
\text { Quality }\end{array}$ & 65 & 69 & 101 & 105 & 109 & 112 & 116 & 165 & 173 & 175 & 178 & 181 & 0 & $\mathrm{~m}^{2}$ \\
\hline
\end{tabular}

These values are converted to a reward by the assumption that the reward of the first state (1) is 1 and the last state (26) is 0 . Normalized state rewards are shown in Table 4.2 .

Table 4.2 Normalized State Rewards

\begin{tabular}{|c|c|c|c|c|c|c|c|c|c|}
\hline State no: & $\mathbf{1}$ & $\mathbf{2}$ & $\mathbf{3}$ & $\mathbf{4}$ & $\mathbf{5}$ & $\mathbf{6}$ & $\mathbf{7}$ & $\mathbf{8}$ & $\mathbf{9}$ \\
\hline $\begin{array}{c}\text { State } \\
\text { Rewards }\end{array}$ & 1.000 & .8333 & .7143 & .6522 & .6000 & .5000 & .4545 & .4167 & .4054 \\
\hline State no: & $\mathbf{1 0}$ & $\mathbf{1 1}$ & $\mathbf{1 2}$ & $\mathbf{1 3}$ & $\mathbf{1 4}$ & $\mathbf{1 5}$ & $\mathbf{1 6}$ & $\mathbf{1 7}$ & $\mathbf{1 8}$ \\
\hline $\begin{array}{c}\text { State } \\
\text { Rewards }\end{array}$ & .3750 & .2586 & .2419 & .2344 & .2308 & .2174 & .1485 & .1429 & .1376 \\
\hline State no: & $\mathbf{1 9}$ & $\mathbf{2 0}$ & $\mathbf{2 1}$ & $\mathbf{2 2}$ & $\mathbf{2 3}$ & $\mathbf{2 4}$ & $\mathbf{2 5}$ & $\mathbf{2 6}$ & \\
\hline $\begin{array}{c}\text { State } \\
\text { Rewards }\end{array}$ & .1339 & .1293 & .0909 & .0867 & .0857 & .0843 & .0829 & 0.000 & \\
\hline
\end{tabular}

The optimum solution provided by the dynamic programming algorithm is given in Table 4.3. In the table ' 0 ' and ' 1 ' indicates 'Do not Update' and 'Update' decision, respectively. 
Table 4.3 The Strategy of First Scenario

\begin{tabular}{|c|c|c|c|c|c|c|c|c|c|c|}
\hline State no: & $\boldsymbol{t}_{\mathbf{1}}$ & $\boldsymbol{t}_{\mathbf{2}}$ & $\boldsymbol{t}_{\mathbf{3}}$ & $\boldsymbol{t}_{\mathbf{4}}$ & $\boldsymbol{t}_{\mathbf{5}}$ & $\boldsymbol{t}_{\mathbf{6}}$ & $\boldsymbol{t}_{\mathbf{7}}$ & $\boldsymbol{t}_{\mathbf{8}}$ & $\boldsymbol{t}_{\mathbf{9}}$ & $\boldsymbol{t}_{\mathbf{1 0}}$ \\
\hline $\mathbf{1}$ & 0 & 0 & 0 & 0 & 0 & 0 & 0 & 0 & 0 & 0 \\
\hline $\mathbf{2}$ & 0 & 0 & 0 & 0 & 0 & 0 & 0 & 0 & 0 & 0 \\
\hline $\mathbf{3}$ & 0 & 0 & 0 & 0 & 0 & 0 & 0 & 0 & 0 & 0 \\
\hline $\mathbf{4}$ & 0 & 0 & 0 & 0 & 0 & 0 & 0 & 1 & 0 & 0 \\
\hline $\mathbf{5}$ & 0 & 0 & 0 & 0 & 0 & 0 & 0 & 1 & 1 & 0 \\
\hline $\mathbf{6}$ & 1 & 1 & 1 & 1 & 1 & 1 & 1 & 1 & 1 & 0 \\
\hline $\mathbf{7}$ & 1 & 1 & 1 & 1 & 1 & 1 & 1 & 1 & 1 & 0 \\
\hline $\mathbf{8}$ & 1 & 1 & 1 & 1 & 1 & 1 & 1 & 1 & 1 & 0 \\
\hline $\mathbf{9}$ & 1 & 1 & 1 & 1 & 1 & 1 & 1 & 1 & 1 & 0 \\
\hline $\mathbf{1 0}$ & 1 & 1 & 1 & 1 & 1 & 1 & 1 & 1 & 1 & 0 \\
\hline $\mathbf{1 1}$ & 1 & 1 & 1 & 1 & 1 & 1 & 1 & 1 & 1 & 0 \\
\hline $\mathbf{1 2}$ & 1 & 1 & 1 & 1 & 1 & 1 & 1 & 1 & 1 & 0 \\
\hline $\mathbf{1 3}$ & 1 & 1 & 1 & 1 & 1 & 1 & 1 & 1 & 1 & 0 \\
\hline $\mathbf{1 4}$ & 1 & 1 & 1 & 1 & 1 & 1 & 1 & 1 & 1 & 0 \\
\hline $\mathbf{1 5}$ & 1 & 1 & 1 & 1 & 1 & 1 & 1 & 1 & 1 & 0 \\
\hline $\mathbf{1 6}$ & 1 & 1 & 1 & 1 & 1 & 1 & 1 & 1 & 1 & 0 \\
\hline $\mathbf{1 7}$ & 1 & 1 & 1 & 1 & 1 & 1 & 1 & 1 & 1 & 0 \\
\hline $\mathbf{1 8}$ & 1 & 1 & 1 & 1 & 1 & 1 & 1 & 1 & 1 & 0 \\
\hline $\mathbf{1 9}$ & 1 & 1 & 1 & 1 & 1 & 1 & 1 & 1 & 1 & 0 \\
\hline $\mathbf{2 0}$ & 1 & 1 & 1 & 1 & 1 & 1 & 1 & 1 & 1 & 0 \\
\hline $\mathbf{2 1}$ & 1 & 1 & 1 & 1 & 1 & 1 & 1 & 1 & 1 & 1 \\
\hline $\mathbf{2 2}$ & 1 & 1 & 1 & 1 & 1 & 1 & 1 & 1 & 1 & 1 \\
\hline $\mathbf{2 3}$ & 1 & 1 & 1 & 1 & 1 & 1 & 1 & 1 & 1 & 1 \\
\hline $\mathbf{2 4}$ & 1 & 1 & 1 & 1 & 1 & 1 & 1 & 1 & 1 & 1 \\
\hline $\mathbf{2 5}$ & 1 & 1 & 1 & 1 & 1 & 1 & 1 & 1 & 1 & 1 \\
\hline $\mathbf{2 6}$ & 0 & 0 & 0 & 0 & 0 & 0 & 0 & 0 & 0 & 0 \\
\hline & & & & & & & \\
\hline
\end{tabular}

After the optimum strategy is obtained, 1000 Monte Carlo simulations are done to observe the number of updates and the average number of drops. Two different probability of detection values are used to show relation between $P_{d}$ value and simulation results. Simulation results are given in Table 4.4. 
Table 4.4 Simulation Results of DP-Based Optimal Resource Allocation for One

Target

\begin{tabular}{|c|c|c|c|c|}
\hline & \multicolumn{2}{|c|}{$P_{d}=0.8$} & \multicolumn{2}{|c|}{$P_{d}=0.4$} \\
\hline $\begin{array}{l}\text { Initial } \\
\text { State }\end{array}$ & $\begin{array}{c}\text { Number of } \\
\text { Update in } \\
10 \text { sec. }\end{array}$ & $\begin{array}{c}\text { Number of } \\
\text { average drop in } \\
1000 \text { simulations }\end{array}$ & $\begin{array}{c}\text { Number of } \\
\text { Update in } \\
10 \text { sec. }\end{array}$ & $\begin{array}{c}\text { Number of } \\
\text { average drop in } \\
1000 \text { simulations }\end{array}$ \\
\hline 1 & 4.6720 & 4 & 3.7030 & 395 \\
\hline 2 & 4.6120 & 3 & 4.6580 & 370 \\
\hline 3 & 4.6400 & 10 & 4.6610 & 367 \\
\hline 4 & 4.6420 & 5 & 4.7050 & 370 \\
\hline 5 & 4.6550 & 8 & 4.6490 & 366 \\
\hline 6 & 5.2950 & 7 & 4.4150 & 428 \\
\hline 7 & 5.2950 & 6 & 5.3230 & 381 \\
\hline 8 & 5.3140 & 9 & 5.2870 & 376 \\
\hline 9 & 5.2760 & 6 & 5.3160 & 385 \\
\hline 10 & 5.2840 & 5 & 5.2790 & 399 \\
\hline 11 & 5.2600 & 13 & 4.8910 & 429 \\
\hline 12 & 5.2490 & 10 & 4.9820 & 443 \\
\hline 13 & 5.2680 & 15 & 4.8700 & 455 \\
\hline 14 & 5.2530 & 11 & 4.9660 & 451 \\
\hline 15 & 5.2700 & 12 & 4.8490 & 454 \\
\hline 16 & 5.1170 & 46 & 4.0710 & 544 \\
\hline 17 & 5.1470 & 37 & 4.0620 & 558 \\
\hline 18 & 5.1110 & 44 & 4.0250 & 571 \\
\hline 19 & 5.1250 & 41 & 4.0870 & 579 \\
\hline 20 & 5.1210 & 43 & 4.0360 & 570 \\
\hline 21 & 4.4050 & 192 & 2.5340 & 743 \\
\hline 22 & 4.3540 & 200 & 2.6560 & 724 \\
\hline 23 & 4.3280 & 207 & 2.6510 & 735 \\
\hline
\end{tabular}




\begin{tabular}{|c|c|c|c|c|}
\hline \multicolumn{5}{|c|}{ Table 4.4 (cont'd) } \\
\hline $\mathbf{2 4}$ & 4.2660 & 220 & 2.6780 & 744 \\
\hline $\mathbf{2 5}$ & 4.2580 & 226 & 2.5910 & 733 \\
\hline AVERAGE & $\mathbf{4 . 9 2 8 7}$ & $\mathbf{5 5 . 2}$ & $\mathbf{4 . 2 3 7 8}$ & $\mathbf{5 0 2 . 8}$ \\
\hline
\end{tabular}

These results are obtained by an algorithm that is described by the pseudo code given in Table 4.5.

Table 4.5 Pseudo Code for DP-Based Optimal Resource Allocation for One Target

\begin{tabular}{|l|}
\hline To obtain optimum strategy: \\
\hline Determine the state transition matrices for update and do not update decisions \\
\hline Determine the rewards for update and do not update decisions \\
\hline Apply dynamic programming algorithm \\
- $\quad$ Calculate the corresponding reward for update decision and calculate each \\
state transition at time $\mathrm{N}$ \\
- Calculate the corresponding reward for do not update decision and calculate \\
- $\quad$ Coach state transition at time $\mathrm{N}$ \\
- $\quad$ Store the highest reward values and corresponding state \\
To obis procedure for time N-1 to time 0. \\
\hline $\begin{array}{l}\text { Define an initial state. } \\
\text { transition matrix }\end{array}$ \\
\hline Check the optimal decision(update/do not update) from the constructed strategy
\end{tabular}




\section{Table 4.5 (cont'd)}

If the decision is update;

- Generate a random variable between zero and one.

- If this random variable is less than probability of detection value, change state due to the do not update state transition matrix

- If this random variable is equal or greater than probability of detection value, change state due to the update state transition matrix

Calculate the number of update decisions and dropped targets that are at the state 26.

The macro manager decision period is $1 \mathrm{sec}$ as the same as Markov decision period. The simulation time is $10 \mathrm{sec}$ and only one look is used for tracking the target at each time instant and at each state. In $10 \mathrm{sec}$, target is tracked nearly five times in the average. So, simulation results show that we can track one target in an acceptable uncertainty level by consuming only $\% 50$ of the resources nearly. By this optimization, remaining resource can be used for other tasks such as tracking another target or may be searching a sector for new targets. The update and drop numbers depend on the initial state.

\subsection{Modified DP-Based Optimal Resource Allocation for One Target with a Rule}

In the previous section, we observed that the number of target drops is quite high. Therefore, we decide to define a rule for each state. This rule characterizes the expected usage of looks related to the state quality as described in Section 3.1.4. The same strategy and inputs are used for this scenario to compare fairly. Simulation results are given in Table 4.6. 
Table 4.6 Simulation Results of Modified DP-Based Optimal Resource Allocation for One Target with a Rule

\begin{tabular}{|c|c|c|c|c|}
\hline & \multicolumn{2}{|c|}{$P_{d}=0.8$} & \multicolumn{2}{|c|}{$P_{d}=0.4$} \\
\hline $\begin{array}{l}\text { Initial } \\
\text { State }\end{array}$ & $\begin{array}{c}\text { Number of } \\
\text { Update in } \\
10 \text { sec. }\end{array}$ & $\begin{array}{c}\text { Number of } \\
\text { average drop in } \\
1000 \text { simulations }\end{array}$ & $\begin{array}{c}\text { Number of } \\
\text { Update in } \\
10 \text { sec. }\end{array}$ & $\begin{array}{c}\text { Number of } \\
\text { average drop in } \\
1000 \text { simulations }\end{array}$ \\
\hline 1 & 4.9890 & 0 & 6.4140 & 2 \\
\hline 2 & 4.9740 & 0 & 6.8990 & 5 \\
\hline 3 & 4.9980 & 0 & 7.0560 & 6 \\
\hline 4 & 5.0170 & 0 & 7.0830 & 6 \\
\hline 5 & 5.0080 & 0 & 7.2230 & 7 \\
\hline 6 & 6.0210 & 0 & 7.2500 & 13 \\
\hline 7 & 6.0360 & 0 & 8.2060 & 8 \\
\hline 8 & 6.0290 & 0 & 8.2290 & 10 \\
\hline 9 & 6.0120 & 0 & 8.1210 & 9 \\
\hline 10 & 6.0040 & 0 & 8.1400 & 12 \\
\hline 11 & 6.0840 & 0 & 8.4010 & 9 \\
\hline 12 & 6.0300 & 0 & 8.3450 & 11 \\
\hline 13 & 6.0760 & 0 & 8.3980 & 13 \\
\hline 14 & 6.0500 & 0 & 8.4270 & 7 \\
\hline 15 & 6.0770 & 0 & 8.4510 & 13 \\
\hline 16 & 6.0710 & 0 & 8.3500 & 14 \\
\hline 17 & 6.0880 & 0 & 8.5620 & 16 \\
\hline 18 & 6.0740 & 0 & 8.4430 & 17 \\
\hline 19 & 6.0810 & 0 & 8.3270 & 17 \\
\hline 20 & 6.0690 & 0 & 8.2810 & 15 \\
\hline 21 & 6.1010 & 0 & 8.0970 & 62 \\
\hline 22 & 6.0990 & 0 & 8.0980 & 72 \\
\hline 23 & 6.1170 & 0 & 7.9950 & 74 \\
\hline
\end{tabular}




\begin{tabular}{|c|c|c|c|c|}
\hline \multicolumn{5}{|c|}{ Table 4.6 (cont'd) } \\
\hline $\mathbf{2 4}$ & 6.0640 & 1 & 7.9790 & 84 \\
\hline $\mathbf{2 5}$ & 6.1030 & 1 & 8.0930 & 81 \\
\hline AVERAGE & $\mathbf{5 . 8 5 0 9}$ & $\mathbf{0 . 0 8}$ & $\mathbf{7 . 9 5 4 7}$ & $\mathbf{2 3 . 3 2}$ \\
\hline
\end{tabular}

By this rule, we reduce the number of target drops significantly. The reason of zero drops at states from 1 to 23 is the high probability of detection value. It is chosen as 0.8 same as the previous scenario. If we decrease this value, we will observe track drops as expected. At the same time, obviously the expected value of the update time is larger than the previous one. To show the relation between probability of detection value and the number of target drops, additional columns are added to the Table 4.4 and Table 4.6. Actually, added rule changes the optimal strategy. But this affect is not significant. So, for fair comparison, we use the same optimal strategy.

\subsection{Optimization-Based Resource Allocation for Two Targets}

DP based solution for more than one target is almost infeasible because of its very large state space. However to assess the approximation done for more realistic problems at this section we generate a new scenario of two targets with a simpler Markov model. Because of the size of the state space increases exponentially with the number of targets and the number of states used in the scenario, we consider a very simple example to obtain the optimal solution. The Markov chain structure of this scenario is given in Figure 4.1. 


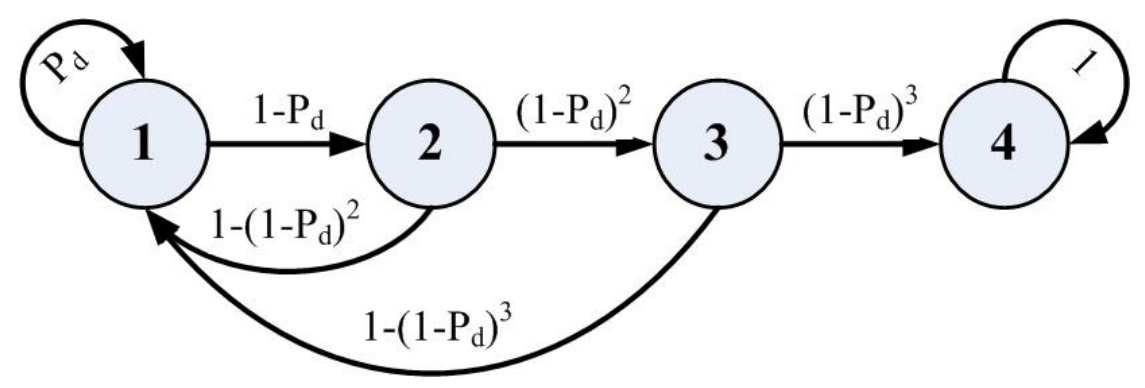

Figure 4.1 A Simple Markov Model of Each Target

Aim is to obtain the optimal strategy by using the joint Markov model. We have only one look at each time instant and determine a policy that maximizes the overall system performance. To achieve this purpose, we need to construct another Markov model that represents joint situations of the targets. The joint Markov model consists of 16 states that are the combination the individual Markov model of two targets. Figure 4.2 shows joint transitions with respect to update decisions of target 1, Figure 4.3 shows joint transitions with respect to update decisions of target 2 and Figure 4.4 shows joint transitions with respect to do not update decision of both targets. Inputs that are selected are given below:

- Probability of detection for target $1\left(P_{d 1}\right)=0.8$

- $\quad$ Probability of detection for target $2\left(P_{d 2}\right)=0.7$

- Nominal utility for target $1\left(U_{\text {nom } 1}\right)=100$

- Nominal utility for target $2\left(U_{n o m 2}\right)=100$

- $\quad$ Time horizon $(N)=10 \mathrm{sec}$

- $\quad$ Number of Monte Carlo simulation $=1000$ 


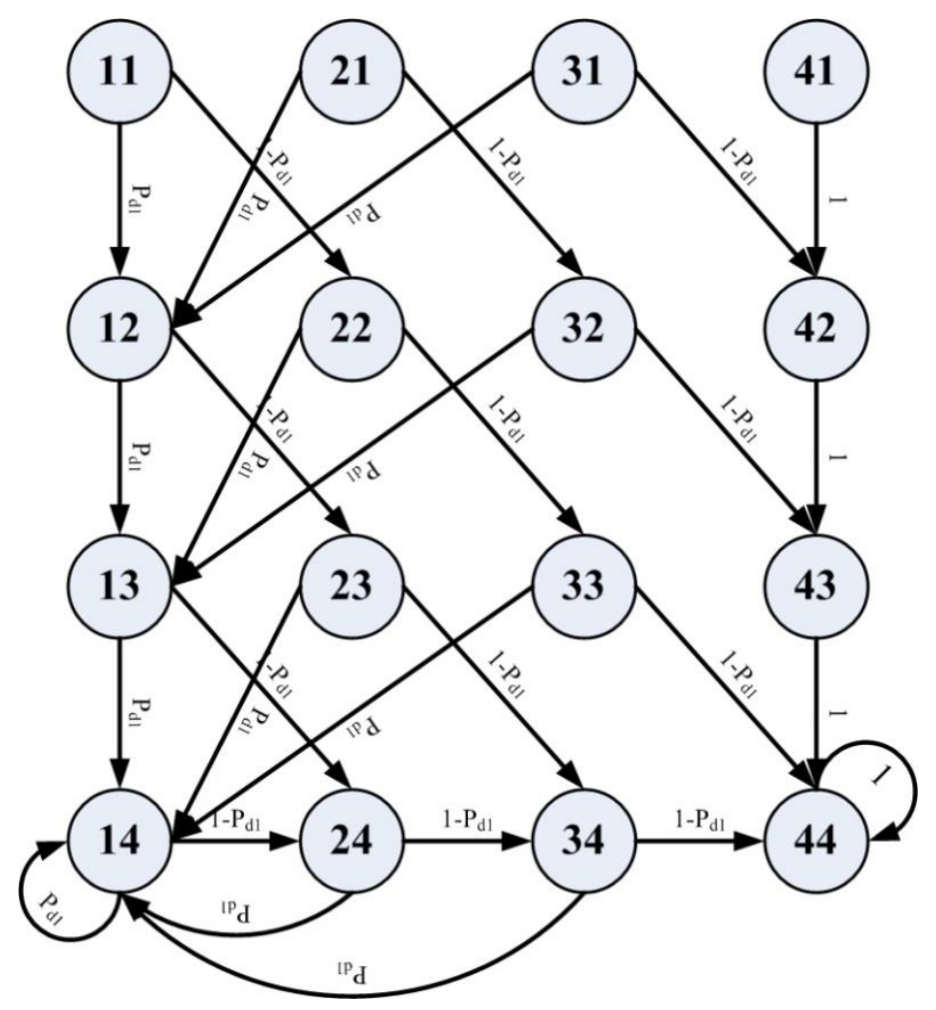

Figure 4.2 Joint Markov Model with Respect to Update Decisions of Target 1

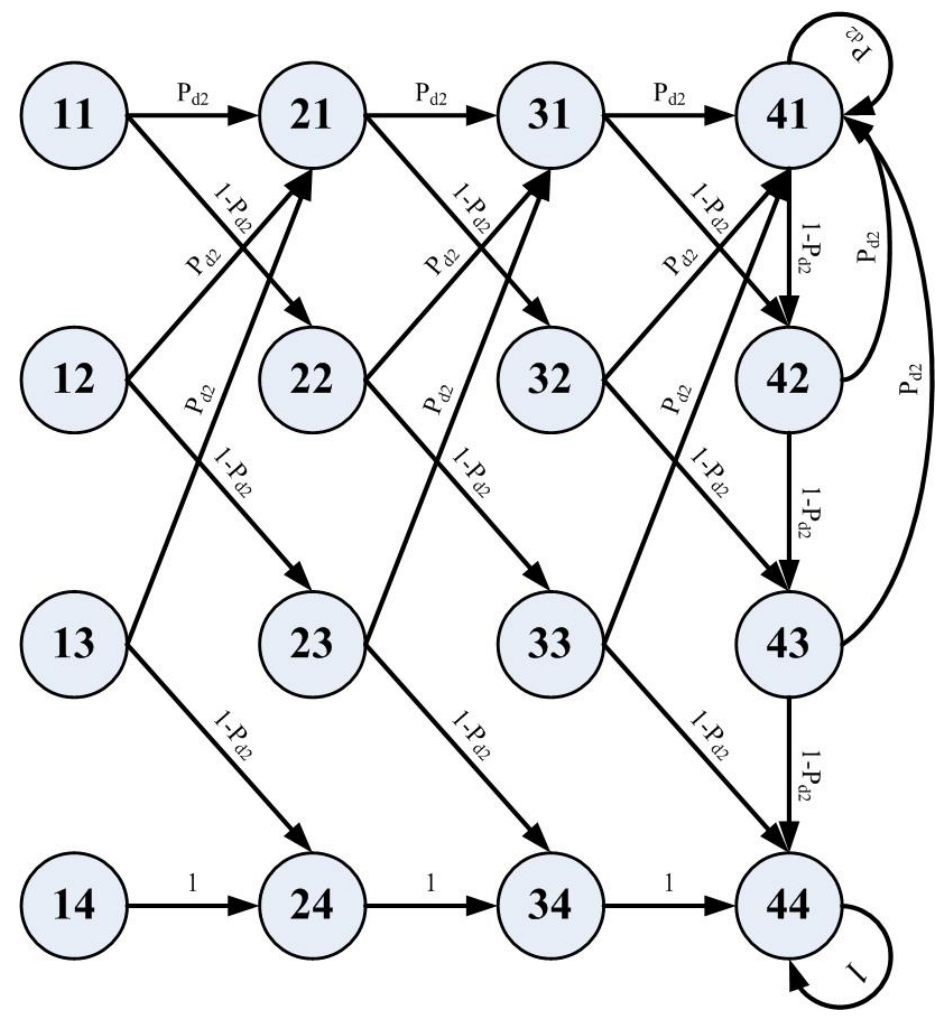

Figure 4.3 Joint Markov Model with Respect to Update Decisions of Target 2 


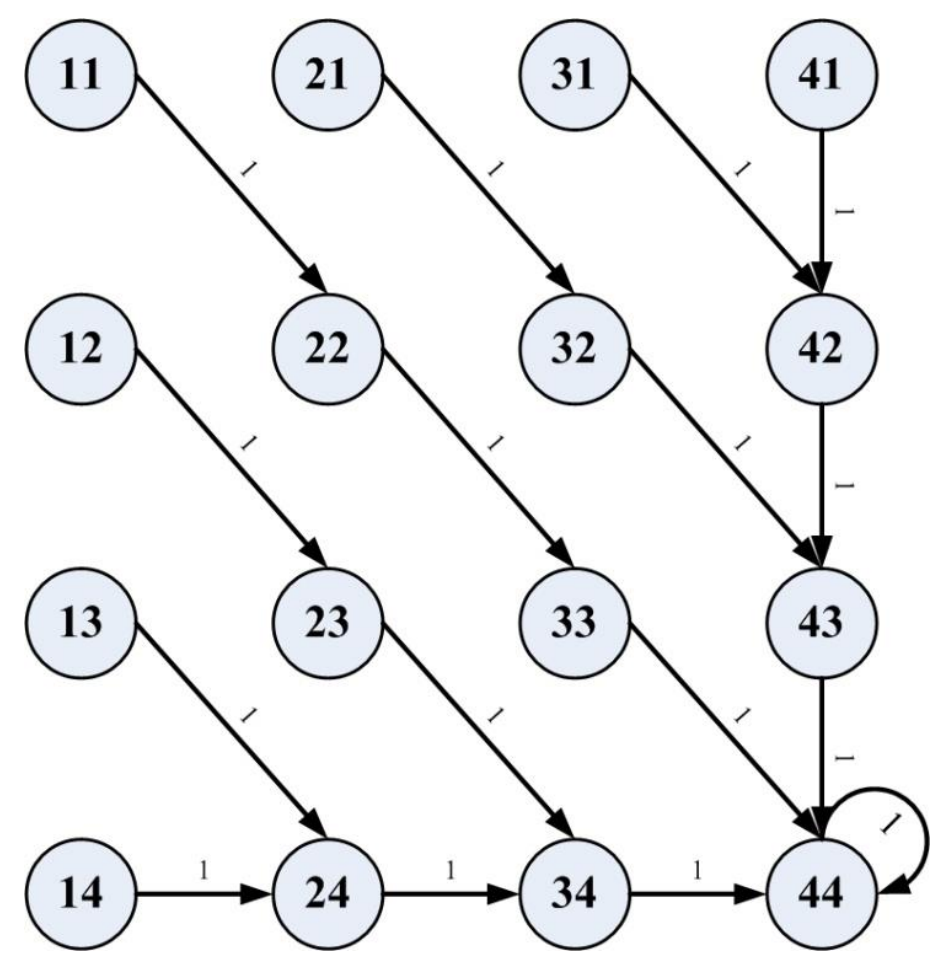

Figure 4.4 Joint Markov Model with Respect to do not Update Decision of Both Targets

Each joint state is defined in Table 4.7. It means,

- If target 1 is in state 1 and target 2 is in state 1 , the joint state will be in state 1 , or

- If target 1 is in state 2 and target 2 is in state 3, the joint state will be in state 7 , and so on. 
Table 4.7 Joint State Space Representation for Two Targets with Four Individual State Markov Model

\begin{tabular}{|c|c|c|c|}
\hline $\begin{array}{c}\text { First } \\
\text { Target's } \\
\text { State } \\
\end{array}$ & $\begin{array}{c}\text { Second } \\
\text { Target's } \\
\text { State } \\
\end{array}$ & Joint State & $\begin{array}{c}\text { Normalized } \\
\text { State Quality } \\
\text { Value } \\
\end{array}$ \\
\hline 1 & 1 & 1 & 100 \\
\hline 1 & 2 & 2 & 90 \\
\hline 1 & 3 & 3 & 70 \\
\hline 1 & 4 & 4 & 15 \\
\hline 2 & 1 & 5 & 90 \\
\hline 2 & 2 & 6 & 80 \\
\hline 2 & 3 & 7 & 50 \\
\hline 2 & 4 & 8 & 10 \\
\hline 3 & 1 & 9 & 70 \\
\hline 3 & 2 & 10 & 50 \\
\hline 3 & 3 & 11 & 30 \\
\hline 3 & 4 & 12 & 5 \\
\hline 4 & 1 & 13 & 15 \\
\hline 4 & 2 & 14 & 10 \\
\hline 4 & 3 & 15 & 5 \\
\hline 4 & 4 & 16 & 0 \\
\hline
\end{tabular}

After the dynamic programming algorithm is applied, optimum decisions are obtained as the output of DP. $t_{i}$ is the time instances of decision horizon. State no column describes the joint state number. Table 4.8 shows the optimal decisions at each time instance $t_{i}$. " 0 " means do not update any target, " 1 " means update target 1 and "2" means update target 2. 
Table 4.8 An Example of Optimized Policy for Joint Markov Model

\begin{tabular}{|c|c|c|c|c|c|c|c|c|c|c|}
\hline State no: & $\boldsymbol{t}_{\mathbf{1}}$ & $\boldsymbol{t}_{\mathbf{2}}$ & $\boldsymbol{t}_{\mathbf{3}}$ & $\boldsymbol{t}_{\mathbf{4}}$ & $\boldsymbol{t}_{\mathbf{5}}$ & $\boldsymbol{t}_{\mathbf{6}}$ & $\boldsymbol{t}_{\mathbf{7}}$ & $\boldsymbol{t}_{\mathbf{8}}$ & $\boldsymbol{t}_{\mathbf{9}}$ & $\boldsymbol{t}_{\mathbf{1 0}}$ \\
\hline $\mathbf{1}$ & 1 & 1 & 1 & 1 & 1 & 1 & 1 & 1 & 2 & 1 \\
\hline $\mathbf{2}$ & 2 & 2 & 2 & 2 & 2 & 2 & 2 & 2 & 2 & 2 \\
\hline $\mathbf{3}$ & 2 & 2 & 2 & 2 & 2 & 2 & 2 & 2 & 2 & 2 \\
\hline $\mathbf{4}$ & 1 & 1 & 1 & 1 & 1 & 1 & 1 & 1 & 1 & 1 \\
\hline $\mathbf{5}$ & 1 & 1 & 1 & 1 & 1 & 1 & 1 & 1 & 1 & 1 \\
\hline $\mathbf{6}$ & 1 & 1 & 1 & 1 & 1 & 1 & 1 & 1 & 1 & 1 \\
\hline $\mathbf{7}$ & 2 & 2 & 2 & 2 & 2 & 2 & 2 & 2 & 2 & 2 \\
\hline $\mathbf{8}$ & 1 & 1 & 1 & 1 & 1 & 1 & 1 & 1 & 1 & 1 \\
\hline $\mathbf{9}$ & 1 & 1 & 1 & 1 & 1 & 1 & 1 & 1 & 1 & 1 \\
\hline $\mathbf{1 0}$ & 1 & 1 & 1 & 1 & 1 & 1 & 1 & 1 & 1 & 1 \\
\hline $\mathbf{1 1}$ & 1 & 1 & 1 & 1 & 1 & 1 & 1 & 1 & 1 & 1 \\
\hline $\mathbf{1 2}$ & 1 & 1 & 1 & 1 & 1 & 1 & 1 & 1 & 1 & 1 \\
\hline $\mathbf{1 3}$ & 2 & 2 & 2 & 2 & 2 & 2 & 2 & 2 & 2 & 2 \\
\hline $\mathbf{1 4}$ & 2 & 2 & 2 & 2 & 2 & 2 & 2 & 2 & 2 & 2 \\
\hline $\mathbf{1 5}$ & 2 & 2 & 2 & 2 & 2 & 2 & 2 & 2 & 2 & 2 \\
\hline $\mathbf{1 6}$ & 0 & 0 & 0 & 0 & 0 & 0 & 0 & 0 & 0 & 0 \\
\hline
\end{tabular}

After the optimum strategy is obtained, 1000 Monte Carlo simulations are run to observe the number of update decisions and the average number of drops for each target. Simulation results are given in Table 4.9. 
Table 4.9 Simulation Results of Optimal Resource Allocation for Joint Markov Model

\begin{tabular}{|c|c|c|c|c|}
\hline & \multicolumn{2}{|c|}{$\begin{array}{c}\text { Target1 } \\
P_{d 1}=0.8\end{array}$} & \multicolumn{2}{|c|}{$\begin{array}{l}\text { Target2 } \\
P_{d 2}=0.7\end{array}$} \\
\hline $\begin{array}{l}\text { Initial } \\
\text { State }\end{array}$ & $\begin{array}{c}\text { Number of } \\
\text { Update in } \\
10 \text { sec. }\end{array}$ & $\begin{array}{c}\text { Number of } \\
\text { average drop in } \\
1000 \text { simulations }\end{array}$ & $\begin{array}{c}\text { Number of } \\
\text { Update in } \\
10 \text { sec. }\end{array}$ & $\begin{array}{c}\text { Number of } \\
\text { average drop in } \\
1000 \text { simulations }\end{array}$ \\
\hline 1 & 5.4820 & 180 & 4.2050 & 365 \\
\hline 2 & 4.6740 & 216 & 4.9490 & 365 \\
\hline 3 & 5.9270 & 140 & 3.8390 & 508 \\
\hline 4 & 9.8450 & 39 & 0.0000 & 1000 \\
\hline 5 & 5.2660 & 239 & 4.3610 & 387 \\
\hline 6 & 6.6830 & 171 & 2.8190 & 600 \\
\hline 7 & 4.8680 & 323 & 4.4560 & 473 \\
\hline 8 & 9.4550 & 93 & 0.0000 & 1000 \\
\hline 9 & 4.2940 & 377 & 5.2250 & 308 \\
\hline 10 & 5.2700 & 311 & 4.0300 & 477 \\
\hline 11 & 8.0290 & 242 & 0.0000 & 1000 \\
\hline 12 & 8.2770 & 209 & 0.0000 & 1000 \\
\hline 13 & 0.0000 & 1000 & 9.4750 & 128 \\
\hline 14 & 0.0000 & 1000 & 8.9330 & 192 \\
\hline 15 & 0.0000 & 1000 & 7.1280 & 367 \\
\hline AVERAGE & 5.2047 & 369.3 & 3.9613 & 544.6 \\
\hline
\end{tabular}

Number of states of the joint Markov chain is increasing exponentially with the number of targets. If the joint Markov model is used to find optimal strategy, we will need to construct very large state space. Actually, four states are not realistic and not enough to represent the quality of a tracked target. In the original scenario, we have eight targets and each target is represented as twenty six states. It means that we need 
to have $26^{8} \times 26^{8} \cong 4,36 \times 10^{22}$ states in state space. This is computationally infeasible. Therefore we need to assume some approximations that are described in Section 3.

\subsection{Optimization-Based Resource Allocation for Two Targets with Approximate DP}

In this section, we compare the results that are obtained by joint Markov model and Lagrange approximation. A scenario is constructed similar to Section 4.3. But this time, Lagrange relaxation method is applied to the objective function. All parameters are same as previous section:

- Probability of detection for target $1\left(P_{d 1}\right)=0.8$

- Probability of detection for target $2\left(P_{d 2}\right)=0.7$

- Nominal utility for target $1\left(U_{\text {nom } 1}\right)=100$

- Nominal utility for target $2\left(U_{\text {nom } 2}\right)=100$

- $\operatorname{Time} \operatorname{horizon}(N)=10 \mathrm{sec}$

- $\quad$ Number of Monte Carlo simulation $=1000$

Markov model that is defined in Figure 4.1 is used for both targets. State rewards are assumed as follows: normalized_state_cov_degeri $=\left[\begin{array}{llll}100 & 70 & 30 & 0\end{array}\right]$

Optimum strategy is obtained for each target. They are defined in Table 4.10 and Table 4.11, respectively.

Table 4.10 An Example of Optimized Policy for Target 1

\begin{tabular}{|c|c|c|c|c|c|c|c|c|c|c|}
\hline State no: & $\boldsymbol{t}_{\mathbf{1}}$ & $\boldsymbol{t}_{\mathbf{2}}$ & $\boldsymbol{t}_{\mathbf{3}}$ & $\boldsymbol{t}_{\mathbf{4}}$ & $\boldsymbol{t}_{\mathbf{5}}$ & $\boldsymbol{t}_{\mathbf{6}}$ & $\boldsymbol{t}_{\mathbf{7}}$ & $\boldsymbol{t}_{\mathbf{8}}$ & $\boldsymbol{t}_{\mathbf{9}}$ & $\boldsymbol{t}_{\mathbf{1 0}}$ \\
\hline $\mathbf{1}$ & 0 & 0 & 0 & 0 & 0 & 0 & 0 & 0 & 0 & 1 \\
\hline $\mathbf{2}$ & 1 & 1 & 1 & 1 & 1 & 1 & 1 & 1 & 1 & 1 \\
\hline $\mathbf{3}$ & 1 & 1 & 1 & 1 & 1 & 1 & 1 & 1 & 1 & 1 \\
\hline $\mathbf{4}$ & 0 & 0 & 0 & 0 & 0 & 0 & 0 & 0 & 0 & 0 \\
\hline
\end{tabular}


Table 4.11 An Example of Optimized Policy for Target 2

\begin{tabular}{|c|c|c|c|c|c|c|c|c|c|c|}
\hline State no: & $\boldsymbol{t}_{\mathbf{1}}$ & $\boldsymbol{t}_{\mathbf{2}}$ & $\boldsymbol{t}_{\mathbf{3}}$ & $\boldsymbol{t}_{\mathbf{4}}$ & $\boldsymbol{t}_{\mathbf{5}}$ & $\boldsymbol{t}_{\mathbf{6}}$ & $\boldsymbol{t}_{\mathbf{7}}$ & $\boldsymbol{t}_{\mathbf{8}}$ & $\boldsymbol{t}_{\mathbf{9}}$ & $\boldsymbol{t}_{\mathbf{1 0}}$ \\
\hline $\mathbf{1}$ & 0 & 0 & 0 & 0 & 0 & 0 & 0 & 0 & 0 & 0 \\
\hline $\mathbf{2}$ & 1 & 1 & 0 & 1 & 1 & 1 & 0 & 1 & 1 & 1 \\
\hline $\mathbf{3}$ & 1 & 1 & 1 & 1 & 1 & 1 & 1 & 1 & 1 & 1 \\
\hline $\mathbf{4}$ & 0 & 0 & 0 & 0 & 0 & 0 & 0 & 0 & 0 & 0 \\
\hline
\end{tabular}

We make the following observations by comparing Tables 4.10 and 4.11 with Table 4.8 .

- Table 4.10 says that 'apply an update operation to target 1 whenever its state is 2 or $3^{\prime}$. These states correspond to the states 5-12 in Table 4.8 which gives the same result except state 7 .

- Table 4.11 says that 'apply update operation if it is at state 3 at all times'. The corresponding states of Table 4.8 are states $3,7,11,15$ and the same result is obtained in the optimal operation at all times except at state 11 .

The differences among these solutions and the optimal one are at the points where both targets request an update. So the results seem to show the partial optimality of the approximate method.

To further investigate the optimality of the approximation the strategy obtained is run for 1000 Monte Carlo simulations. Simulation results are given in Table 4.12. 
Table 4.12 Simulation Results of Optimization-Based Resource Allocation with Approximate DP

\begin{tabular}{|c|c|c|c|c|}
\hline & \multicolumn{2}{|c|}{$\begin{array}{l}\text { Target1 } \\
P_{d 1}=0.8\end{array}$} & \multicolumn{2}{|c|}{$\begin{array}{l}\text { Target2 } \\
P_{d 2}=0.7\end{array}$} \\
\hline $\begin{array}{l}\text { Initial } \\
\text { State }\end{array}$ & $\begin{array}{c}\text { Number of } \\
\text { Update in } \\
10 \text { sec. }\end{array}$ & $\begin{array}{c}\text { Number of } \\
\text { average drop in } \\
1000 \text { simulations }\end{array}$ & $\begin{array}{c}\text { Number of } \\
\text { Update in } \\
10 \text { sec. }\end{array}$ & $\begin{array}{c}\text { Number of } \\
\text { average drop in } \\
1000 \text { simulations }\end{array}$ \\
\hline 1 & 5.2560 & 153 & 4.7070 & 349 \\
\hline 2 & 5.2290 & 142 & 4.4380 & 438 \\
\hline 3 & 5.2650 & 141 & 3.4430 & 557 \\
\hline 4 & 5.2440 & 155 & 0.0000 & 1000 \\
\hline 5 & 5.7910 & 180 & 4.6650 & 367 \\
\hline 6 & 5.7140 & 187 & 4.3920 & 444 \\
\hline 7 & 5.7730 & 195 & 3.4260 & 561 \\
\hline 8 & 5.7760 & 186 & 0.0000 & 1000 \\
\hline 9 & 4.8430 & 377 & 4.6510 & 361 \\
\hline 10 & 4.8740 & 325 & 4.4220 & 436 \\
\hline 11 & 4.8250 & 324 & 3.3360 & 593 \\
\hline 12 & 4.9150 & 299 & 0.0000 & 1000 \\
\hline 13 & 0.0000 & 1000 & 4.6460 & 344 \\
\hline 14 & 0.0000 & 1000 & 4.4710 & 437 \\
\hline 15 & 0.0000 & 1000 & 3.4470 & 568 \\
\hline AVERAGE & 5.2921 & 377.6 & 4.1703 & 563.6 \\
\hline
\end{tabular}

If we compare the results of Section 4.3 and 4.4, we will see that the numbers of update decisions and the numbers of average drops are close each other. This means our approximation is good enough. 


\subsection{Optimization-Based Resource Allocation for Eight Targets with Approximate DP}

The first scenario that we have studied is a single target that we applied the DP based solution. On this scenario we observed that we do not need to update this target at every time instant to consume radar resources efficiently. Then, a simple scenario with two targets is constructed to and the optimal strategy is obtained on a simple model. The same problem is solved via Lagrange relaxation and results were compared. Results are close to each other. Now, we expand the scenario that is described in Section 3 is chosen to observe the overall system performance.

In the new scenario we have eight targets and each of them has 26-state Markov model that is described in Figure 3.3.

Inputs that are selected by the operator are given below:

- Probability of detection for target $1\left(P_{d 1}\right)=0.8$

- Probability of detection for target $2\left(P_{d 2}\right)=0.7$

- Probability of detection for target $3\left(P_{d 3}\right)=0.6$

- Probability of detection for target $4\left(P_{d 4}\right)=0.6$

- Probability of detection for target $5\left(P_{d 5}\right)=0.7$

- Probability of detection for target $6\left(P_{d 6}\right)=0.7$

- Probability of detection for target $7\left(P_{d 7}\right)=0.8$

- Probability of detection for target $8\left(P_{d 8}\right)=0.6$

- Nominal utility for target $1\left(U_{\text {nom } 1}\right)=100$

- Nominal utility for target $2\left(U_{\text {nom } 2}\right)=100$

- Nominal utility for target $3\left(U_{\text {nom } 3}\right)=100$

- Nominal utility for target $4\left(U_{\text {nom } 4}\right)=100$

- Nominal utility for target $5\left(U_{\text {nom } 5}\right)=100$

- Nominal utility for target $6\left(U_{\text {nom6 }}\right)=100$

- Nominal utility for target $7\left(U_{\text {nom } 7}\right)=100$

- Nominal utility for target $8\left(U_{\text {nom } 8}\right)=100$ 
- $\quad$ Time horizon $(N)=10 \mathrm{sec}$

- Number of Monte Carlo simulation $=1000$

- Discrete parameterization of state rewards is the same as Section 4.1

We assume that the radar can send beams at every 200 milliseconds. It means that one look for tracking task is nearly 200 milliseconds. In best case, five targets can be tracked or in worst case, one target consumes all resources in macro management interval because macro manager makes decisions at every second. This is obviously not a realistic; however the aim here is to demonstrate the effectiveness of the algorithm. Since we define a rule in Section 3.1.4 that determines the state transition probabilities depending on the current state, we calculate the expected state dependent load for each target. Then, utilities are computed by nominal utilities and normalized state rewards that are described in Section 3.1.2 and Section 3.1.3. Our aim is to obtain an (near) optimal strategy that decides on which tracks should be updated. This decision requires the maximization of the utility function but we are also interested with number of drops. This is achieved by allocating the scarce radar resource in an optimal way during the time horizon. $\lambda$ 's are adjusted by two ways as we mentioned in Section 3.4 and the Table 4.21 shows the performance similarities between these two methods. Therefore, optimal strategies for each target are obtained by using 'fminsearch' function of MATLAB and they are given in Table 4.13 to Table 4.20. These are obtained by dynamic programming solution and Lagrange relaxation that are described in Section 3. 
Table 4.13 The Optimal Strategy of First Target

\begin{tabular}{|c|c|c|c|c|c|c|c|c|c|c|}
\hline State no: & $\boldsymbol{t}_{\mathbf{1}}$ & $\boldsymbol{t}_{\mathbf{2}}$ & $\boldsymbol{t}_{\mathbf{3}}$ & $\boldsymbol{t}_{\mathbf{4}}$ & $\boldsymbol{t}_{\mathbf{5}}$ & $\boldsymbol{t}_{\mathbf{6}}$ & $\boldsymbol{t}_{\mathbf{7}}$ & $\boldsymbol{t}_{\mathbf{8}}$ & $\boldsymbol{t}_{\mathbf{9}}$ & $\boldsymbol{t}_{\mathbf{1 0}}$ \\
\hline $\mathbf{1}$ & 0 & 0 & 0 & 0 & 0 & 0 & 0 & 0 & 0 & 1 \\
\hline $\mathbf{2}$ & 0 & 0 & 0 & 0 & 0 & 0 & 1 & 0 & 1 & 1 \\
\hline $\mathbf{3}$ & 0 & 0 & 0 & 0 & 1 & 1 & 1 & 0 & 1 & 1 \\
\hline $\mathbf{4}$ & 0 & 0 & 1 & 1 & 1 & 1 & 1 & 1 & 1 & 1 \\
\hline $\mathbf{5}$ & 0 & 1 & 1 & 1 & 1 & 1 & 1 & 1 & 1 & 1 \\
\hline $\mathbf{6}$ & 0 & 1 & 1 & 1 & 1 & 1 & 1 & 1 & 1 & 1 \\
\hline $\mathbf{7}$ & 1 & 1 & 1 & 1 & 1 & 1 & 1 & 1 & 1 & 1 \\
\hline $\mathbf{8}$ & 1 & 1 & 1 & 1 & 1 & 1 & 1 & 1 & 1 & 1 \\
\hline $\mathbf{9}$ & 1 & 1 & 1 & 1 & 1 & 1 & 1 & 1 & 1 & 1 \\
\hline $\mathbf{1 0}$ & 1 & 1 & 1 & 1 & 1 & 1 & 1 & 1 & 1 & 1 \\
\hline $\mathbf{1 1}$ & 1 & 1 & 1 & 1 & 1 & 1 & 1 & 1 & 1 & 1 \\
\hline $\mathbf{1 2}$ & 1 & 1 & 1 & 1 & 1 & 1 & 1 & 1 & 1 & 1 \\
\hline $\mathbf{1 3}$ & 1 & 1 & 1 & 1 & 1 & 1 & 1 & 1 & 1 & 1 \\
\hline $\mathbf{1 4}$ & 1 & 1 & 1 & 1 & 1 & 1 & 1 & 1 & 1 & 1 \\
\hline $\mathbf{1 5}$ & 1 & 1 & 1 & 1 & 1 & 1 & 1 & 1 & 1 & 1 \\
\hline $\mathbf{1 6}$ & 1 & 1 & 1 & 1 & 1 & 1 & 1 & 1 & 1 & 1 \\
\hline $\mathbf{1 7}$ & 1 & 1 & 1 & 1 & 1 & 1 & 1 & 1 & 1 & 1 \\
\hline $\mathbf{1 8}$ & 1 & 1 & 1 & 1 & 1 & 1 & 1 & 1 & 1 & 1 \\
\hline $\mathbf{1 9}$ & 1 & 1 & 1 & 1 & 1 & 1 & 1 & 1 & 1 & 1 \\
\hline $\mathbf{2 0}$ & 1 & 1 & 1 & 1 & 1 & 1 & 1 & 1 & 1 & 1 \\
\hline $\mathbf{2 1}$ & 1 & 1 & 1 & 1 & 1 & 1 & 1 & 1 & 1 & 1 \\
\hline $\mathbf{2 2}$ & 1 & 1 & 1 & 1 & 1 & 1 & 1 & 1 & 1 & 1 \\
\hline $\mathbf{2 3}$ & 1 & 1 & 1 & 1 & 1 & 1 & 1 & 1 & 1 & 1 \\
\hline $\mathbf{2 4}$ & 1 & 1 & 1 & 1 & 1 & 1 & 1 & 1 & 1 & 1 \\
\hline $\mathbf{2 5}$ & 1 & 1 & 1 & 1 & 1 & 1 & 1 & 1 & 1 & 1 \\
\hline $\mathbf{2 6}$ & 0 & 0 & 0 & 0 & 0 & 0 & 0 & 0 & 0 & 0 \\
\hline & & & & & & & \\
\hline
\end{tabular}


Table 4.14 The Optimal Strategy of Second Target

\begin{tabular}{|c|c|c|c|c|c|c|c|c|c|c|}
\hline State no: & $\boldsymbol{t}_{\mathbf{1}}$ & $\boldsymbol{t}_{\mathbf{2}}$ & $\boldsymbol{t}_{\mathbf{3}}$ & $\boldsymbol{t}_{\mathbf{4}}$ & $\boldsymbol{t}_{\mathbf{5}}$ & $\boldsymbol{t}_{\mathbf{6}}$ & $\boldsymbol{t}_{\mathbf{7}}$ & $\boldsymbol{t}_{\mathbf{8}}$ & $\boldsymbol{t}_{\mathbf{9}}$ & $\boldsymbol{t}_{\mathbf{1 0}}$ \\
\hline $\mathbf{1}$ & 0 & 0 & 0 & 0 & 0 & 0 & 0 & 0 & 0 & 0 \\
\hline $\mathbf{2}$ & 0 & 0 & 0 & 0 & 0 & 0 & 0 & 0 & 0 & 1 \\
\hline $\mathbf{3}$ & 0 & 0 & 0 & 0 & 0 & 0 & 0 & 0 & 1 & 1 \\
\hline $\mathbf{4}$ & 0 & 0 & 0 & 0 & 0 & 0 & 0 & 0 & 1 & 1 \\
\hline $\mathbf{5}$ & 0 & 0 & 0 & 0 & 0 & 0 & 0 & 0 & 1 & 1 \\
\hline $\mathbf{6}$ & 0 & 0 & 0 & 0 & 0 & 0 & 0 & 1 & 1 & 1 \\
\hline $\mathbf{7}$ & 0 & 0 & 0 & 0 & 1 & 1 & 1 & 1 & 1 & 1 \\
\hline $\mathbf{8}$ & 0 & 0 & 1 & 1 & 1 & 1 & 1 & 1 & 1 & 1 \\
\hline $\mathbf{9}$ & 0 & 0 & 1 & 1 & 1 & 1 & 1 & 1 & 1 & 1 \\
\hline $\mathbf{1 0}$ & 0 & 1 & 1 & 1 & 1 & 1 & 1 & 1 & 1 & 1 \\
\hline $\mathbf{1 1}$ & 0 & 0 & 1 & 1 & 1 & 1 & 1 & 1 & 1 & 1 \\
\hline $\mathbf{1 2}$ & 0 & 1 & 1 & 1 & 1 & 1 & 1 & 1 & 1 & 1 \\
\hline $\mathbf{1 3}$ & 0 & 1 & 1 & 1 & 1 & 1 & 1 & 1 & 1 & 1 \\
\hline $\mathbf{1 4}$ & 0 & 1 & 1 & 1 & 1 & 1 & 1 & 1 & 1 & 1 \\
\hline $\mathbf{1 5}$ & 0 & 1 & 1 & 1 & 1 & 1 & 1 & 1 & 1 & 1 \\
\hline $\mathbf{1 6}$ & 1 & 1 & 1 & 1 & 1 & 1 & 1 & 1 & 1 & 1 \\
\hline $\mathbf{1 7}$ & 1 & 1 & 1 & 1 & 1 & 1 & 1 & 1 & 1 & 1 \\
\hline $\mathbf{1 8}$ & 1 & 1 & 1 & 1 & 1 & 1 & 1 & 1 & 1 & 1 \\
\hline $\mathbf{1 9}$ & 1 & 1 & 1 & 1 & 1 & 1 & 1 & 1 & 1 & 1 \\
\hline $\mathbf{2 0}$ & 1 & 1 & 1 & 1 & 1 & 1 & 1 & 1 & 1 & 1 \\
\hline $\mathbf{2 1}$ & 1 & 1 & 1 & 1 & 1 & 1 & 1 & 1 & 1 & 1 \\
\hline $\mathbf{2 2}$ & 1 & 1 & 1 & 1 & 1 & 1 & 1 & 1 & 1 & 1 \\
\hline $\mathbf{2 3}$ & 1 & 1 & 1 & 1 & 1 & 1 & 1 & 1 & 1 & 1 \\
\hline $\mathbf{2 4}$ & 1 & 1 & 1 & 1 & 1 & 1 & 1 & 1 & 1 & 1 \\
\hline $\mathbf{2 5}$ & 1 & 1 & 1 & 1 & 1 & 1 & 1 & 1 & 1 & 1 \\
\hline $\mathbf{2 6}$ & 0 & 0 & 0 & 0 & 0 & 0 & 0 & 0 & 0 & 0 \\
\hline & & & & & & & \\
\hline
\end{tabular}


Table 4.15 The Optimal Strategy of Third Target

\begin{tabular}{|c|c|c|c|c|c|c|c|c|c|c|}
\hline State no: & $\boldsymbol{t}_{\mathbf{1}}$ & $\boldsymbol{t}_{\mathbf{2}}$ & $\boldsymbol{t}_{\mathbf{3}}$ & $\boldsymbol{t}_{\mathbf{4}}$ & $\boldsymbol{t}_{\mathbf{5}}$ & $\boldsymbol{t}_{\mathbf{6}}$ & $\boldsymbol{t}_{\mathbf{7}}$ & $\boldsymbol{t}_{\mathbf{8}}$ & $\boldsymbol{t}_{\mathbf{9}}$ & $\boldsymbol{t}_{\mathbf{1 0}}$ \\
\hline $\mathbf{1}$ & 0 & 0 & 0 & 0 & 0 & 0 & 0 & 0 & 0 & 0 \\
\hline $\mathbf{2}$ & 0 & 0 & 0 & 0 & 0 & 0 & 0 & 0 & 0 & 0 \\
\hline $\mathbf{3}$ & 0 & 0 & 0 & 0 & 0 & 0 & 0 & 0 & 0 & 0 \\
\hline $\mathbf{4}$ & 0 & 0 & 0 & 0 & 0 & 0 & 0 & 0 & 0 & 0 \\
\hline $\mathbf{5}$ & 0 & 0 & 0 & 0 & 0 & 0 & 0 & 0 & 0 & 0 \\
\hline $\mathbf{6}$ & 0 & 0 & 0 & 0 & 0 & 0 & 0 & 0 & 0 & 0 \\
\hline $\mathbf{7}$ & 0 & 0 & 0 & 0 & 0 & 0 & 0 & 0 & 0 & 0 \\
\hline $\mathbf{8}$ & 0 & 0 & 0 & 0 & 0 & 0 & 0 & 0 & 0 & 0 \\
\hline $\mathbf{9}$ & 0 & 0 & 0 & 0 & 0 & 0 & 0 & 0 & 0 & 0 \\
\hline $\mathbf{1 0}$ & 0 & 0 & 0 & 0 & 0 & 0 & 0 & 0 & 0 & 0 \\
\hline $\mathbf{1 1}$ & 0 & 0 & 0 & 0 & 0 & 0 & 0 & 0 & 0 & 0 \\
\hline $\mathbf{1 2}$ & 0 & 0 & 0 & 0 & 0 & 0 & 0 & 0 & 0 & 0 \\
\hline $\mathbf{1 3}$ & 0 & 0 & 0 & 0 & 0 & 0 & 0 & 1 & 0 & 0 \\
\hline $\mathbf{1 4}$ & 0 & 0 & 0 & 0 & 0 & 0 & 0 & 1 & 0 & 0 \\
\hline $\mathbf{1 5}$ & 0 & 0 & 0 & 0 & 0 & 0 & 0 & 1 & 0 & 0 \\
\hline $\mathbf{1 6}$ & 0 & 1 & 0 & 1 & 1 & 1 & 1 & 1 & 1 & 0 \\
\hline $\mathbf{1 7}$ & 0 & 1 & 0 & 1 & 1 & 1 & 1 & 1 & 1 & 0 \\
\hline $\mathbf{1 8}$ & 0 & 1 & 0 & 1 & 1 & 1 & 1 & 1 & 1 & 0 \\
\hline $\mathbf{1 9}$ & 0 & 1 & 0 & 1 & 1 & 1 & 1 & 1 & 1 & 0 \\
\hline $\mathbf{2 0}$ & 0 & 1 & 0 & 1 & 1 & 1 & 1 & 1 & 1 & 0 \\
\hline $\mathbf{2 1}$ & 1 & 1 & 1 & 1 & 1 & 1 & 1 & 1 & 1 & 1 \\
\hline $\mathbf{2 2}$ & 1 & 1 & 1 & 1 & 1 & 1 & 1 & 1 & 1 & 1 \\
\hline $\mathbf{2 3}$ & 1 & 1 & 1 & 1 & 1 & 1 & 1 & 1 & 1 & 1 \\
\hline $\mathbf{2 4}$ & 1 & 1 & 1 & 1 & 1 & 1 & 1 & 1 & 1 & 1 \\
\hline $\mathbf{2 5}$ & 1 & 1 & 1 & 1 & 1 & 1 & 1 & 1 & 1 & 1 \\
\hline $\mathbf{2 6}$ & 0 & 0 & 0 & 0 & 0 & 0 & 0 & 0 & 0 & 0 \\
\hline & & & & & & & \\
\hline
\end{tabular}


Table 4.16 The Optimal Strategy of Fourth Target

\begin{tabular}{|c|c|c|c|c|c|c|c|c|c|c|}
\hline State no: & $\boldsymbol{t}_{\mathbf{1}}$ & $\boldsymbol{t}_{\mathbf{2}}$ & $\boldsymbol{t}_{\mathbf{3}}$ & $\boldsymbol{t}_{\mathbf{4}}$ & $\boldsymbol{t}_{\mathbf{5}}$ & $\boldsymbol{t}_{\mathbf{6}}$ & $\boldsymbol{t}_{\mathbf{7}}$ & $\boldsymbol{t}_{\mathbf{8}}$ & $\boldsymbol{t}_{\mathbf{9}}$ & $\boldsymbol{t}_{\mathbf{1 0}}$ \\
\hline $\mathbf{1}$ & 0 & 0 & 0 & 0 & 0 & 0 & 0 & 0 & 0 & 0 \\
\hline $\mathbf{2}$ & 0 & 0 & 0 & 0 & 0 & 0 & 0 & 0 & 0 & 0 \\
\hline $\mathbf{3}$ & 0 & 0 & 0 & 0 & 0 & 0 & 0 & 0 & 0 & 0 \\
\hline $\mathbf{4}$ & 0 & 0 & 0 & 0 & 0 & 0 & 0 & 0 & 0 & 0 \\
\hline $\mathbf{5}$ & 0 & 0 & 0 & 0 & 0 & 0 & 0 & 0 & 0 & 0 \\
\hline $\mathbf{6}$ & 0 & 0 & 0 & 0 & 0 & 0 & 0 & 0 & 0 & 0 \\
\hline $\mathbf{7}$ & 0 & 0 & 0 & 0 & 0 & 0 & 0 & 0 & 0 & 0 \\
\hline $\mathbf{8}$ & 0 & 0 & 0 & 0 & 0 & 0 & 0 & 0 & 0 & 0 \\
\hline $\mathbf{9}$ & 0 & 0 & 0 & 0 & 0 & 0 & 0 & 0 & 0 & 0 \\
\hline $\mathbf{1 0}$ & 0 & 0 & 0 & 0 & 0 & 0 & 0 & 0 & 0 & 0 \\
\hline $\mathbf{1 1}$ & 0 & 0 & 0 & 0 & 0 & 0 & 0 & 0 & 0 & 0 \\
\hline $\mathbf{1 2}$ & 0 & 0 & 0 & 0 & 0 & 0 & 0 & 0 & 0 & 0 \\
\hline $\mathbf{1 3}$ & 0 & 0 & 0 & 0 & 0 & 0 & 0 & 1 & 0 & 0 \\
\hline $\mathbf{1 4}$ & 0 & 0 & 0 & 0 & 0 & 0 & 0 & 1 & 0 & 0 \\
\hline $\mathbf{1 5}$ & 0 & 0 & 0 & 0 & 0 & 0 & 0 & 1 & 0 & 0 \\
\hline $\mathbf{1 6}$ & 0 & 1 & 0 & 1 & 1 & 1 & 1 & 1 & 1 & 0 \\
\hline $\mathbf{1 7}$ & 0 & 1 & 0 & 1 & 1 & 1 & 1 & 1 & 1 & 0 \\
\hline $\mathbf{1 8}$ & 0 & 1 & 0 & 1 & 1 & 1 & 1 & 1 & 1 & 0 \\
\hline $\mathbf{1 9}$ & 0 & 1 & 0 & 1 & 1 & 1 & 1 & 1 & 1 & 0 \\
\hline $\mathbf{2 0}$ & 0 & 1 & 0 & 1 & 1 & 1 & 1 & 1 & 1 & 0 \\
\hline $\mathbf{2 1}$ & 1 & 1 & 1 & 1 & 1 & 1 & 1 & 1 & 1 & 1 \\
\hline $\mathbf{2 2}$ & 1 & 1 & 1 & 1 & 1 & 1 & 1 & 1 & 1 & 1 \\
\hline $\mathbf{2 3}$ & 1 & 1 & 1 & 1 & 1 & 1 & 1 & 1 & 1 & 1 \\
\hline $\mathbf{2 4}$ & 1 & 1 & 1 & 1 & 1 & 1 & 1 & 1 & 1 & 1 \\
\hline $\mathbf{2 5}$ & 1 & 1 & 1 & 1 & 1 & 1 & 1 & 1 & 1 & 1 \\
\hline $\mathbf{2 6}$ & 0 & 0 & 0 & 0 & 0 & 0 & 0 & 0 & 0 & 0 \\
\hline & & & & & & & \\
\hline
\end{tabular}


Table 4.17 The Optimal Strategy of Fifth Target

\begin{tabular}{|c|c|c|c|c|c|c|c|c|c|c|}
\hline State no: & $\boldsymbol{t}_{\mathbf{1}}$ & $\boldsymbol{t}_{\mathbf{2}}$ & $\boldsymbol{t}_{\mathbf{3}}$ & $\boldsymbol{t}_{\mathbf{4}}$ & $\boldsymbol{t}_{\mathbf{5}}$ & $\boldsymbol{t}_{\mathbf{6}}$ & $\boldsymbol{t}_{\mathbf{7}}$ & $\boldsymbol{t}_{\mathbf{8}}$ & $\boldsymbol{t}_{\mathbf{9}}$ & $\boldsymbol{t}_{\mathbf{1 0}}$ \\
\hline $\mathbf{1}$ & 0 & 0 & 0 & 0 & 0 & 0 & 0 & 0 & 0 & 0 \\
\hline $\mathbf{2}$ & 0 & 0 & 0 & 0 & 0 & 0 & 0 & 0 & 0 & 1 \\
\hline $\mathbf{3}$ & 0 & 0 & 0 & 0 & 0 & 0 & 0 & 0 & 1 & 1 \\
\hline $\mathbf{4}$ & 0 & 0 & 0 & 0 & 0 & 0 & 0 & 0 & 1 & 1 \\
\hline $\mathbf{5}$ & 0 & 0 & 0 & 0 & 0 & 0 & 0 & 0 & 1 & 1 \\
\hline $\mathbf{6}$ & 0 & 0 & 0 & 0 & 0 & 0 & 0 & 1 & 1 & 1 \\
\hline $\mathbf{7}$ & 0 & 0 & 0 & 0 & 1 & 1 & 1 & 1 & 1 & 1 \\
\hline $\mathbf{8}$ & 0 & 0 & 1 & 1 & 1 & 1 & 1 & 1 & 1 & 1 \\
\hline $\mathbf{9}$ & 0 & 0 & 1 & 1 & 1 & 1 & 1 & 1 & 1 & 1 \\
\hline $\mathbf{1 0}$ & 0 & 1 & 1 & 1 & 1 & 1 & 1 & 1 & 1 & 1 \\
\hline $\mathbf{1 1}$ & 0 & 0 & 1 & 1 & 1 & 1 & 1 & 1 & 1 & 1 \\
\hline $\mathbf{1 2}$ & 0 & 1 & 1 & 1 & 1 & 1 & 1 & 1 & 1 & 1 \\
\hline $\mathbf{1 3}$ & 0 & 1 & 1 & 1 & 1 & 1 & 1 & 1 & 1 & 1 \\
\hline $\mathbf{1 4}$ & 0 & 1 & 1 & 1 & 1 & 1 & 1 & 1 & 1 & 1 \\
\hline $\mathbf{1 5}$ & 0 & 1 & 1 & 1 & 1 & 1 & 1 & 1 & 1 & 1 \\
\hline $\mathbf{1 6}$ & 1 & 1 & 1 & 1 & 1 & 1 & 1 & 1 & 1 & 1 \\
\hline $\mathbf{1 7}$ & 1 & 1 & 1 & 1 & 1 & 1 & 1 & 1 & 1 & 1 \\
\hline $\mathbf{1 8}$ & 1 & 1 & 1 & 1 & 1 & 1 & 1 & 1 & 1 & 1 \\
\hline $\mathbf{1 9}$ & 1 & 1 & 1 & 1 & 1 & 1 & 1 & 1 & 1 & 1 \\
\hline $\mathbf{2 0}$ & 1 & 1 & 1 & 1 & 1 & 1 & 1 & 1 & 1 & 1 \\
\hline $\mathbf{2 1}$ & 1 & 1 & 1 & 1 & 1 & 1 & 1 & 1 & 1 & 1 \\
\hline $\mathbf{2 2}$ & 1 & 1 & 1 & 1 & 1 & 1 & 1 & 1 & 1 & 1 \\
\hline $\mathbf{2 3}$ & 1 & 1 & 1 & 1 & 1 & 1 & 1 & 1 & 1 & 1 \\
\hline $\mathbf{2 4}$ & 1 & 1 & 1 & 1 & 1 & 1 & 1 & 1 & 1 & 1 \\
\hline $\mathbf{2 5}$ & 1 & 1 & 1 & 1 & 1 & 1 & 1 & 1 & 1 & 1 \\
\hline $\mathbf{2 6}$ & 0 & 0 & 0 & 0 & 0 & 0 & 0 & 0 & 0 & 0 \\
\hline & & & & & & & \\
\hline
\end{tabular}


Table 4.18 The Optimal Strategy of Sixth Target

\begin{tabular}{|c|c|c|c|c|c|c|c|c|c|c|}
\hline State no: & $\boldsymbol{t}_{\mathbf{1}}$ & $\boldsymbol{t}_{\mathbf{2}}$ & $\boldsymbol{t}_{\mathbf{3}}$ & $\boldsymbol{t}_{\mathbf{4}}$ & $\boldsymbol{t}_{\mathbf{5}}$ & $\boldsymbol{t}_{\mathbf{6}}$ & $\boldsymbol{t}_{\mathbf{7}}$ & $\boldsymbol{t}_{\mathbf{8}}$ & $\boldsymbol{t}_{\mathbf{9}}$ & $\boldsymbol{t}_{\mathbf{1 0}}$ \\
\hline $\mathbf{1}$ & 0 & 0 & 0 & 0 & 0 & 0 & 0 & 0 & 0 & 0 \\
\hline $\mathbf{2}$ & 0 & 0 & 0 & 0 & 0 & 0 & 0 & 0 & 0 & 1 \\
\hline $\mathbf{3}$ & 0 & 0 & 0 & 0 & 0 & 0 & 0 & 0 & 1 & 1 \\
\hline $\mathbf{4}$ & 0 & 0 & 0 & 0 & 0 & 0 & 0 & 0 & 1 & 1 \\
\hline $\mathbf{5}$ & 0 & 0 & 0 & 0 & 0 & 0 & 0 & 0 & 1 & 1 \\
\hline $\mathbf{6}$ & 0 & 0 & 0 & 0 & 0 & 0 & 0 & 1 & 1 & 1 \\
\hline $\mathbf{7}$ & 0 & 0 & 0 & 0 & 1 & 1 & 1 & 1 & 1 & 1 \\
\hline $\mathbf{8}$ & 0 & 0 & 1 & 1 & 1 & 1 & 1 & 1 & 1 & 1 \\
\hline $\mathbf{9}$ & 0 & 0 & 1 & 1 & 1 & 1 & 1 & 1 & 1 & 1 \\
\hline $\mathbf{1 0}$ & 0 & 1 & 1 & 1 & 1 & 1 & 1 & 1 & 1 & 1 \\
\hline $\mathbf{1 1}$ & 0 & 0 & 1 & 1 & 1 & 1 & 1 & 1 & 1 & 1 \\
\hline $\mathbf{1 2}$ & 0 & 1 & 1 & 1 & 1 & 1 & 1 & 1 & 1 & 1 \\
\hline $\mathbf{1 3}$ & 0 & 1 & 1 & 1 & 1 & 1 & 1 & 1 & 1 & 1 \\
\hline $\mathbf{1 4}$ & 0 & 1 & 1 & 1 & 1 & 1 & 1 & 1 & 1 & 1 \\
\hline $\mathbf{1 5}$ & 0 & 1 & 1 & 1 & 1 & 1 & 1 & 1 & 1 & 1 \\
\hline $\mathbf{1 6}$ & 1 & 1 & 1 & 1 & 1 & 1 & 1 & 1 & 1 & 1 \\
\hline $\mathbf{1 7}$ & 1 & 1 & 1 & 1 & 1 & 1 & 1 & 1 & 1 & 1 \\
\hline $\mathbf{1 8}$ & 1 & 1 & 1 & 1 & 1 & 1 & 1 & 1 & 1 & 1 \\
\hline $\mathbf{1 9}$ & 1 & 1 & 1 & 1 & 1 & 1 & 1 & 1 & 1 & 1 \\
\hline $\mathbf{2 0}$ & 1 & 1 & 1 & 1 & 1 & 1 & 1 & 1 & 1 & 1 \\
\hline $\mathbf{2 1}$ & 1 & 1 & 1 & 1 & 1 & 1 & 1 & 1 & 1 & 1 \\
\hline $\mathbf{2 2}$ & 1 & 1 & 1 & 1 & 1 & 1 & 1 & 1 & 1 & 1 \\
\hline $\mathbf{2 3}$ & 1 & 1 & 1 & 1 & 1 & 1 & 1 & 1 & 1 & 1 \\
\hline $\mathbf{2 4}$ & 1 & 1 & 1 & 1 & 1 & 1 & 1 & 1 & 1 & 1 \\
\hline $\mathbf{2 5}$ & 1 & 1 & 1 & 1 & 1 & 1 & 1 & 1 & 1 & 1 \\
\hline $\mathbf{2 6}$ & 0 & 0 & 0 & 0 & 0 & 0 & 0 & 0 & 0 & 0 \\
\hline & & & & & & & \\
\hline
\end{tabular}


Table 4.19 The Optimal Strategy of Seventh Target

\begin{tabular}{|c|c|c|c|c|c|c|c|c|c|c|}
\hline State no: & $\boldsymbol{t}_{\mathbf{1}}$ & $\boldsymbol{t}_{\mathbf{2}}$ & $\boldsymbol{t}_{\mathbf{3}}$ & $\boldsymbol{t}_{\mathbf{4}}$ & $\boldsymbol{t}_{\mathbf{5}}$ & $\boldsymbol{t}_{\mathbf{6}}$ & $\boldsymbol{t}_{\mathbf{7}}$ & $\boldsymbol{t}_{\mathbf{8}}$ & $\boldsymbol{t}_{\mathbf{9}}$ & $\boldsymbol{t}_{\mathbf{1 0}}$ \\
\hline $\mathbf{1}$ & 0 & 0 & 0 & 0 & 0 & 0 & 0 & 0 & 0 & 1 \\
\hline $\mathbf{2}$ & 0 & 0 & 0 & 0 & 0 & 0 & 1 & 0 & 1 & 1 \\
\hline $\mathbf{3}$ & 0 & 0 & 0 & 0 & 1 & 1 & 1 & 0 & 1 & 1 \\
\hline $\mathbf{4}$ & 0 & 0 & 1 & 1 & 1 & 1 & 1 & 1 & 1 & 1 \\
\hline $\mathbf{5}$ & 0 & 1 & 1 & 1 & 1 & 1 & 1 & 1 & 1 & 1 \\
\hline $\mathbf{6}$ & 0 & 1 & 1 & 1 & 1 & 1 & 1 & 1 & 1 & 1 \\
\hline $\mathbf{7}$ & 1 & 1 & 1 & 1 & 1 & 1 & 1 & 1 & 1 & 1 \\
\hline $\mathbf{8}$ & 1 & 1 & 1 & 1 & 1 & 1 & 1 & 1 & 1 & 1 \\
\hline $\mathbf{9}$ & 1 & 1 & 1 & 1 & 1 & 1 & 1 & 1 & 1 & 1 \\
\hline $\mathbf{1 0}$ & 1 & 1 & 1 & 1 & 1 & 1 & 1 & 1 & 1 & 1 \\
\hline $\mathbf{1 1}$ & 1 & 1 & 1 & 1 & 1 & 1 & 1 & 1 & 1 & 1 \\
\hline $\mathbf{1 2}$ & 1 & 1 & 1 & 1 & 1 & 1 & 1 & 1 & 1 & 1 \\
\hline $\mathbf{1 3}$ & 1 & 1 & 1 & 1 & 1 & 1 & 1 & 1 & 1 & 1 \\
\hline $\mathbf{1 4}$ & 1 & 1 & 1 & 1 & 1 & 1 & 1 & 1 & 1 & 1 \\
\hline $\mathbf{1 5}$ & 1 & 1 & 1 & 1 & 1 & 1 & 1 & 1 & 1 & 1 \\
\hline $\mathbf{1 6}$ & 1 & 1 & 1 & 1 & 1 & 1 & 1 & 1 & 1 & 1 \\
\hline $\mathbf{1 7}$ & 1 & 1 & 1 & 1 & 1 & 1 & 1 & 1 & 1 & 1 \\
\hline $\mathbf{1 8}$ & 1 & 1 & 1 & 1 & 1 & 1 & 1 & 1 & 1 & 1 \\
\hline $\mathbf{1 9}$ & 1 & 1 & 1 & 1 & 1 & 1 & 1 & 1 & 1 & 1 \\
\hline $\mathbf{2 0}$ & 1 & 1 & 1 & 1 & 1 & 1 & 1 & 1 & 1 & 1 \\
\hline $\mathbf{2 1}$ & 1 & 1 & 1 & 1 & 1 & 1 & 1 & 1 & 1 & 1 \\
\hline $\mathbf{2 2}$ & 1 & 1 & 1 & 1 & 1 & 1 & 1 & 1 & 1 & 1 \\
\hline $\mathbf{2 3}$ & 1 & 1 & 1 & 1 & 1 & 1 & 1 & 1 & 1 & 1 \\
\hline $\mathbf{2 4}$ & 1 & 1 & 1 & 1 & 1 & 1 & 1 & 1 & 1 & 1 \\
\hline $\mathbf{2 5}$ & 1 & 1 & 1 & 1 & 1 & 1 & 1 & 1 & 1 & 1 \\
\hline $\mathbf{2 6}$ & 0 & 0 & 0 & 0 & 0 & 0 & 0 & 0 & 0 & 0 \\
\hline & & & & & & & \\
\hline
\end{tabular}


Table 4.20 The Optimal Strategy of Eighth Target

\begin{tabular}{|c|c|c|c|c|c|c|c|c|c|c|}
\hline State no: & $\boldsymbol{t}_{\mathbf{1}}$ & $\boldsymbol{t}_{\mathbf{2}}$ & $\boldsymbol{t}_{\mathbf{3}}$ & $\boldsymbol{t}_{\mathbf{4}}$ & $\boldsymbol{t}_{\mathbf{5}}$ & $\boldsymbol{t}_{\mathbf{6}}$ & $\boldsymbol{t}_{\mathbf{7}}$ & $\boldsymbol{t}_{\mathbf{8}}$ & $\boldsymbol{t}_{\mathbf{9}}$ & $\boldsymbol{t}_{\mathbf{1 0}}$ \\
\hline $\mathbf{1}$ & 0 & 0 & 0 & 0 & 0 & 0 & 0 & 0 & 0 & 0 \\
\hline $\mathbf{2}$ & 0 & 0 & 0 & 0 & 0 & 0 & 0 & 0 & 0 & 0 \\
\hline $\mathbf{3}$ & 0 & 0 & 0 & 0 & 0 & 0 & 0 & 0 & 0 & 0 \\
\hline $\mathbf{4}$ & 0 & 0 & 0 & 0 & 0 & 0 & 0 & 0 & 0 & 0 \\
\hline $\mathbf{5}$ & 0 & 0 & 0 & 0 & 0 & 0 & 0 & 0 & 0 & 0 \\
\hline $\mathbf{6}$ & 0 & 0 & 0 & 0 & 0 & 0 & 0 & 0 & 0 & 0 \\
\hline $\mathbf{7}$ & 0 & 0 & 0 & 0 & 0 & 0 & 0 & 0 & 0 & 0 \\
\hline $\mathbf{8}$ & 0 & 0 & 0 & 0 & 0 & 0 & 0 & 0 & 0 & 0 \\
\hline $\mathbf{9}$ & 0 & 0 & 0 & 0 & 0 & 0 & 0 & 0 & 0 & 0 \\
\hline $\mathbf{1 0}$ & 0 & 0 & 0 & 0 & 0 & 0 & 0 & 0 & 0 & 0 \\
\hline $\mathbf{1 1}$ & 0 & 0 & 0 & 0 & 0 & 0 & 0 & 0 & 0 & 0 \\
\hline $\mathbf{1 2}$ & 0 & 0 & 0 & 0 & 0 & 0 & 0 & 0 & 0 & 0 \\
\hline $\mathbf{1 3}$ & 0 & 0 & 0 & 0 & 0 & 0 & 0 & 1 & 0 & 0 \\
\hline $\mathbf{1 4}$ & 0 & 0 & 0 & 0 & 0 & 0 & 0 & 1 & 0 & 0 \\
\hline $\mathbf{1 5}$ & 0 & 0 & 0 & 0 & 0 & 0 & 0 & 1 & 0 & 0 \\
\hline $\mathbf{1 6}$ & 0 & 1 & 0 & 1 & 1 & 1 & 1 & 1 & 1 & 0 \\
\hline $\mathbf{1 7}$ & 0 & 1 & 0 & 1 & 1 & 1 & 1 & 1 & 1 & 0 \\
\hline $\mathbf{1 8}$ & 0 & 1 & 0 & 1 & 1 & 1 & 1 & 1 & 1 & 0 \\
\hline $\mathbf{1 9}$ & 0 & 1 & 0 & 1 & 1 & 1 & 1 & 1 & 1 & 0 \\
\hline $\mathbf{2 0}$ & 0 & 1 & 0 & 1 & 1 & 1 & 1 & 1 & 1 & 0 \\
\hline $\mathbf{2 1}$ & 1 & 1 & 1 & 1 & 1 & 1 & 1 & 1 & 1 & 1 \\
\hline $\mathbf{2 2}$ & 1 & 1 & 1 & 1 & 1 & 1 & 1 & 1 & 1 & 1 \\
\hline $\mathbf{2 3}$ & 1 & 1 & 1 & 1 & 1 & 1 & 1 & 1 & 1 & 1 \\
\hline $\mathbf{2 4}$ & 1 & 1 & 1 & 1 & 1 & 1 & 1 & 1 & 1 & 1 \\
\hline $\mathbf{2 5}$ & 1 & 1 & 1 & 1 & 1 & 1 & 1 & 1 & 1 & 1 \\
\hline $\mathbf{2 6}$ & 0 & 0 & 0 & 0 & 0 & 0 & 0 & 0 & 0 & 0 \\
\hline & & & & & & & \\
\hline
\end{tabular}


After optimum strategies are obtained, state independent loads of each target are calculated under the assumption that target can be in any state at initial time instant $k=0$ with equal probability. Then total state independent load is computed by summing all individual state independent loads. Total state independent load is the comparison variable to check that the constraints are satisfied. It is adjusted by Lagrange multipliers. Optimal Lagrange multipliers and corresponding state independent loads are calculated by 'fminsearch' function and new search function that are described in Section for each time instances and shown in Table 4.21.

Table 4.21 Optimal Lagrange Multipliers for Each Time Instances

\begin{tabular}{|c|c|c|c|c|}
\hline & \multicolumn{2}{|c|}{ By New Search Function } & \multicolumn{2}{c|}{ By 'fminsearch' Function } \\
\hline Time & $\boldsymbol{\lambda}$ & $\begin{array}{c}\text { State Independent } \\
\text { Load }\end{array}$ & $\boldsymbol{\lambda}$ & $\begin{array}{c}\text { State Independent } \\
\text { Load }\end{array}$ \\
\hline $\boldsymbol{t}_{\mathbf{1}}$ & 251.7537 & 0.9132 & 254.5421 & 0.9148 \\
\hline $\boldsymbol{t}_{\mathbf{2}}$ & 243.6306 & 0.8873 & 244.1334 & 0.9288 \\
\hline $\boldsymbol{t}_{\mathbf{3}}$ & 240.1710 & 0.8587 & 239.5007 & 0.8799 \\
\hline $\boldsymbol{t}_{\mathbf{4}}$ & 234.7200 & 0.8718 & 237.1603 & 0.9073 \\
\hline $\boldsymbol{t}_{\mathbf{5}}$ & 229.1232 & 0.9831 & 231.7598 & 0.9926 \\
\hline $\boldsymbol{t}_{\mathbf{6}}$ & 227.6864 & 0.9214 & 227.4633 & 0.9191 \\
\hline $\boldsymbol{t}_{\mathbf{7}}$ & 222.0630 & 0.9694 & 222.1429 & 0.9409 \\
\hline $\boldsymbol{t}_{\mathbf{8}}$ & 212.0499 & 0.9515 & 210.2093 & 0.9664 \\
\hline $\boldsymbol{t}_{\mathbf{9}}$ & 185.3023 & 0.9662 & 185.2750 & 0.9944 \\
\hline $\boldsymbol{t}_{\mathbf{1 0}}$ & 128.8356 & 0.9665 & 128.6952 & 0.9689 \\
\hline
\end{tabular}

As it is seen both $\lambda$ search functions give similar results. Therefore we use only one of them while obtaining results. After the constraints are satisfied and optimal strategies are obtained, 1000 Monte Carlo simulations are done to observe the number of updates and the average number of drops for each target and also number of coincidence for overloads. Since we have actually $26^{8}$ states to represent all state combination of all targets, it is not possible to show all results. Therefore, we chose some random initial states that are generated by 'rand' function of MATLAB and related results are given in Table 4.23. Initial states columns show initial states of targets orderly. For example, 2-7-15-3-21-12-8-6 refers to first targets is in state 2, 
second target is in state 7, third target is in state 15 initially and so on. Selected initial states of targets that are outputs of MATLAB code are given in Table 4.22. Tx's are target numbers.

Table 4.22 Selected Initial States of Targets

\begin{tabular}{|c|c|c|c|c|c|c|c|c|}
\hline $\begin{array}{c}\text { Initial State } \\
\text { Combination }\end{array}$ & $\mathbf{T 1}$ & $\mathbf{T 2}$ & $\mathbf{T 3}$ & $\mathbf{T 4}$ & $\mathbf{T 5}$ & $\mathbf{T 6}$ & $\mathbf{T 7}$ & $\mathbf{T 8}$ \\
\hline $\mathbf{1}$ & 10 & 20 & 13 & 11 & 17 & 4 & 3 & 19 \\
\hline $\mathbf{2}$ & 18 & 16 & 13 & 2 & 3 & 4 & 21 & 14 \\
\hline $\mathbf{3}$ & 8 & 18 & 7 & 18 & 8 & 18 & 23 & 10 \\
\hline $\mathbf{4}$ & 20 & 20 & 13 & 24 & 12 & 21 & 4 & 24 \\
\hline $\mathbf{5}$ & 5 & 21 & 12 & 14 & 19 & 15 & 7 & 10 \\
\hline $\mathbf{6}$ & 24 & 11 & 18 & 8 & 15 & 22 & 14 & 16 \\
\hline $\mathbf{7}$ & 12 & 11 & 23 & 4 & 15 & 7 & 23 & 9 \\
\hline $\mathbf{8}$ & 2 & 7 & 5 & 11 & 9 & 19 & 23 & 13 \\
\hline $\mathbf{9}$ & 8 & 18 & 4 & 2 & 4 & 5 & 11 & 7 \\
\hline $\mathbf{1 0}$ & 17 & 9 & 19 & 14 & 10 & 3 & 2 & 1 \\
\hline
\end{tabular}

In Table 4.23 and Table 4.24, below notations are used.

$\mathrm{U}=$ Average number of update decision

$\mathrm{D}=$ Average number of target drops

$\mathrm{C}=$ Average number of conflicts in 10 seconds 
Table 4.23 Simulation Results of Optimization-Based Resource Allocation with Approximate DP

\begin{tabular}{|c|c|c|c|c|c|c|c|c|c|c|c|c|}
\hline & U & 年 & $\begin{array}{l}0 \\
0 \\
0\end{array}$ & 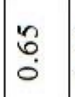 & $\stackrel{m}{0}$ & $\begin{array}{l}m \\
? \\
0\end{array}$ & $\vec{\sigma}$ & 导. & "ָ & $\stackrel{m}{-}$ & $\begin{array}{l}\hat{a} \\
\hat{o}\end{array}$ & 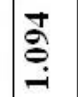 \\
\hline \multirow{2}{*}{ 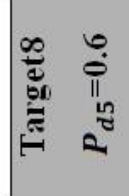 } & A & 오 & - & $\approx$ & in & $\infty$ & $\approx$ & $\exists$ & 0 & 0 & 0 & $\hat{\sigma}$ \\
\hline & $\triangleright$ & 尽 & $\begin{array}{l}\hat{a} \\
\grave{i} \\
\tilde{n}\end{array}$ & $\begin{array}{l}+ \\
\text { ते } \\
\text { ले }\end{array}$ & 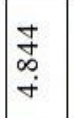 & $\mid \begin{array}{l}8 \\
\vdots \\
\dot{j} \\
m\end{array}$ & $\begin{array}{l}n \\
\tilde{m} \\
m \\
m \\
m\end{array}$ & 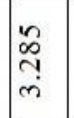 & $\mid \begin{array}{l}\vec{E} \\
m \\
m \\
m\end{array}$ & $\begin{array}{l}\vec{f} \\
\tilde{n} \\
\tilde{m}\end{array}$ & 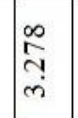 & के \\
\hline \multirow{2}{*}{ 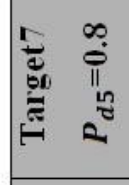 } & A & 0 & - & 0 & 0 & 0 & 0 & 0 & 0 & 0 & 0 & 7 \\
\hline & $D$ & 苟 & $\begin{array}{l}\infty \\
7 \\
\infty \\
\infty\end{array}$ & $\mid$\begin{tabular}{l|}
0 \\
0 \\
0 \\
$\infty$
\end{tabular} & 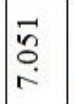 & \begin{tabular}{l}
$\infty$ \\
$\infty$ \\
\hdashline \\
\end{tabular} & 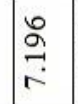 & $\begin{array}{l}\infty \\
\infty \\
\frac{\infty}{\infty} \\
\infty\end{array}$ & 囟 & 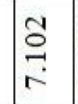 & 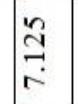 & तु \\
\hline \multirow{2}{*}{ 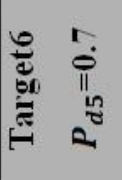 } & A & 0 & 0 & 0 & 0 & 0 & - & 0 & 0 & 0 & 10 & $\overline{5}$ \\
\hline & $D$ & 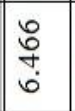 & $\begin{array}{c}0 \\
\infty \\
\\
\vdots \\
b\end{array}$ & \begin{tabular}{|l|}
$\infty$ \\
$\infty$ \\
$\infty$ \\
$r$ \\
\end{tabular} & 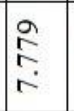 & \begin{tabular}{|l|} 
\\
0 \\
0 \\
$r$ \\
\end{tabular} & $\stackrel{a}{\stackrel{2}{r}}$ & $\begin{array}{l}\vec{\infty} \\
\infty \\
\infty \\
0 \\
0\end{array}$ & $\begin{array}{l}\text { Dे } \\
\infty \\
\\
\end{array}$ & $\begin{array}{l}\text { 음 } \\
\text { ஸุ } \\
0\end{array}$ & 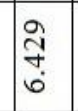 & g̊. \\
\hline \multirow{2}{*}{ 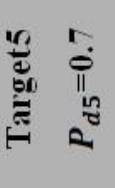 } & A & 0 & 0 & 0 & 0 & 0 & 0 & 0 & 0 & 0 & 0 & 0 \\
\hline & $D$ & م. & 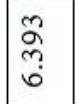 & $\begin{array}{l}\overrightarrow{0} \\
\infty \\
0 \\
0\end{array}$ & $\mid$\begin{tabular}{l|}
$\infty$ \\
0 \\
0 \\
0 \\
0
\end{tabular} & $\mid \begin{array}{l}+ \\
⿱ \\
\infty \\
r \\
r\end{array}$ & $\begin{array}{l}m \\
0 \\
0 \\
0\end{array}$ & 㒸 & 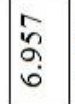 & 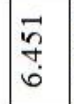 & $\mid \begin{array}{l}\infty \\
\infty \\
\infty \\
0 \\
0\end{array}$ & बू. \\
\hline \multirow{2}{*}{ 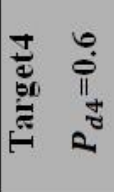 } & A & - & 0 & $\Rightarrow$ & $\exists$ & 0 & a & 0 & - & - & 0 & $\underset{\oplus}{\mathbf{m}}$ \\
\hline & 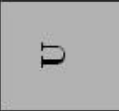 & $\begin{array}{l}\stackrel{9}{0} \\
\dot{+} \\
\dot{y}\end{array}$ & \begin{tabular}{|l|}
$m$ \\
$m$ \\
$m$ \\
$m$
\end{tabular} & 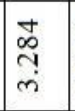 & \begin{tabular}{|c|} 
\\
0 \\
0 \\
in
\end{tabular} & \begin{tabular}{|l|}
$n$ \\
$\infty$ \\
11 \\
$m$
\end{tabular} & $\begin{array}{l}m \\
\tilde{n} \\
\tilde{m}\end{array}$ & $\begin{array}{l}\stackrel{J}{m} \\
\text { m. } \\
\text { m. }\end{array}$ & \begin{tabular}{|l|} 
\\
$m$ \\
$m$ \\
$m$ \\
$m$
\end{tabular} & \begin{tabular}{|l|} 
\\
ले \\
$\tilde{m}$ \\
$\dot{m}$
\end{tabular} & $\begin{array}{l}\vec{F} \\
m \\
m\end{array}$ & $\underset{\mathscr{\sigma}}{\mathscr{\sigma}}$ \\
\hline \multirow{2}{*}{ 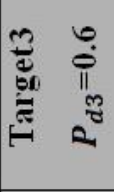 } & $\theta$ & $a$ & 0 & $\cong$ & 0 & 0 & $\approx$ & 0 & - & $\mathrm{d}$ & 0 & 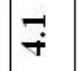 \\
\hline & $\triangleright$ & $\begin{array}{l}\vec{n} \\
m \\
m\end{array}$ & \begin{tabular}{|l|} 
\\
$m$ \\
$m$ \\
$m$ \\
$m$
\end{tabular} & $\begin{array}{l}\text { I } \\
\text { m. } \\
\text { r. }\end{array}$ & $\begin{array}{l}\infty \\
m \\
m \\
m\end{array}$ & \begin{tabular}{|l|}
$n$ \\
$n$ \\
$m$ \\
$m$
\end{tabular} & \begin{tabular}{|l|} 
\\
\\
$m$ \\
$m$ \\
$m$
\end{tabular} & $\overrightarrow{\vec{a}}$ & 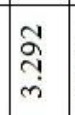 & $\mid \begin{array}{l}m \\
\dot{+} \\
\dot{m} \\
\dot{m}\end{array}$ & $\begin{array}{l}\tilde{n} \\
\tilde{y} \\
\tilde{n}\end{array}$ & $\begin{array}{l}\stackrel{8}{\circ} \\
\stackrel{\leftrightarrow}{\circ}\end{array}$ \\
\hline \multirow{2}{*}{ 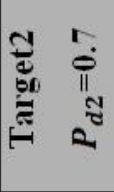 } & $\theta$ & 0 & 0 & 0 & 0 & 4 & 0 & 0 & 0 & 0 & 0 & $\stackrel{\text { ğ }}{\varrho}$ \\
\hline & $\triangleright$ & $\begin{array}{l}n \\
0 \\
\infty \\
\end{array}$ & 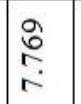 & \begin{tabular}{|l|} 
\\
$\infty$ \\
$\infty$ \\
\end{tabular} & \begin{tabular}{|c|}
$\infty$ \\
$\infty$ \\
\\
\end{tabular} & \begin{tabular}{l|}
0 \\
0 \\
\\
\end{tabular} & $\begin{array}{l}0 \\
0 \\
0 \\
0 \\
0\end{array}$ & $\begin{array}{l}\text { ปे } \\
\text { ه̊ } \\
\text { b. }\end{array}$ & 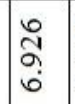 & $\mid \begin{array}{c}5 \\
5 \\
5 \\
5\end{array}$ & \begin{tabular}{l|}
$\overrightarrow{1}$ \\
0 \\
0 \\
0
\end{tabular} & 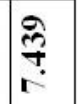 \\
\hline \multirow{3}{*}{ 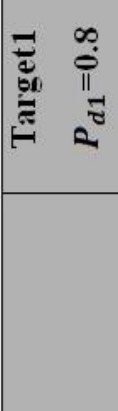 } & A & 0 & 0 & 0 & 0 & 0 & 0 & 0 & 0 & 0 & 0 & 0 \\
\hline & $\triangleright$ & 今े & \begin{tabular}{l}
$n$ \\
\hdashline \\
\end{tabular} & $\underset{7}{3}$ & $\begin{array}{l}3 \\
\stackrel{2}{-} \\
\end{array}$ & 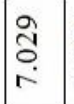 & $\mid \begin{array}{l}0 \\
\infty \\
0 \\
\infty \\
\infty\end{array}$ & $\underset{\substack{1\\
}}{\mathbb{4}}$ & $\stackrel{\circ}{\stackrel{7}{r}}$ & $\begin{array}{l}\vec{\infty} \\
\vec{r} \\
\vec{r}\end{array}$ & $\stackrel{\overrightarrow{9}}{\vec{r}}$ & בָ \\
\hline & 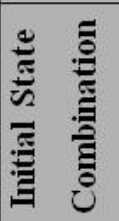 & -1 & N & n & $\tau$ & 10 & 0 & $\pi$ & $\infty$ & $a$ & 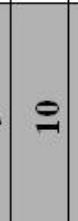 & 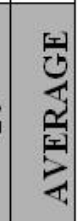 \\
\hline
\end{tabular}


Results show that there is a strong relation between probability of detection value and the average number of update decision and average number of target drops. While average number of update decision increases with the probability of detection value, average number of target drops decreases, because of the reward of better quality state is higher than the less quality state. Therefore, algorithm tries to maximize overall gain.

The same simulation is done for different nominal utilities $\left(U_{\text {nom }}\right)$. As expected, targets that have higher nominal utility consume more radar resources. Therefore, the average number of update decision increases with nominal utilities. On the other hand, nominal utilities affect the overall system performance, significantly. But if it is selected as too high compared to state reward, then objective function can be dominated by utility function and update decisions will be meaningless. Therefore it should be selected appropriate as possible.

Table 4.23 shows that there are some conflicts in time horizon. Conflict means the radar resources are not enough to perform macro manager demand. This is because the optimal policy is obtained by using expected loads. Therefore, we define additional decision maker in simulation. This additional rule makes a decision at each time instant. It sorts the current state of targets and starts to allocate the resource from lower quality target to higher quality target. This procedure checks the available remaining resources after an update decision of a target. When there is no available resource, even if macro manager makes an update decision, internal procedure changes this update decision to don't update decision due to lack of available resources. By this way, the number of conflicts is reduced to zero. Same initial conditions are used for scenario that has internal procedure to show that the average number of conflicts is zero. Results are given in Table 4.24. 
Table 4.24 Simulation Results of Optimization-Based Resource Allocation with Approximate DP and Internal Procedure

\begin{tabular}{|c|c|c|c|c|c|c|c|c|c|c|c|c|}
\hline & U & ¿ & $\stackrel{8}{\circ}$ & $\stackrel{\circ}{\circ}$ & $\stackrel{0}{\circ}$ & $\stackrel{0}{0}$ & 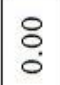 & $\stackrel{8}{0}$ & : & $\begin{array}{l}8 \\
0 \\
0\end{array}$ & $\begin{array}{l}8 \\
0\end{array}$ & $\stackrel{\mathscr{g}}{\stackrel{\rho}{\oplus}}$ \\
\hline \multirow{2}{*}{ 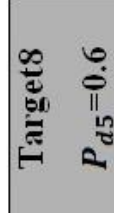 } & D & $\infty$ & $m$ & $\infty$ & in & $\exists$ & m & $\approx$ & 0 & 으 & - & $\stackrel{\infty}{\infty}$ \\
\hline & $D$ & $\begin{array}{l}\infty \\
\infty \\
\text { in } \\
m\end{array}$ & $\begin{array}{l}\text { वे } \\
\text { ले }\end{array}$ & $\stackrel{n}{\underset{m}{m}}$ & 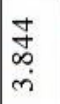 & $\begin{array}{l}\infty \\
\text { o } \\
\text { ch } \\
\text { m. }\end{array}$ & $\begin{array}{l}\hat{o} \\
\dot{0} \\
\dot{m}\end{array}$ & 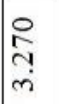 & $\begin{array}{l}0 \\
\stackrel{0}{n} \\
m \\
m\end{array}$ & $\begin{array}{l}\infty \\
\infty \\
\text { ch } \\
m\end{array}$ & $\begin{array}{l}\infty \\
\infty \\
\text { co } \\
\end{array}$ & $\stackrel{\infty}{\infty}$ \\
\hline \multirow{2}{*}{ 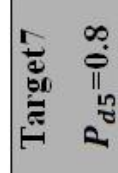 } & A & 0 & 0 & 4 & 0 & -1 & 0 & a & 0 & - & 0 & $\stackrel{?}{\because}$ \\
\hline & $D$ & 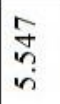 & $\begin{array}{l}0 \\
\vdots \\
\text { a } \\
6\end{array}$ & $\begin{array}{l}0 \\
0 \\
0 \\
0 \\
0\end{array}$ & 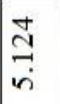 & $\begin{array}{c}\hat{a} \\
\text { ले } \\
\text { b. }\end{array}$ & 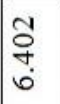 & $\frac{n}{6}$ & 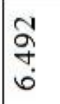 & ஓे & 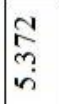 & $\frac{5}{6}$ \\
\hline \multirow{2}{*}{ 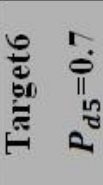 } & A & 0 & 0 & 0 & $\stackrel{a}{a}$ & 0 & $\stackrel{\infty}{\sim}$ & - & 0 & 0 & 0 & $\underset{\text { in }}{9}$ \\
\hline & $D$ & $\begin{array}{l}n \\
\infty \\
\infty \\
\infty \\
i n\end{array}$ & $\begin{array}{l}n \\
\tilde{m} \\
0 \\
\dot{0}\end{array}$ & 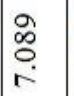 & $\frac{n}{n}$ & $\begin{array}{l}\vec{r} \\
\text { ñ } \\
0\end{array}$ & 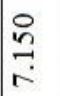 & $\begin{array}{l}\hat{D} \\
\infty \\
i n \\
i n\end{array}$ & $\begin{array}{l}\vec{b} \\
\vec{r}\end{array}$ & $\begin{array}{l}\mathcal{y} \\
\text { J } \\
i n \\
i n\end{array}$ & $\begin{array}{l}n \\
\hat{a} \\
i n \\
i n\end{array}$ & $\begin{array}{l}\hat{ٌ} \\
\text { iู }\end{array}$ \\
\hline \multirow{2}{*}{ 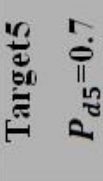 } & A & $N$ & 0 & N & in & 0 & $N$ & 0 & - & 0 & - & $\stackrel{?}{-}$ \\
\hline & $D$ & $\begin{array}{l}0 \\
0 \\
\infty \\
0 \\
0\end{array}$ & $\begin{array}{l}0 \\
\stackrel{m}{7} \\
0\end{array}$ & $\begin{array}{l}\hat{0} \\
0 \\
0 \\
0\end{array}$ & $\begin{array}{l}\text { o } \\
\text { of } \\
\text { m. }\end{array}$ & $\begin{array}{l}\stackrel{0}{0} \\
\text { m. } \\
r \\
r\end{array}$ & $\begin{array}{l}0 \\
0 \\
\vdots \\
0 \\
0\end{array}$ & 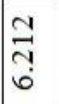 & 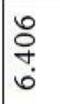 & $\begin{array}{l}0 \\
\infty \\
\stackrel{D}{a} \\
i n\end{array}$ & 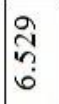 & 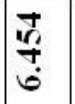 \\
\hline \multirow{2}{*}{ 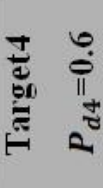 } & A & $\stackrel{2}{2}$ & -1 & $\approx$ & r & - & 9 & 0 & $m$ & $\approx$ & N & ?? \\
\hline & $D$ & $\begin{array}{l}\infty \\
\text { ஸे } \\
\text { nె }\end{array}$ & $\begin{array}{l}0 \\
m \\
m \\
m \\
m\end{array}$ & $\begin{array}{l}m \\
\tilde{n} \\
\end{array}$ & $\begin{array}{l}\hat{a} \\
\infty \\
\infty \\
\dot{\sigma}\end{array}$ & $\begin{array}{l}\infty \\
\stackrel{\infty}{m} \\
\dot{m}\end{array}$ & $\begin{array}{l}\stackrel{n}{n} \\
m \\
m \\
m\end{array}$ & $\begin{array}{l}\text { İ } \\
\text { Ny } \\
\text { m. }\end{array}$ & $\begin{array}{l}\vec{b} \\
\text { ì } \\
m\end{array}$ & $\begin{array}{l}\stackrel{0}{2} \\
\stackrel{y}{y} \\
m\end{array}$ & 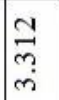 & $\underset{\dot{p}}{\stackrel{9}{+}}$ \\
\hline \multirow{2}{*}{ 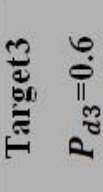 } & D & 0 & -1 & $\because 2$ & - & $\stackrel{ }{-1}$ & $a$ & $\infty$ & - & N & 0 & $\stackrel{T}{\beth}$ \\
\hline & $D$ & $\begin{array}{c}\text { 尺े } \\
\text { mై }\end{array}$ & 㣽 & $\underset{\sim}{\stackrel{ }{\prime}}$ & $\begin{array}{l}0 \\
\text { for } \\
m \\
m \\
m\end{array}$ & $\begin{array}{l}0 \\
\text { dut } \\
\text { ì } \\
\text { m. }\end{array}$ & 今̂ & $\underset{\dot{\sigma}}{\stackrel{\Xi}{\sigma}}$ & $\begin{array}{l}\stackrel{n}{m} \\
m \\
m \\
m\end{array}$ & 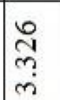 & 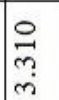 & $\underset{7}{T}$ \\
\hline \multirow{2}{*}{ 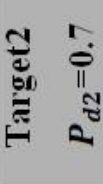 } & A & 0 & 0 & 0 & $a$ & 0 & 0 & - & 0 & 0 & 0 & تِ \\
\hline & $D$ & 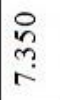 & $\begin{array}{l}n \\
2 \\
0 \\
0 \\
0\end{array}$ & $\begin{array}{l}0 \\
\stackrel{2}{0} \\
\stackrel{+}{r}\end{array}$ & 亦 & $\frac{7}{\vec{n}}$ & $\begin{array}{c}m \\
\substack{n \\
m \\
0}\end{array}$ & $\begin{array}{l}\stackrel{8}{ } \\
\text { ले } \\
\text { b. }\end{array}$ & $\begin{array}{l}0 \\
\text { D } \\
\text { లn } \\
0\end{array}$ & 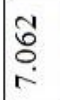 & 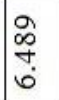 & 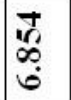 \\
\hline \multirow{3}{*}{ 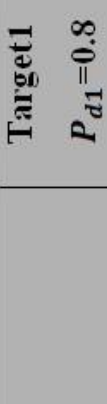 } & A & 0 & 0 & 0 & 0 & 0 & $N$ & 0 & 0 & 0 & - & $\stackrel{9}{\rho}$ \\
\hline & $D$ & $\begin{array}{l}0 \\
0 \\
0 \\
0 \\
0\end{array}$ & $\begin{array}{l}\tilde{n} \\
\text { ầ } \\
\text { b }\end{array}$ & 总 & 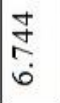 & 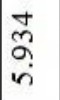 & 旁 & $\begin{array}{c}n \\
\hat{n} \\
\\
0\end{array}$ & $\begin{array}{l}\hat{y} \\
\infty \\
\infty \\
i n\end{array}$ & \begin{tabular}{l}
$\frac{1}{2}$ \\
ñ \\
\hdashline \\
6
\end{tabular} & $\begin{array}{l}\infty \\
0 \\
0 \\
0 \\
0\end{array}$ & 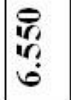 \\
\hline & 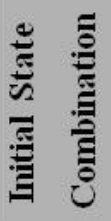 & -1 & $N$ & es & $T$ & in & 6 & $r$ & $\infty$ & $a$ & $\varrho$ & 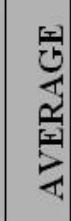 \\
\hline
\end{tabular}





\section{CHAPTER 5}

\section{CONCLUSIONS}

In this section, conclusion and future work parts are represented.

\subsection{Conclusion}

In this thesis, the focus is the sensor management for multifunction radar systems. We formulated the radar resource management problem for electronically steered antenna radars as a stochastic optimal control problem. We modeled performance of radar tracking as a constrained Markov decision processes. Since stochastic dynamic programming approach is computationally intractable, the overall problem was separated into components instead of using joint Markov model to optimize large scale stochastic control problem by hierarchical time decomposition and Lagrange relaxation. Lagrange relaxation is used to decrease the state space dimension. Hierarchical time decomposition divided time scale into two levels that are called as micro management and macro management. We deal with macro management part in our studies. Macro manager constructed the policy which is optimal for a given objective function under the resource constraints. 
Lagrange relaxation algorithm which is a version of the one given in [32] is generated and tested for eight target scenario. The approximation done in the Lagrange relaxation algorithm is justified on a simple scenario.

The contributions of this thesis can be summarized as follows.

- In order to handle global optimization problem which is highly complex to solve, usually the overall problem is divided into many smaller sub-problems that can be considered separately.

- High priority targets can be observed more frequently by sending agile beams in different direction and an arbitrary order.

- More targets can be tracked in an acceptable uncertainty level by using adaptive tracking

- A new rule reduces the number of dropped targets.

\subsection{Future Works}

Some suggested topics for future studies are given as follows.

- An improvement can be done for the extended representation of state space.

- Tracking performance model that is constructed by Markov chains can be developed further.

- Motion model can be developed for maneuvering targets.

- Target's probabilities of detections can be adjusted by internally.

- Search function can be added to the algorithms.

- Track initiation and track mix processes can be added to the algorithms.

- Different scenarios can be added with two or more ESA radars.

- Multiple radars can be allocated to multiple targets - see [37] for a similar problem. 


\section{REFERENCES}

[1] Skolnik M.I., Introduction to Radar Systems, McGraw-Hill, Inc, Singapore, 2nd edn., 1981.

[2] [Online] Available: 30.01.2015

http://www.militaryaerospace.com/articles/print/volume-19/issue-6/features/specialreport/radar-technology-looks-to-the-future.html

[3] Hero A.O., and Cochran D., Sensor Management: Past, Present, and Future, IEEE, vol. 11, no. 12, pp. 3064-3075, 2011.

[4] Krishnamurthy V., Algorithms for optimal scheduling and management of hidden Markov model sensors, IEEE, vol. 50, issue. 6, pp. 1382-1397, 2002

[5] Mark A. Richards, James A. Scheer, and William A. Holm, Principles of modern radar, Scitech Publishing, Inc, 2010

[6] Gokula Krishnan S., Active Electronically Scanned Array - (AESA) Radar, page 22, 2010

[7] Bar-Shalom Y., and Li X., Estimation and Tracking, Principles Techniques and Software, Norwood, MA: Artech House, 1993.

[8] Wintenby J., Resource Allocation in Airborne Surveillance Radar, Ph.D. dissertation, Chalmers University of Technology, Sweden, 2003.

[9] Orguner U., EE793 Target Tracking Lecture Notes, Dept. Electrical and Electronics Engineering, Middle East Technical University, Ankara, Turkey, 2012. 
[10] Blackman S., Multiple-Target Tracking with Radar Applications, Artech House, 1986.

[11] Kalman R. E., A New Approach to Linear Filtering and Prediction Problems, Transactions of the ASME-Journal of Basic Engineering, 82 (Series D): pp. 35-45, 1960.

[12] Gelb A., et. al., Applied Optimal Estimation, Cambridge, MA: The M.I.T. Press, 1974.

[13] Gallager G. Robert, Stochastic Processes: Theory for Applications, Cambridge University Press, New York, 2014.

[14] McIntyre G. A., and Hintz K. J., An Information Theoretic Approach to Sensor Scheduling, $10^{\text {th }}$ Annual Int. Aerosense Symp. Proc. SPIE, vol.2755, Orlando, FL, 1996, pp. 304-312.

[15] Kalandros M., and Pao L., Controlling Target Estimate Covariance in Centralized Multi-sensor Systems, Proc. 1998 American Control Conf., pp. 27492753, 1998,

[16] Schmaedeke W., and Kastella K., Information Based Sensor Management and IMMKF, Signal and Data Processing Of Small Targets, Proc. SPIE, vol. 3373, pp. 390-401, 1998.

[17] Blackman, S., and Popoli, R., Design and Analysis of Modern Tracking Systems, Norwood, MA: Artech House, 1999. Ch 15.3, pp. 983-995

[18] Blackman, S., and Popoli, R., Design and Analysis of Modern Tracking Systems, Norwood, MA: Artech House, 1999. Ch 15.3.3 pp. 992, Table 15.2.

[19] Blackman, S., and Popoli, R., Design and Analysis of Modern Tracking Systems, Norwood, MA: Artech House, 1999. Ch 15.3.3 pp. 988-999, Table 15.1. 
[20] Blackman, S., and Popoli, R., Design and Analysis of Modern Tracking Systems, Norwood, MA: Artech House, 1999. Ch 15.5.2 pp. 1008, Figure 15.6.

[21] Blackman, S., and Popoli, R., Design and Analysis of Modern Tracking Systems, Norwood, MA: Artech House, 1999. Ch 15.5.3 pp. 1009-1014.

[22] Blackman, S., and Popoli, R., Design and Analysis of Modern Tracking Systems, Norwood, MA: Artech House, 1999. Ch 15.5 pp. 1004-1053.

[23] Weinberg L., Scheduling Multifunction Radar Systems, IEEE EastCon 77 Record, 1977, pp. 10-4A-10-4I

[24] Salinger S. N., and Wangsness D., Target Handling Capacity of a Phased-Array Tracking Radar, IEEE Trans. Aerospace and Electronic Systems, vol. AES-8, no. 1, 1972, pp. 43-50.

[25] Scheff B. H., and Hammel D. G., Real-Time Computer Control Of Phase Array Radars, IEEE EastCon 1967, vol. AES-3 no. 6, Nov. 1967, pp. 198-206.

[26] French S., Sequencing and Scheduling: An Introduction to the Mathematics of the Job-Shop, New York: John Wiley \& Sons, 1982.

[27] Blackman, S., and Popoli, R., Design and Analysis of Modern Tracking Systems, Norwood, MA: Artech House, 1999

[28] Koch W., On adaptive parameter control for phased-array tracking, In Proceedings of the SPIE Conference on Signal and Data Processing of Small Targets, 1999, 3809.

[29] Strömberg D., and Grahn P., Scheduling of Tasks in Phased Array Radar, In Proceedings of IEEE International Symposium on Phased Array Systems and Technology, 1996.

[30] Blackman, S., and Popoli, R., Design and Analysis of Modern Tracking Systems, Norwood, MA: Artech House, 1999. Ch 15.5.6 pp. 1021-1023. 
[31] Washburn, R., Schneider, M., and Fox, J., Stochastic Dynamic Programming Based Approaches to Sensor Resource Management, In Proceedings of 5th International Conference on Information Fusion, 2002.

[32] Wintenby J., and Krishnamurthy V., Hierarchical Resource Management in Adaptive Airborne Surveillance Radars, IEEE Transactions on Aerospace and Electronics Engineering, vol. 42, no. 2, April 2006.

[33] Krishnamurthy V., How to Schedule Measurements of a Noisy Markov Chain for Decision Making, IEEE Trans Information Theory, vol. 59, no. 7, July 2013.

[34] Bertsekas, D., Dynamic Programming and Optimal Control (2nd ed.), Belmont, MA: Athena Scientific, 2000.

[35] Bellman, R., Dynamic Programming, Princeton, NJ: Princeton University Press, 1957.

[36] Castãnon, D., Approximate dynamic programming for sensor management, In Proceedings of the 36th Conference on Decision and Control, 1997.

[37] Maskery M., Krishnamurthy V., and O'Regan C., Decentralized algorithms for netcentric force protection against anti-ship missiles, IEEE Transactions on Aerospace and Electronic Systems, vol. 43, no. 4, 2007, pp. 1351-1372.

[38] [Online] Available: 30.01.2015

http://aviationintel.com/the-great-radar-race-aesa-development-in-high-gear/

[39] Mallick M., Krishnamurthy V., Vo B., Integrated tracking classification and sensor management, New Jersey: John Wiley \& Sons, 2013. 